\title{
CS Research Square \\ Biocontrol Potential of The Phloridin-Degrading Bacillus Licheniformis XNRB-3 Against Apple Replant Disease
}

\author{
Duan Yanan \\ Shandong Agricultural University \\ Zhao Lei \\ Shandong Agricultural University \\ Jiang Weitao \\ Shandong Agricultural University \\ Chen Ran \\ Shandong Agricultural University \\ Zhang Rong \\ Shandong Agricultural University \\ Chen Xuesen \\ Shandong Agricultural University \\ Yin Chengmiao \\ Shandong Agricultural University \\ Mao Zhiquan ( $\nabla$ mzhiquan@sdau.edu.cn) \\ Shandong Agricultural University https://orcid.org/0000-0001-6498-1299
}

\section{Research}

Keywords: Apple replant disease, Fusarium spp., biocontrol, Biolog, endophytic bacillus, antibiosis

Posted Date: November 9th, 2021

DOI: https://doi.org/10.21203/rs.3.rs-1039511/v1

License: @) (7) This work is licensed under a Creative Commons Attribution 4.0 International License. Read Full License 


\section{Abstract}

Background: Apple replant disease (ARD) is a common occurrence in many major apple-growing areas worldwide, seriously hindering the development of the apple industry. To avoid the shortcomings of chemical fungicides currently used to control ARD, it is necessary to find sustainable and effective control methods. Here, an endophytic phloridin-degrading Bacillus licheniformis XNRB-3 was isolated from the root tissue of healthy apple trees, and its control effect on apple replant disease (ARD) and its how to alleviates the pathogen pressure via changes in soil microbiomes were studied.

Results: The addition of strain XNRB-3 in Fusarium infested soils significantly reduced the number of pathogens in the soil, thus resulting in a lower disease incidence, and the relative control effect reached more than $60 \%$. The fermentation broth can also protect the roots of the plants from Fusarium infection. These antagonistic effects were further validated using an in vitro assay in which the pathogen control was related to growth and spore germination inhibition via directly secreted antimicrobial substances and and indirect interspecific competition for nutrients. The antifungal organic compounds in the fermentation metabolites were identified using GC-MS technology. Among them, alpha-bisabolol and 2,4-di-tert-butylphenol had significant inhibitory effects on many planted pathogenic fungi. Butanedioic acid, monomethyl ester, and dibutyl phthalate can promote the root elongation and lateral root development of Arabidopsis plants. The potential of strain XNRB-3 to control ARD was later validated using microbial fertilizer inoculation in pot and field experiment. The addition of strain XNRB-3 significantly promoted the growth of plants, and the activity of enzymes related to disease resistance (SOD, POD, and CAT) was also significantly enhanced. It also reduced the abundance of Fusarium and the content of phenolic acids in the rhizosphere soil, improved soil microbial community structure and nutritional conditions, and increased soil microbial diversity and activity, as well as soil enzyme activity.

Conclusions: The incorporation of strain XNRB-3 in the soil alleviated the damage of soil-borne pathogens to plants by reducing the relative abundance of pathogenic fungi and the content of phenolic acids, and inducing disease resistance of plants. Taken together, $B$. licheniformis XNRB-3 could be developed into a promising biocontrol and plant-growth-promoting agent. This provides a new management strategy to control ARD.

\section{Introduction}

Apple replant disease (ARD) is a soil sickness caused by biotic and abiotic factors. It occurs in major apple cultivation areas worldwide and poses a major threat to the development of the apple industry (Laurent et al., 2010; Tewoldemedhin et al., 2011). This disease is most harmful to young replanted trees, and it can reduce the growth of trees, increase the susceptibility of trees to diseases, discolor roots, result in root tip necrosis, and reduce root biomass, which can ultimately lead to plant death within the first growing season; the yield and quality of fruit trees more than 20 years old is decreased in plants with ARD, and death can occur in severe cases (Van Schoor et al., 2009; Mazzola and Manici, 2012; Tilston et al., 2020; Yim et al., 2020; Balbín-Suárez et al., 2021). An increasing number of studies have shown that biotic factors are the main factors that cause ARD, including nematodes (Pratylenchus spp.), fungi (Rhizoctonia solani, llyonectria, Fusarium, Alternaria, and Cylindrocarpon), and oomycetes (Pythium, Humicola, and Phytophthora) (Van Schoor et al., 2009; Weerakoon et al., 2012; Hewavitharana and Mazzola, 2016; Tilston et al., 2020). Abiotic factors may also play an important role in replanting problems, such as soil structure, the accumulation of phenolic compounds or phytotoxins in disease-affected roots, and nutrition (Hofmann et al., 2009; Wang et al., 2014).

Previous studies have suggested that Fusarium is one of the main pathogens contributing to the occurrence of ARD in China, South Africa, and Italy (Van Schoor et al., 2009; Kelderer et al., 2012; Yin et al., 2017; Wang et al., 2018; Sheng et al., 2020; Duan et al., 2021). Fusarium survives in soil in the absence of hosts for up to 10 years as chlamydospores; consequently, traditional methods of control such as crop rotation are typically ineffective (Liu et al., 2018 ). Yin et al. (2017) found that root exudates can stimulate the germination of Fusarium conidia, and the infectious hyphae from the conidia penetrate the roots of the host plant, resulting in plant death. Therefore, conidia are the most important structures mediating the survival of pathogens and initial infection; they are also some of the direct targets for the biological control of Fusarium. Currently, chemical fungicides and soil disinfestation with methyl bromideare the main commercially available approaches for controlling ARD (Dandurand et al., 2019). However, methyl bromide is now being phased out from agriculture because of environmental contamination and associated health threats (Raymaekers et al., 2020). The application of biological control agents (BCAs) is considered an eco-friendly and sustainable method for reducing the effects of plant diseases and has become increasingly used in many countries (Zalila-Kolsi et al., 2016; Chowdhury et al., 2020).

Plant growth-promoting rhizobacteria (PGPR) are a group of bacteria that colonize plant roots and promote plant growth and development (Kloepper and Beauchamp, 1992). Many diverse bacterial genera such as Bacillus, Klebsiella, and Pseudomonas can colonize various plant organs. These bacteria can stimulate plant growth, increase yield, reduce pathogen infection, and reduce biotic or abiotic plant stress under a wide range of environmental conditions without conferring pathogenicity, making them prime candidate BCAs for their ability to effectively control many different plant diseases in crops (Compant et al., 2010; Kumar et al., 2011; Ji et al., 2014; Liu X et al., 2019). Bacteria of the genus Bacillus produce heat and desiccation-resistant spores and are thus more suitable for use in biofungicides (Pérez-García et al. 2011). BCAs control plant pathogens and harmful microorganisms through the production of antibiotics, antifungal metabolites, and the degradation of the cell wall by different enzymes (Santoyo et al., 2012; Chowdhury et al., 2015; Eljounaidi et al., 2016; Afzal et al., 2019). In addition to antifungal activity, they can also facilitate plant growth through $\mathrm{N}_{2}$ fixation; the solubilization of insoluble phosphorus; the production of siderophores, phytohormones (e.g., IAA), and volatile organic compounds (VOCs); and induced systemic resistance (Ahemad and Khan, 2011; Gao et al., 2017 ). The 2-nonanone and 2-heptanone produced by $B$. amyloliquefaciens L3 isolated from the rhizosphere of watermelon have been shown to have strong antifungal properties against F. oxysporum f. sp. Niveum (FON); the VOCs acetoin and 2,3-butanediol produced by it promote plant growth (Wu et al., 2019). Marques et al. (2010) found that all the bacterial isolates produce indole acetic acid, hydrogen cyanide, and ammonia when tested in vitro for their plant growth-promoting (PGP) abilities. Azabou et al. (2020) isolated a B. velezensis OEE1 from root tissue with a strong control effect on Verticillium wilt that can significantly reduce the final mean disease severity index (FMS), percentage of dead plants (PDP), and area under disease progress curve (AUDPC). However, there are relatively few biological control agents for Bacillus that can be used to control ARD. There is thus a need for more research on biological control agents to expand the scope of ARD biological control weapons. 
In this study, a strain of $B$. licheniformis XNRB-3 that degrades phloridin was isolated from the root tissue of healthy apple trees in a replanted orchard. The purpose of this study was to (a) characterize the antagonistic activity of the bacterial isolate XNRB-3 against Fusarium, (b) evaluate the ability of strain XNRB3 to degrade phloridin and promote plant growth, (c) optimize its biocontrol activity against ARD, (d) evaluate the root colonization ability under greenhouse conditions, (e) identify the main antimicrobial compounds involved in its antifungal activity, and (f) verify the effect of XNRB-3 against ARD under outdoor potting and field conditions.

\section{Materials And Methods}

\subsection{Microorganisms and growth conditions}

The culture of plant fungal pathogen used in this study were preserved and provided by the National Key Laboratory of Crop Biology, College of Horticultural Science and Engineering, Shandong Agricultural University. Stock cultures were maintained on potato dextrose agar (PDA) plates at $4^{\circ} \mathrm{C}$. Pre-cultures were established by transferring a stock agar plug containing mycelia onto fresh PDA plates and incubating for 6 days at $28^{\circ} \mathrm{C}$.

\subsection{Isolation and screening of bacteria for biocontrol activity}

The rhizosphere soil and root system were taken from healthy apple trees in the replanted orchard (replanted for 4-5 years on old apple orchards (more than 25 years old)) in the Northwest Loess region. Apple trees with ARD symptoms (twig growth retardation or death) were common in the sampled orchards. The basic information of the sampled sites are presented in Table S1. The sampled orchards use mainly Malus baccata (Linn.) Borkh. as the rootstock and Malus pumila Mill as the main scion. The isolation and screening of antagonistic bacteria refer to the method of Filippi et al. (2011) and Afzal et al. (2017), with some modifications. Rhizobacteria were isolated by the serial dilution method. Ten grams of rhizosphere soil in $90 \mathrm{~mL}$ of sterile saline (0.85\%) was diluted to $10^{-7}$ and an aliquot of $100 \mu \mathrm{L}$ of each dilution was distributed on nutrient agar (Beef extract $3.0 \mathrm{~g}$, peptone $5.0 \mathrm{~g}$, sodium chloride $3.0 \mathrm{~g}$, and agar $20.0 \mathrm{~g}, 1 \mathrm{~L}$ ). Roots were cleaned thoroughly with tap water and cut into small pieces, which were sterilized with chlorox (Commercial bleach) for 5 min and five washes with autoclaved distilled water. Surface sterilized roots were macerated in mortar and pestle, followed by the serial dilution of the extract in $0.03 \mathrm{M} \mathrm{MgSO}_{4}$ up to $10^{-3}$ and plated on nutrient agar. All plate incubated at $30^{\circ} \mathrm{C}$ for $24 \mathrm{~h}$. Morphologically distinct colonies were replicated and purified isolates were stored in cryogenic tubes. The bacterial strains were further purified and then screened for antagonistic activity toward plant fungal pathogen using dual culture technique (Wu et al., 2019). Briefly, a $3 \mathrm{~mm}$ agar plug from the edge of a 6-day-old culture of plant fungal pathogen on PDA was placed in the middle of fresh PDA plate. The bacterial strains were spot inoculated in the edge of the plate and incubated at $28^{\circ} \mathrm{C}$. The PDA plate inoculated only with plant fungal pathogen was used as control treatment. Plates were incubated at $28^{\circ} \mathrm{C}$ until control plates covered the entire surface. The colony diameter was calculated by measuring the average diameter in two perpendicular directions. The percentage inhibition was calculated using the formula (Li et al., 2020). I=(C-T)/(CD) $\times 100$. Where I: \% inhibition, C: the colony diameter of the control $(\mathrm{mm})$, T: colony diameter of the treatment ( $\mathrm{mm})$ and D: plug diameter (mm). Three replicates of each treatment were performed and the assays were repeated three times.

\subsection{Identification of Antagonistic Strain}

\subsubsection{Morphological and Biochemical identification}

Morphological identification of bacteria is based on the methods of Zhao et al. (2018).

Biochemical identification of bacteria is based on the methods of Dong and Cai. (2001) and Garrity et al. (2009).

\subsubsection{Identification with Biolog GEN III Micro Station System}

The GEN III MicroPlate ${ }^{T M}$ test panel provides a standardized micromethod using 94 biochemical tests to profile and identify a broad range of Gram-negative and Gram-positive bacteria (Bochner, 1989). Biolog's Microbial Identification Systems software (e.g.OmniLog ${ }^{\circledR}$ Data Collection) is used to identify the bacterium from its phenotypic pattern in the Biolog GEN III microplate (Biolog Inc., Hayward, CA, USA). Tetrazolium redox dyes are used to colorimetrically indicate utilization of the carbon sources or resistance to inhibitory chemicals. The similarity of metabolic fingerprints between XNRB-3 and standard strains in the kinetic database was analyzed by the Biolog Retrospect 2.0 Data Management Software. The results were considered to be more accurate when the SIM value $>0.5$ and the DIST value $<5.00$ are satisfied (Tjurin, 1965).

\subsubsection{DNA extraction, PCR amplification, and phylogenetic analysis}

Genomic DNA was extracted from the obtained isolates using the Bacteria Genomic DNA Extraction Kit (Tiangen Corporation Ltd, Beijing, China) according to the manufacturer's instructions (Sambrook and Russell, 2001). The selected isolates were identified through 16S ribosomal RNA gene (16S rDNA), DNA gyrase subunit A (gyrA), DNA gyrase subunit B (gyrB), and RNA polymerase subunit B (rpoB) (Yamamoto and Harayama, 1995; Chun and Bae, 2000; Zalila-Kolsi et al., 2016; Somerville et al., 2020). PCR amplification was performed in an Applied Biosystems 2720 Thermal Cycler (Applied Biosystems Inc., USA) refer to the method of Duan et al. (2021). The primers and annealing temperatures are presented in Table S2. PCR products purified using an DNA Gel Recovery Kit (AxyPrep, Hangzhou, China) according to the manufacturer's instructions, and sequenced on an ABI 3730XL (Applied Biosystems Inc., USA) at Personalbio Gene Biotech Co., Ltd (Qingdao, China).

For phylogenetic analyses, 16S rDNA, gyrA, gyrB, and rpoB sequences of strain XNRB-3 were aligned to the GenBank database using NCBI BLAST. Maximum likelihood (ML) phylogenies were constructed for the sequence datasets using RAxML-HPC2 on XSEDE (8.2.12) (Stamatakis, 2014). Tree diagrams were created in FigureTree v1.4.3 and Adobe Illustrator CS6.

2.4 PCR detection of antibiotic biosynthesis genes

Page $3 / 40$ 
Genes related to the biosynthesis of lipopeptides, dipeptides and polyketides were detected by PCR using primers listed in Table S3 and following steps described by Hsieh et al. (2004), Cao et al. (2012), and Hussein et al. (2017). PCR reactions were carried out in a $25 \mu l$ reaction volume containing $1 \mu l$ genomic DNA, $2.5 \mu \mathrm{l} 10 \times$ PCR buffer, $20 \mathrm{mM} \mathrm{MgCl}_{2}, 0.2 \mathrm{mM}$ of each dNTP, $0.5 \mu \mathrm{M}$ of each primer and $1.25 \mathrm{U}$ Taq DNA polymerase (Takara, Dalian). Amplification was performed with a Applied Biosystems 2720 Thermal Cycler (Applied Biosystems Inc., USA) programmed for one cycle of $94^{\circ} \mathrm{C}$ for $5 \mathrm{~min}$, followed by $35 \mathrm{cycles}$ of $94^{\circ} \mathrm{C}$ for $30 \mathrm{~s}$, annealing for $30 \mathrm{~s}$ at $52^{\circ} \mathrm{C}$ for ituC, yndJ, bamC and sboA specific primers, whereas those for srf, srf $A B$, ituD, fen, fenB and $q k$ were set to $58^{\circ} \mathrm{C}$ and $72^{\circ} \mathrm{C}$ for $1 \mathrm{~min}$, and extension at $72^{\circ} \mathrm{C}$ for $7 \mathrm{~min}$. The amplifications were analysed by electrophoresis of $5 \mu$ in an $1.5 \%$ agarose gel followed by ultraviolet visualisation.

\subsection{Optimization of fermentation conditions}

Seed culture of $B$. licheniformis XNRB-3 was prepared by inoculating single colony into $100 \mathrm{ml}$ of LB broth (tryptone $10 \mathrm{~g}$, yeast extract $5 \mathrm{~g}$, NaCl $10 \mathrm{~g}$, pH 7.0 ) and incubated at $37^{\circ} \mathrm{C}$ for overnight with agitation (180 rpm).

\subsubsection{Single factor test}

Batch fermentation was carried out in 250-mL Erlenmeyer flasks containing $100 \mathrm{ml}$ of fermentation medium (glucose $22 \mathrm{~g}$, trypone $5.4 \mathrm{~g}, \mathrm{KH}_{2} \mathrm{PO}_{4} 2.4 \mathrm{~g}, \mathrm{CaCl}_{2}$ $0.25 \mathrm{~g}, \mathrm{MgSO}_{4} 0.5 \mathrm{~g}, 1 \mathrm{~L}, \mathrm{pH} 7.0$ ) inoculated with 3-10\% (v/v) seed culture and incubated at $37^{\circ} \mathrm{C}$ with agitation (180 rpm) for $72 \mathrm{~h}(\mathrm{Qiao}$ et al., 2012 ). Measure the $\mathrm{OD}_{600}$ absorbance value of the bacterial solution at different incubation times, and use the the serial dilution method to count (Figure $\mathrm{S} 1 \mathrm{~A}$ ).

Choose sucrose, maltose, glucose, lactose and soluble starch as carbon sources, set 5 concentrations of $0.5 \%, 1.0 \%, 1.5 \%, 2.0 \%$, and $2.5 \%$, choose yeast extract, peptone, $\left(\mathrm{NH}_{4}\right)_{2} \mathrm{SO}_{4}$, beef extract, $\mathrm{NH}_{4} \mathrm{NO}_{3}$, Urea and $\mathrm{NH}_{4} \mathrm{Cl}$ as nitrogen sources, set a total of 5 concentrations of $0.1 \%, 0.5 \%, 1.0 \%, 1.5 \%$, and $2.0 \%$, Select $\mathrm{KH}_{2} \mathrm{PO}_{4}, \mathrm{CaCl}_{2}, \mathrm{MgSO}_{4}, \mathrm{NaCl}, \mathrm{MnSO}_{4}$ and $\mathrm{KCl}$ as inorganic salts, remove one inorganic salt at a time, and investigate its influence on the growth of strain XNRB-3. According to the results of the inorganic salt removal test, select three important inorganic salts, set a total of 5 concentrations of $0.02 \%$, 0.05 $\%, 0.1 \%, 0.15 \%$, and $0.20 \%$, and design the orthogonal experiment according to the orthogonal table to determine the best combination of inorganic salts.

Set $25,50,100,125$, and $150 \mathrm{~mL}$ total 5 filling volume (250-mL Erlenmeyer flask), 100, 150, 180, 200, and $250 \mathrm{rpm}$ total $5 \mathrm{speeds}, 25,30,37,40$, and $50{ }^{\circ} \mathrm{C}$ total 5 culture temperatures, use $\mathrm{HCl}\left(0.1 \mathrm{~mol} \mathrm{~L}^{-1}\right)$ and $\mathrm{NaOH}\left(0.1 \mathrm{~mol} \mathrm{~L}^{-1}\right)$ to adjust the $\mathrm{pH}$ of the liquid medium to $5.5,6.5,7.0,7.5,8.0,8.5$, and 9.5 , respectively. When the above fermentation conditions were optimized, except for the test single factor as a variable, the other conditions were unchanged, Each treatment contains three repetitions. Determine the $24 \mathrm{~h} \mathrm{OD}_{600}$ (diluted 4 times) and the antibacterial rate, and combined with the results of single factor experiment, orthogonal experiment (Orthogonality Experiment Assistant V3.1), Plackett-Burman and Box-Behnken (Design-Expert 8.0.6) in response surface analysis (RSM) optimized the composition and fermentation conditions of B. licheniformis XNRB-3 sporulation shake flask fermentation medium (Anthony et al., 2009).

\subsection{Antagonistic effects of extracellular metabolites on Fusarium}

\subsubsection{Effect of strain XNRB-3 on Fusarium spore germination}

The effect of strain XNRB-3 on the germination of Fusarium spores refers to the method of Yu et al. (2011), with some modifications. Bacterial suspensions were made by suspending cells cultured on NA plates in $10 \mathrm{mM} \mathrm{MgSO}_{4}$. The density of the bacterial suspensions was adjusted to $1 \times 10^{8} \mathrm{CFU}$ ml ${ }^{-1}$, The spores of Fusarium obtained refers to the method of Duan et al. (2021). Each suspension (about $50 \mu \mathrm{L}$ ) were then placed on a microscope slide, and kept at $20{ }^{\circ} \mathrm{C}$ on moistened, sterilizedfilter paper placed in Petri dishes for $24 \mathrm{~h}$. The germination percentages of conidia (200 conidia for each treatment) were measured using the Nikon BX-51 fluorescence microscope. The conidium was considered germinated when the length of the germ tube length was at least equal to the diameter of the conidium. This experiment was repeated three times.

\subsubsection{Effect of cell-free culture filtrate on Fusarium hyphae}

Refer to the method of Abdelmoteleb et al. (2017) to obtain the cell-free culture filtrate (CFCF) of strain XNRB-3. Bacteria were grown on optimized liquid fermentation medium at $33^{\circ} \mathrm{C}$, with constant shaking at $191 \mathrm{rpm}$ and after $24 \mathrm{~h}$ of incubation to obtain fermentation broth (FB), FB were removed by centrifugation at $10,000 \mathrm{rpm}$ for $10 \mathrm{~min}$ at $4{ }^{\circ} \mathrm{C}$. The supernatant (extracellular medium) was passed through a $0.22-\mu \mathrm{m}$ Nylon $66 \mathrm{microporous} \mathrm{membrane} \mathrm{to}$ obtain CFCF. Effect of cell-free culture filtrate on Fusarium hyphae refers to the method of Duan et al. (2021). The samples were sent to Keshang Biotech Co., Ltd. for scanning electron microscope observation.

\subsection{Plant growth promoting activities}

Ability of strain XNRB-3 to promote plant growth was tested with reference to the method in Table S4. FB of $B$. licheniformis XNRB-3 were centrifuged at $13,400 \mathrm{~g}$ for $10 \mathrm{~min}$. The supernatant (extracellular medium) was removed and frozen at $4{ }^{\circ} \mathrm{C}$ for analysis of amino acids. Amino acids were pre-column derivatized with PITC and were separated and quantified under the optimum condition (running buffer $30 \mathrm{mM}$ phosphate and $3 \mathrm{mM} \beta$ - $\mathrm{CD}$ at pH 7.0 ; voltage of $20 \mathrm{kV}$ ) by Biochrom $30^{+}$amino acid analyzer (Biochrom, U.K) attached to a PA800 high performance capillary electrophoresis (HPCE) system equipped with an on-column ultra violet detector system (Genstech Biotechnology Co., Ltd, Shanghai, China) refer to the method of Ren et al. (2012). The capillaries were Bare Fused-Silica Capillary-50 $\mu \mathrm{m}$ ID, $375 \mu \mathrm{m}$ OD, $67 \mathrm{~cm}$ (pkg of 3) (Shkmsw Biotechnology Co., Ltd, Shanghai, China). Individual amino acid concentrations were calculated by comparing the specific amino acid peak area to a standard curve for that amino acid (Ren et al., 2012).

Phytohormones extraction and quantification by gas chromatography-mass spectrometry/selected ion monitoring (GC-MS/SIM) (Shimadzu, Japan) refer to the method of Shahzad et al. (2019). Briefly, B. licheniformis XNRB-3 was grown in optimized liquid fermentation medium for seven days. After seven days, the pure culture filtrate in which $B$. licheniformis XNRB-3 was grown was supplemented with [D5]-IAA, [2H2] GA, [( \pm )-3,5,5,7,7,7-d6]-ABA] as an internal standard, 
extracted, and subjected to GC-MS/SIM for determination and quantification. Further, the GC/MS used for quantification was equipped with a HP-5 capillary column HP-5 (30 m length, $0.25 \mathrm{~mm}$ ID, $0.25 \mu \mathrm{m}$ film, $325^{\circ} \mathrm{C}$ maximum temperature) and used $\mathrm{He}(99.999 \%$,) was as the carrier gas with a head pressure of $30 \mathrm{kPa}$, an injector temperature of $200^{\circ} \mathrm{C}$, and an ionizing voltage of $70 \mathrm{eV}$. Phytohormones concentrations were calculated from ratios of peak area of sample to a corresponding internal standard.

\subsection{Determination of microorganisms using phloridin as carbon source 2.8.1 Preparation of $0 \sim 10 \mathrm{mmol} / \mathrm{L}$ phloridin culture medium}

Chemical compounds of phloridin, Cinnamic acid (CA), Ferulic acid (FA), Benzoic acid (BA) and P-hydroxybenzoic acid (PHBA) are Sigma products (Sigma, StLouis, MO). Mineral salt medium (MSM) $\left(\mathrm{K}_{2} \mathrm{HPO}_{4} 5.8 \mathrm{~g},\left(\mathrm{NH}_{4}\right)_{2} \mathrm{SO}_{4} 2.0 \mathrm{~g}, \mathrm{KH}_{2} \mathrm{PO}_{4} 4.5 \mathrm{~g}, \mathrm{CaCl}_{2} 0.02 \mathrm{~g}, \mathrm{MgCl}_{2} 0.16 \mathrm{~g}, \mathrm{FeCl}_{3} 0.0018 \mathrm{~g}, \mathrm{Na}_{2} \mathrm{MoO}_{4} \cdot 2 \mathrm{H}_{2} \mathrm{O} 0.0024\right.$ $\mathrm{g}, \mathrm{MnCl}_{2} \cdot 2 \mathrm{H}_{2} \mathrm{O} 0.0015 \mathrm{~g}$ in $\left.1 \mathrm{~L}, \mathrm{pH} 7.0\right)$ containing phloridin $(0 \sim 10 \mathrm{mmol} / \mathrm{L})$ as the sole carbon source was used to isolate degrading bacteria. Agar plates were prepared by adding agar $\left(18 \mathrm{~g} \mathrm{~L}^{-1}\right)$ to the MSM, and MSM solution with phloridin was used to determine the maximum absorption wavelength and standard curve, and the operation should be protected from light as much as possible (Pant et al., 2013).

\subsubsection{Tests of microbial growth and phenolic degradation}

Measure the absorbance value of MSM solution with phloridin $\left(10 \mathrm{mmol} \mathrm{L}^{-1}\right)$ at each wavelength to determine that the maximum absorbance wavelength was $280 \mathrm{~nm}$ (Table S5), Prepare the MSM solution with a total of 11 concentrations of $0-10 \mathrm{mmol} \mathrm{L}^{-1}$. Use MSM solution with 0 mmol L ${ }^{-1}$ phloridin as the reference solution for blank calibration. Determine the absorbance value at $280 \mathrm{~nm}$. Take the absorbance value as the ordinate and the phlorizin concentration as the abscissa to make a standard curve (Figure $2 \mathrm{P}$ ).

Tests of microbial growth and phenolic acid degradation in MSM solution refer to the method of Wang et al. (2021), with some modifications. Strain XNRB-3 was inoculated into MSM with $0 \sim 10 \mathrm{mmol} \mathrm{L}^{-1}$ phloridin and cultured at $33^{\circ} \mathrm{C}$ in the dark to determine the maximum tolerance of phloridin (Figure $2 \mathrm{~N}$ ). Strain XNRB-3 was inoculated with $6 \mathrm{ml}$ of liquid fermentation medium in a $15 \mathrm{ml}$ plastic tube with cover, followed by overnight incubation at $33^{\circ} \mathrm{C}$. After centrifugation at $2500 \mathrm{~g}$ for $5 \mathrm{~min}$, the supernatant was discarded and the pellet was diluted to an $\mathrm{OD}_{600}$ value of $1.0 \mathrm{using}$ dd $\mathrm{H}_{2} \mathrm{O}$. Afterwards, $0.1 / 0.2 \mathrm{ml}$ of the resuspended isolates was transferred to $10 \mathrm{ml} \mathrm{MSM}$ solution with phloridin $\left(3 \mathrm{mmol} \mathrm{L}{ }^{-1}\right)$ and incubated for $60 \mathrm{~h}$ in the dark at $33^{\circ} \mathrm{C}$ with shaking $(191$ rev $\left.\mathrm{min}^{-1}\right) .1 \mathrm{ml}$ of the bacterial suspension was taken from each treatment and was centrifuged at $13000 \mathrm{~g}$ for $5 \mathrm{~min}$, and the supernatant to detect $\mathrm{OD}_{280}$, Converted to the concentration of phloridin according to the standard curve. Degradation rate of phloridin $=$ (phloridin concentration in uninoculated culture solution-phloridin concentration in inoculated culture solution)/phloridin concentration in uninoculated culture solution $\times 100 \%$.

To test the isolate's ability to utilize other phenolic acids, Strain XNRB-3 was inoculated into MSM solution with $0.5 \mathrm{~g} \mathrm{~L}^{-1}$ of CA, FA, BA or PHBA, and their growth was tested according to the previously described method, and $0.2 \mathrm{ml}$ of the suspension was transferred to $10 \mathrm{ml}$ of MSM solution with $0.5 \mathrm{~g} \mathrm{L^{-1 }}$ of CA, FA, BA or PHBA. After incubation for $12,24,36,48$ and $60 \mathrm{~h}$ at $33^{\circ} \mathrm{C}$ with shaking $\left(190 \mathrm{rev} \mathrm{min}{ }^{-1}\right), 1 \mathrm{ml}$ of the bacterial suspension was taken from each

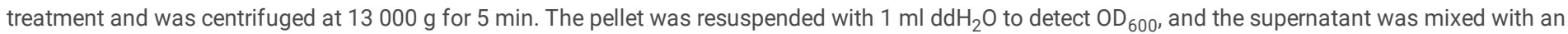
equal volume of methanol. Then, $0.1 \mathrm{ml}$ of the mixed solution was added to $1.9 \mathrm{ml}$ of $50 \%$ methanol solution, and was sterilized by filtering through $0.22 \mu \mathrm{m}$ pore-size filter membranes prior to HPLC analysis. The control used was MSM solution of phenolic acids but without bacteria, all assays were performed in triplicate.

The concentrations of phenolic acids were detected based on peak areas using external standards using an UltiMate 3000 HPLC system (Dionex, USA). All separations were performed using Symmetry ${ }^{\circledR}$ C 18 column ( $4.6 \mathrm{~mm} \times 150 \mathrm{~mm}, 5.0 \mu \mathrm{m}$; Waters, Milford, MA, USA). Mobile phase solutions were $0.1 \%$ methanoic acid $+2 \%$ methanol (A) and acetonitrile (B). The gradient elution composition used was as follows: 0 min, $96 \%$ A plus $4 \%$ B 10 min; $10 \%$ A plus $90 \%$ B $16 \mathrm{~min} ; 96 \%$ A plus $4 \%$ B 30 min; with a flow rate of $1.0 \mathrm{ml} \mathrm{min}^{-1}$, an injection volume of $10 \mu \mathrm{l}$, a column temperature of $20^{\circ} \mathrm{C}$ and UV detection at 280 $\mathrm{nm}$.

\subsubsection{Soil treatment with microbes and analysis of phenolic acid degradation}

The soil obtained from a 31-year-old apple orchard in Manzhuang Town, Taian, China (117.081039 longitude, 36.06682 latitude) was dried at $60^{\circ} \mathrm{C}$ for $6 \mathrm{~h}$ and and was passed through a $0.84-\mathrm{mm}$ sieve. $30 \mu \mathrm{g} \mathrm{g}^{-1}$ of Phloridzin, $10 \mu \mathrm{g} \mathrm{g}^{-1}$ of CA, $90 \mu \mathrm{g} \mathrm{g}^{-1}$ of BA, $100 \mu \mathrm{g} \mathrm{g}{ }^{-1}$ of FA, and $20 \mu \mathrm{g} \mathrm{g}{ }^{-1}$ of PHBA was added to the dried soil. The soil was dried again at $60^{\circ} \mathrm{C}$ for $2 \mathrm{~h} .200 \mathrm{~mL}$ with $\mathrm{OD}_{600}=1.0$ of bacterial suspension was added to $1 \mathrm{~kg}$ of soil; sterile water was used as control. Each treatment consisted of three replicates. After incubation for 3,6 and 9 days at $25^{\circ} \mathrm{C} / 20^{\circ} \mathrm{C}(16 \mathrm{~h} / 8 \mathrm{~h}$, light/dark), and ddH $\mathrm{O}$ was added to keep the soil moist. $60 \mathrm{~g}$ of soil was obtained from each pot for HPLC analysis (Zhang ZY et al., 2010).

Analysis of phenolic degradation was conducted using the method of Yin et al., (2013), with few modifications. A sample of dry soil (60 g) was passed through a 12-mesh sieve and mixed with diatomaceous earth, then placed into a 100-ml extraction tank. ASE 350 Fast Solvent Extractor (Dionex, USA) was used to perform the extraction. First, absolute ethanol was used as the extraction solvent, and static extraction was performed for 5 min at $120^{\circ} \mathrm{C}$ and 10.3 MPa with 2 cycle times, a purge volume of $60 \%$, and a purge time of $90 \mathrm{~s}$. Then the same sample was extracted again under the same conditions using methanol as the extraction solvent. After the extraction was completed, the two solvents were mixed and concentrated under reduced pressure at $34^{\circ} \mathrm{C}$ to near dryness, then reconstituted with $1 \mathrm{ml}$ methanol and passed through a 0.22- $\mu \mathrm{m}$ organic phase filter membrane for HPLC analysis.

The HPLC analysis procedure followed that described by Xiang et al. (2021). An UltiMate 3000 HPLC system (Dionex, USA) was used for quantification with an Symmetry ${ }^{\circledR}$ C 18 column ( $4.6 \mathrm{~mm} \times 250 \mathrm{~mm}, 5.0 \mu \mathrm{m}$; Waters, Milford, MA, USA), and a column temperature of $30^{\circ} \mathrm{C}$. Mobile phase A was acetonitrile, and mobile phase $\mathrm{B}$ was water (adjusted to $\mathrm{pH} 2.8$ with acetic acid). The flow rate was $1.0 \mathrm{~mL} \mathrm{~min}{ }^{-1}$, the automatic injection volume was $10 \mu \mathrm{L}$, and the detection

Page $5 / 40$ 
wavelength was $280 \mathrm{~nm}$. HPLC solvents are purchased from Burdick \&Jackson Inc. (Muskegon, MI). The retention time was used for qualitative analysis, and the peak area external standard method was used for quantification

\subsection{Root Colonization Assay}

To investigate root colonization refer to the method of Yu et al. (2011), a spectinomycin- and rifampin-resistant mutant of XNRB-3 was obtained by inoculation of XNRB-3 into LB (Luria-Bertani) medium containing gradually increasing concentrations of spectinomycin and rifampin (20, 50, 75, 100, 150, 200, 250, and $300 \mathrm{mg} \mathrm{mL}^{-1}$ ), and a mutant resistant to $300 \mathrm{mg} \mathrm{mL}^{-1}$ spectinomycin and rifampin was used in the study (Figure 20). In March 2017, Malus hupeheusis Rehd. seeds were stratified at $4^{\circ} \mathrm{C}$ for about 30 days. After the seeds had become white, they were sown in nutrient bowls filled with seedling substrate (organic matter $\geq 45 \%$, pH 5.8-6.5, EC $1.0-1.5 \mathrm{~ms} / \mathrm{cm}$ ). When the seedlings had grown six true leaves, disease-free plants of similar size were selected for use in subsequent experiments.

The ability of $B$. licheniformis XNRB-3 to colonize roots was determined according to the method of Sanei and Razav. (2011), with some modifications. Malus hupeheusis Rehd. Seedlings were carefully uprooted from the substrate, their roots thoroughly washed in tap water without intentional wounding, and dipped in a bacterial suspension $\left(1 \times 10^{8} \mathrm{CFU} \mathrm{ml^{-1 }}\right)$ for $10 \mathrm{~min}$. For the control treatment, plants were treated similarly except that roots were dipped in $10 \mathrm{mM}$ $\mathrm{MgSO}_{4} .7 \mathrm{H}_{2} \mathrm{O}$. Plants were then transplanted (one per pot) into pots (AC 140) filled with an autoclaved $\left(121^{\circ} \mathrm{C}, 1 \mathrm{~h}\right.$, twice on consecutive days) soil mixture (vermiculite/soil/vermiculite, 1:3:1, vol/vol/vol). There were four replicated plants for each treatment in a randomized complete block design. Plants were incubated under greenhouse conditions. The air temperature during the experiment fluctuated between $18^{\circ} \mathrm{C}$ and $33^{\circ} \mathrm{C}$. Plants were watered as needed. To determine colonization of root tissue by bacteria, plants were uprooted delicately from pots and the root systems were thoroughly washed under running tap water, dried with sterile filter paper, and cut into 1-cm long pieces. For each plant, samples of $2 \mathrm{~g}$ of root pieces were surface-deinfested in $1 \%$ NaOCl for 3 min, washed three times in sterile distilled water, and ground in $10 \mathrm{ml}$ of $10 \mathrm{mM} \mathrm{MgSO} \mathrm{m}_{4} \cdot 7 \mathrm{H}_{2} \mathrm{O}$ using an autoclaved pestle and mortar. Serial dilutions of the macerates were plated onto LB agar (LB supplemented with spectinomycin and rifampin at $300 \mathrm{mg} \mathrm{mL}^{-1}$ ) and incubated at $37^{\circ} \mathrm{C}$ for $48 \mathrm{~h}$. Then, bacterial colonies were counted and bacterial populations were expressed as colony-forming units (cfu) $/ \mathrm{g}$ of fresh root tissue.

\subsection{The protective effect of strain XNRB-3 on plant roots}

According to the method of Duan et al. (2021), the root system of M. hupehensis Rehd. seedlings was treated with the FB of strain XNRB-3 and the spore suspension of Fusarium. The roots were placed in a sterile centrifuge tube that contained $2.5 \%$ glutaraldehyde fixative and sent to Keshang Biotech Co., Ltd. for paraffin sectioning and Periodic Acid Schiff (PAS) staining (Shao et al., 2019).

\subsection{Biological control of the strain XNRB-3}

The ability of strain XNRB-3 to control ARD was investigated in an Fusarium-infested sterilized soil following the method described by Wu et al. (2019), with some modifications. Treatments included: a sterilized soil inoculated with sterile distilled water as a negative control, a sterilized soil inoculated with Fusarium as a positive control, and sterilized soil inoculated with Fusarium and the strain XNRB-3. Each treatment included 15 M. hupeheusis Rehd. Seedlings. The spore suspension of Fusarium $\left(10^{6}\right.$ spores $\left.\mathrm{mL}^{-1}\right)$ was first drenched into the sterilized soil, followed by a suspension of strain XNRB-3 $\left(10^{9} \mathrm{CFU} \mathrm{ml}{ }^{-1}\right)$. The final concentration of Fusarium $\left(10^{5}\right.$ spores $\left.\mathrm{g}^{-1}\right)$ and strain XNRB-3 $\left(10^{8} \mathrm{CFUg}^{-1}\right)$ in the growth substrates. Plant seedlings were then transplanted in the substrate trays (AC140: the outer diameter is $12.5 \mathrm{~cm}$, the inner diameter is $11 \mathrm{~cm}$, and the height is $9.5 \mathrm{~cm}$ ), and then grown at $16 \mathrm{hr}$ light/ $8 \mathrm{hr}$ dark at $28^{\circ} \mathrm{C}$. Plants were watered as required for plant growth and disease development.

Each pot contained one $M$. hupehensis seedling, and all pots were arranged randomly with three replicates per treatment and 15 pots per replicate. Disease severity was estimated over the course of 5 weeks starting 1 week after inoculation. Scoring of wilting symptoms on a 0-4 scale was performed using the criteria developed by Azabou et al. (2020). 0 = healthy plant or plant without symptoms; $1=1-33 \%$ of plant tissue affected by chlorosis, leaf and shoot necrosis, or defoliation; $2=34-66 \%$ affected tissue; $3=67-100 \%$ affected tissue; and $4=$ dead plant. The percentage of dead plants (PDP) was measured to estimate wilt severity and the ability of plants in different treatment groups to recover from the disease. The area under the disease progress curve (AUDPC) (López-Escudero et al., 2004) for each treatment was assessed according to the formula AUDPC $=[(\mathrm{t} / 2 \times(\mathrm{S} 2+2 \times \mathrm{S} 3+\cdots+2 \mathrm{Si}-1+\mathrm{Si})) / 4 \times \mathrm{n}] \times 100$, where $\mathrm{t}$ is the interval between observations in days, $\mathrm{Si}$ is the final mean severity (disease index), 4 is the maximum disease rating, and $\mathrm{n}$ is the number of observations. The final mean severity of symptoms (FMS) was calculated as $\mathrm{FMS}=\sum(\mathrm{NixXi}) / \mathrm{ni}$, where $\mathrm{Ni}$ is the number of plants with symptoms, $\mathrm{Xi}$ is the value of the symptom score, and ni is the number of diseased plants. Disease intensity (DI) based on the wilting symptoms was calculated using the equation $\mathrm{DI}$ (\%) $=100 \times \sum(\mathrm{Ni} \times \mathrm{Xi}) /(15 \times 4)$, where $\mathrm{Ni}$ is the number of plants with symptoms, $\mathrm{Xi}$ is the value of the symptom score, 15 is the total number of plants, and 4 is the maximum disease rating (Cachinero et al., 2002). The relative control effect $(\%)=\left(\mathrm{DI}_{\mathrm{CK}}-\mathrm{DI}_{\mathrm{T}}\right) / \mathrm{DI} \mathrm{IK}_{\mathrm{C}} \times 100$. Disease incidence $(\%)=$ number of diseased plants/total number of plants $\times 100$ (Wu et al., 2019). In order to fulfill Koch's postulates, isolates from discolored fibrous roots were also obtained from all dead plants at the end of the experiment. Isolation and identification of each organism were performed to the genus level. The growth substrate samples near to plant root rhizophere were collected at weekly after transplanting and stored at $-20^{\circ} \mathrm{C}$. The population of Fusarium in the growth substrate samples were determined by real-time PCR.

\subsection{Separation and Identification of extracellular metabolites}

\subsubsection{Inhibition of mycelial growth by cell-free culture filtrate}

The cell-free culture filtrate was used to assess influence of extracellular metabolites on Fusarium radial growth as described by Azabou et al. (2020), with some modifications. Bacterial culture was grown in a shaker incubator at $100 \mathrm{rpm}$ for $72 \mathrm{~h}$. Culture was then centrifuged at $10,000 \mathrm{rpm}$ for $5 \mathrm{~min}$ at $4^{\circ} \mathrm{C}$. The

Page 6/40 
supernatant was collected and filtrated through $0.22 \mu \mathrm{m}$ membrane filters. Cell-free culture filtrate was added to a warm PDA medium $\left(55^{\circ} \mathrm{C}\right)$ to final concentrations (from 5-75\%). PDA plates without culture filtrate were used as controls. Fungal mycelial plugs of 5 mm diameter were placed centrally in amended media and incubated at $25^{\circ} \mathrm{C}$ until negative control growth covers the whole surface of the plate. Growth inhibition of the pathogen was measured using the same formula previously described.

\subsubsection{Identification of extracellular metabolites by GC-MS}

The fermentation supernatant of strain XNRB-3 was extracted with ethyl acetate, and then concentrated under reduced pressure with Rotary Evaporator N1300D-WB (Tokyo, Japan) to obtain a crude extract. A small amount of methanol was added to dissolve extracts, and passed through a Nylon66 $0.22-\mu \mathrm{m}$ filter membrane, stored in a refrigerator at $4{ }^{\circ} \mathrm{C}$. The compounds in the active extract were identified by gas chromatography-mass spectrometry (GC-MS) followed by an NIST17 database search. The GC-MS analysis was performed on a GCMS-QP2010 Plus instrument (Shimadzu, Japan). The peak area normalization method was used to calculate the relative content of each component. The chromatographic and mass spectrometry conditions according to the method of Duan et al. (2021).

\subsubsection{Verification of synthetic compounds against plant fungal pathogen}

Among the identified extracellular metabolites, 16 standard compounds were purchased from the reagent company (Table S6). The antifungal activity of the standard compounds was assessed using the I-plate system described by by Yuan et al. (2012). The I-plates added with methanol or distilled water were used as control. The colony diameter of plant fungal pathogen was recorded after 7 days incubating. The experiment was repeated three times.

\subsubsection{Plant growth promotion activities of synthetic compounds}

The plant growth promotion activities of the 16 compounds were measured by the modified method described by Wu et al. (2019). The synthetic compounds were diluted separately in alcohol, and $20 \mu \mathrm{l}$ of the resulting suspension was applied to a sterile filter paper disk on the other side of the I-plate. A total of 10 $\mu \mathrm{g}, 100 \mu \mathrm{g}, 500 \mu \mathrm{g}$, and $1,000 \mu \mathrm{g}$ doses of each synthetic compounds were tested. Each treatment was repeated for three times. The fresh weight of the Arabidopsis thaliana Col-0 seedlings was measured after 10 days.

\subsection{Carrier characteristics}

15 carriers purchased from different Chinese commercial enterprises through taobao were used as formulation carriers for strain XNEB-3. The selected properties of these carrier candidates are listed in Table S7. The carriers were dried to a moisture content of $5 \%$ in an oven (Shangdong, China) at $80^{\circ} \mathrm{C}$ for 24 $\mathrm{h}$, finely ground in a hammer mill to pass through a 1-mm screen, and stored at room temperature for further studies.

The effect of the carrier as a substrate on the survival of strain XNEB-3 was evaluated using plastic bottles equipped with a $0.22-\mu \mathrm{m}$ filter membrane in the cap to allow air exchange refer to the method of Wei et al. (2015), with some modifications. $20 \mathrm{~mL}$ of fermentation broth of strain XNRB-3 was mixed with 100 $\mathrm{g}$ of each carrier (sterilization at $115^{\circ} \mathrm{C}$ for $30 \mathrm{~min}$ ). Carriers treated with $20 \mathrm{~mL}$ of aseptic fermentation broth were used as controls. Each treatment included three replications (three bottles). In addition, these plastic bottles were covered with black plastic bags to avoid the influence of light on the survival of strain XNRB-3. The bottles were stored at $25^{\circ} \mathrm{C}$ and periodically sampled at $0,10,20,30,60,90,120$, and 180 days post-inoculation. The population of strain XNRB-3 in each carrier at each sampling time point was determined by the plate count method using LB medium.

Four key factors including Inoculation amount, $\mathrm{pH}$, Temperature, and Rotating speed were selected to carry out the Box-Behnken test design with four factors and three levels. When the above fermentation conditions were optimized, except for the test single factor as a variable, the other conditions were unchanged, and the population number of strain XNRB-3 was determined for 180 days. Using Box-Behnken (Design-Expert 8.0.6) in response surface analysis (RSM) to optimize the solid fermentation conditions of strain XNRB-3(Anthony et al., 2009).

\subsection{Pot experiment.}

Soil was collected from a 31-year-old apple orchard in Manzhuang Town, Taian, China (117.081039 longitude, 36.06682 latitude). The soil samples were collected $80 \mathrm{~cm}$ from the trunk and $20-40 \mathrm{~cm}$ from the soil surface using the five-point sampling method. Physicochemical properties of the tested soil are presented in Table S8.

The BIO product was produced by Chuangdi Microbial Resources Co., Ltd. (Dezhou, China). The mixture of cow manure compost and wheat straw (1:2, w/w) was aerobically fermented with XNRB-3 for 6 days at $40^{\circ} \mathrm{C}$, and the bacterial density was $5.0 \times 10^{9} \mathrm{CFU} \cdot \mathrm{g}^{-1}$. All operations are carried out under optimized fermentation conditions. The content of OM was $46.21 \%$, TN was $2.36 \%, \mathrm{P}_{2} \mathrm{O}_{5}$ was $1.49 \%$, and $\mathrm{K}_{2} \mathrm{O}$ was $3.03 \%$.

The pot experiment was conducted at the National Apple Engineering Experiment Center of the Horticultural Science and Engineering College of Shandong Agricultural University and the State Key Laboratory of Crop Biology (117.156540 longitude, 36.164443 latitude). In May 2017, M. hupehensis seedlings were transplanted into clay pots $(38 \times 28 \times 26 \mathrm{~cm})$ that contained $75.43 \mathrm{~kg}$ of soil. There were 2 seedlings per pot and 20 pots per treatment. Potted soil was divided into the following four treatments: 31-year-old orchard soil (CK1), 31-year-old orchard soil fumigated with methyl bromide (CK2), bacterial fertilizer carrier treatment (T1), and XNRB-3 bacterial fertilizer treatment (T2). The application amount of bacterial fertilizer and manure carrier accounted for about $1 \%$ 
of the soil weight (Ma et al., 2018). Plants received normal watering and manure management, and samples from each treatment were obtained on July 15 , August 15, and September 15, 2017. Three pots from each treatment were randomly selected, and the soil was removed from the surface layer and the pot. Soil impurities were removed using a 2-mm sieve, and the soil samples were stored in separate sealed pockets.

\subsection{Field experimental trials}

In order to test the potential of XNRB-3 bacterial fertilizer to prevent and control ARD under field conditions. The field test was carried out in Wangtou Village, Laizhou City (Shandong China, Lon:119.814701, Lat:37.095159). Physicochemical properties of the tested soil are presented in Table S8. After the apple orchard was rebuilt, severe ARD occurred, the growth of fruit trees was weak, and the survival rate was less than 50\%. In March 2020, 28-year-old trees were removed from the orchard, and the replanted orchard was simultaneously established. The apple seedlings used in the experiment were two-year-old grafted seedlings. The rootstock and spike combination was Yanfu 3/T337. The grafted seedlings had a stem thickness of about $10 \mathrm{~mm}$ and a fixed stem to $1.4 \mathrm{~m}$. They were purchased from Laizhou Nature Horticultural Technology Co., Ltd. The row spacing of the plants is $1.5 \mathrm{~m} \times 4 \mathrm{~m}$, and the tree shape is pruned to a spindle shape. The production of XNRB-3 bacterial fertilizer is as above.

The experiment consisted of 4 treatments: 28-year-old orchard soil (CK1), 28-year-old orchard soil fumigated with methyl bromide (CK2), bacterial fertilizer carrier treatment (T1), and XNRB-3 bacterial fertilizer treatment (T2). Dig a planting hole of $80 \mathrm{~cm}^{3}$ according to the row spacing, mix the bacterial manure carrier and XNRB-3 bacterial manure with soil and backfill. The amount of application for each young tree is controlled at $1 \mathrm{~kg}$, and 20 trees are treated for each. A new application will be carried out at the beginning of the second spring. All indexes were measured on 15 July and 20 October, 2020,2021 . The surface soil was removed, and multiple samples within a radius of $0.5 \mathrm{~m}$ around the apple saplings in different treatments were collected. Each treatment was repeated 3 times. Impurities such as the root system and weeds, soil animals and stones were removed, after which the samples were divided into 3 portions: one part was stored in a refrigerator at $4{ }^{\circ} \mathrm{C}$ for the determination of the soil microbial structure; one part was naturally dried for soil enzyme activity, soil nutrients, and soil phenolic acid detection; one part was stored in a refrigerator at $-80{ }^{\circ} \mathrm{C}$ for DNA extraction and perform real-time fluorescence quantitative analysis (Sheng et al., 2020).

\subsection{Measurement indices}

\subsubsection{Physical and chemical properties of soil}

Soil physical and chemical properties and nutritional characteristics were measured as described by Zhang et al.(2021) and Xiang et al.(2021). Determination of nitrogen in soil by the Kjeldahl method (Bremner, 1960), $\mathrm{pH}$ and electrolytic conductivity was measured using a sample to water ratio of 1: 2.5 (w/v) with a PHS-3E digital pH meter (LEICl, Shanghai) and DDSJ-318 conductivity Meter (Lei Magnetic, Shanghai). Soil particle size distribution (the percentage of clay, silt, and sand) was determined by the hydrometer method (Avery, 1973).

\subsubsection{Microbial culture methods}

Referring to the method of Zhang et al. (2014), the populations of soil microbes (bacteria, fungi, and actinomycetes) were assessed using the dilution method of plate counting. The bacteria, fungi, and actinomycetes were incubated with beef broth peptone substrate, Potato dextrose agar (PDA, Difco), and Gause No. 1 substrate, respectively. The colony-forming unit (CFUs) per gram of dry soil was used as the unit of the populations of bacteria, fungi, and actinomycetes.

\subsubsection{Biomass and related parameters}

The height, new shoot growth, and ground diameter were measured with a rice meter and a vernier caliper (Sangon Biotech, Shanghai). The fresh and dry weights were measured with an electronic balance (OLABO, China). A Microtek ScanMaker i800 Plus scanner (Shanghai Zhongjing Technology Co., Ltd., China) was used to scan the root system. A Wanshen LA-S series plant root analysis system was used to process the sample images; total root length, surface area, forks, and tips were measured. Respiratory rate was measured by the methods of Gao et al. (2010). Roots of uniform diameter were selected, cut into 2 $\mathrm{mm}$ lengths $(\sim 0.1 \mathrm{~g})$, and placed in buffer in the measurement cuvette of the OXY-LAB oxygen electrode system (Hansatech, UK) at $25^{\circ} \mathrm{C}$ for respiration measurement.

\subsubsection{Enzyme activity}

Superoxide dismutase (SOD) activity was measured as described in Zhang et al. (2009), peroxidase (POD) activity as described in Omran. (1980), catalase (CAT) activity as described in Singh et al. (2010), and malondialdehyde (MDA) content as described in Hu et al. (2012). Soil urease, acid phosphatase (ACP), catalase, and sucrase activities were assayed by the colorimetric method, the disodium phenyl phosphate method, the permanganate titration method, and the 3,5-dinitrosalicylic acid (DNS) method, respectively (Guan, 1986). All enzyme activities are expressed based on soil dry weight.

\subsubsection{DNA extraction and Real-time quantitative analysis}

Sieved fresh soil (5.0 g) was used for DNA extraction with the PowerMax soil DNA isolation kit (MO BIO Laboratories Inc., Carlsbad, CA). Quantitative PCR amplifications for standard and environmental DNA samples were performed with a total volume of $20 \mu$ in each reaction using the SYBR ${ }^{\circledR}$ Premix Ex Taq $^{\text {TM }}$ 
(TaKaRa, Japan) and a CFX96 Touch ${ }^{\text {TM }}$ Real-Time PCR Detection System (Bio-Rad, USA) following the method of Duan et al. (2021). The concentration of plasmid DNA was measured and converted to copy concentration using the following equation as described by Whelan et al. (2003): DNA (copy)=[6.02 $\times 1023$ (copies mol $\left.{ }^{-1}\right) \times$ DNA amount (g)]/[DNA length (bp) $\times 660\left(\mathrm{gmol}^{-1} \mathrm{bp}^{-1}\right)$ ]. The primers and annealing temperatures are presented in Table S2. Sterile water was used as a negative control to replace the template. All real-time PCR reactions were done in technical triplicates such that each treatment was analyzed nine times.

\subsubsection{Terminal-restriction fragment length polymorphism (T-RFLP) analysis}

DNA was amplified using the universal primers 27F-FAM/1492R and ITS1F-FAM/ITS4R (Table S2) that target the bacterial variable region of the 16S rRNA gene and the fungal ITS region between the 18S and 28S rRNA regions, respectively. The specific steps refer to the method of Quéric and Soltwedel. (2012) and Xu et al. (2019). PCR products were cleaned with the EZNA PCR purification kit (Omega Bio-Tek, USA) following the manufacturer's instructions and quantified using a DNAmaster nuclei acid and protein analyzer (Dynamica, United Kingdom). The purified PCR product ( 500 ng) was digested by the restriction endonuclease MspI (TaKaRa, Japan) for 16S rRNA gene amplicons and HinfI (TaKaRa, Japan) for ITS amplicons in two separate reactions according to their respective protocols (Yu et al., 2014; Zhang et al., 2018) and sequenced by Sangon Biotech Co., Ltd. (Shanghai, China).

\subsubsection{Biolog plate analysis}

Biolog-ECO plates (Biolog Inc., Hayward, CA, USA) and a plate reader (Multiskan MK3 ELISA) were used to determine the community level physiological profiles. The assessment method was referenced from previous studies (Classen et al., 2003; Ge et al., 2018), with some modifications. Briefly, $3 \mathrm{~g}$ of incubated soil was mixed in $27 \mathrm{~mL}$ of a sterile $\mathrm{NaCl}$ solution $(0.85 \%, \mathrm{~m} / \mathrm{v})$ and then oscillated at $220 \mathrm{rpm}$ for 30 min. After the suspensions settled for $10 \mathrm{~min}$, $3 \mathrm{~mL}$ aliquots of the suspensions were added to $27 \mathrm{~mL}$ of a sterile $\mathrm{NaCl}$ solution $(0.85 \%, \mathrm{~m} / \mathrm{v})$ as tenfold serial dilutions until a final $1: 1000$ dilution was reached; $150 \mu \mathrm{L}$ of the supernatants was then added to each well of the Biolog-ECO plates. Microplates were incubated at $25^{\circ} \mathrm{C}$ and $85 \% \pm 5 \%$ humidity in a dark room. The rate of utilization is indicated by the reduction of tetrazolium violet, a redox indicator dye, which changes from colorless to purple. Data were recorded at $590 \mathrm{~nm}$ every $24 \mathrm{~h}$ up to $168 \mathrm{~h}$. The OD values at the $96 \mathrm{~h}$ incubation were used for subsequent statistical analyses (Dang et al., 2015). All treatments had three triplicates.

During data treatment, OD readings from the control wells were subtracted from the OD of the treatment wells. Wells with negative OD well responses were coded as zeroes. Average well color development (AWCD) and average absorbance of each category were calculated in line with the recommendations of Garland. (1996). Indices of Shannon-Wiener diversity index, Shannon evenness index, Mclntosh index, and Simpson diversity index were used to evaluate the richness and dominance of species in the soil microbial community (Dang et al., 2015). According to the method described by Ge et al.(2018), principal component analysis (PCA) was used to analyze the data of Biolog-ECO microplates.

(1) AWCD $=[\Sigma(C i-R)] / n$. In formula (1), Ci is the absorbance value of each reaction well at $590 \mathrm{~nm}, \mathrm{R}$ is the absorbance value of the control well, and $\mathrm{n}$ is the number of wells.

(2) Shannon-Wiener diversity index $\left(\mathrm{H}^{\prime}\right)$ reflects the species richness.

$\mathrm{H}^{\prime}=-\sum \mathrm{Pi} . \operatorname{In}(\mathrm{Pi})$. The Pi represents the ratio of the absorbance value in the $\mathrm{i}^{\text {th }}$ (1 to 31$)$ well to the total absorbance values of all wells.

(3) Shannon evenness index (E): $E=H^{\prime} / H m a x=H^{\prime} / I n S$, S represents the total number of utilized carbon sources (31 carbon sources), the number of wells that vary in color.

(4) Simpson diversity index (D) reflects the most common species of the community, and was often used to assess the dominance degree of microbial community. $\mathrm{D}=1-\Sigma(\mathrm{Pi})^{2}$

(5) Mclntosh index was used to measure the homogeneity degree of the community.

$\mathrm{U}=\sqrt{\Sigma} \mathrm{ni}^{2}$. ni was the relative absorbance of the $\mathrm{i}^{\text {th }}$ hole $(\mathrm{Ci}-\mathrm{R})$.

\subsection{Statistical analysis}

All statistical analyses were performed with the IBM SPSS 20.0 (IBM SPSS Statistics, IBM Corporation, USA). One-way analysis of variance (ANOV A) was performed. Comparisons were made using the least significant difference (LSD) test, and differences were considered significant at the $p<0.05$ level. The figures were plotted with Microsoft Excel 2013 (Microsoft Corporation) and Graphpad prism 7.0 (GraphPad software, Inc., USA).

T-RFLP profiles were analyzed using the Peak ScannerTMSoftware v1.0 (ThermoFisher Scientific, Wilmington, USA) with an exclusion of,T-RFs less than 50 bp in length or contributing less than $0.5 \%$ of peak area in each sample for subsequent analyses. The apparent T-RFs sizes in capillary electrophoresis are compared against MiCA database to analysis the phylotype. The R statistical platform (v.4.1.1) was used for Principal coordinates (PCoA) and cluster analysis to study the difference of sample community composition. The differences between samples were calculated by Bray-curtis, and analysis of similarity (ANOSIM) was conducted to identify the significant differences between the fungal communities (Liu et al., 2019a; Xu et al., 2020). Richness index (SR) and evenness index (E) were calculated by Bio-dap software were calculated by Bio-dap software (Duan et al., 2021). 


\section{Results}

\subsection{Isolation and identification of bacteria for biocontrol activity}

The bacterium XNRB-3 was isolated from the root system of a healthy fruit tree in a replanted orchard in Jincheng City, Shanxi Province. This bacterium had the strongest inhibitory effect on plant pathogenic fungi, with an inhibition rate of more than $70 \%$. F. oxysporum and Alternaria alternata had the strongest inhibition rates, reaching $84.52 \%$ and $84.59 \%$, respectively (Figure 1 C).

Strain XNRB-3 was cultured on LB agar at $37^{\circ} \mathrm{C}$ for $24 \mathrm{~h}$; the surface of the colony was white with irregular edges, and the surface was flat to convex, smooth, and opaque (Figure S2 A). It formed biofilms when grown in liquid medium. Inspection under a fluorescence microscope (100x/1.30 oil lens) revealed that individual bacteria were long and rod-shaped; they also formed ovoid spores $(0.5-0.7 \times 1.0-1.4 \mu \mathrm{m})$ and were mesophytic or subterminal, and their gram stain was positive (Figure S2 B-C). Observation with a SU-8010 scanning electron microscope revealed that individual bacteria were rod-shaped, with blunt ends at both ends and without flagella; bacteria grew solitary and were paired or chain-like; and their size was (0.1-0.8) $\mu \mathrm{m} \times(1.5-3.5) \mu \mathrm{m}($ Figure S2 D-I).

Physiological and biochemical tests revealed that strain XNRB-3 could produce hydrogen peroxide and hydrogen sulfide, hydrolyze starch, reduce nitrate, and use sucrose. The results of the contact enzyme, Voges-Proskauer reaction, and methyl red reaction tests were positive, whereas the results of the indole enzyme, arginine bihydrolysis reaction, citrate enzyme, and glucose fermentation reaction tests were negative. According to Bergey's Manual of Systematic Bacteriology (2nd edition) and the Common Bacterial Identification Manual, strain HSB-2 matched the physiological and biochemical properties of $B$. licheniformis (Table S9).

Tests of the carbon source utilization and chemical sensitivity using a Biolog GEN III MicroPlate ${ }^{\text {TM }}$ revealed that strain XNRB-3 can utilize 32 carbon sources such as dextrin, D-maltose, and pentabiose and is sensitive to $\mathrm{pH} 6,1 \% \mathrm{NaCl}, 4 \% \mathrm{NaCl}$, and $8 \% \mathrm{NaCl}$ conditions. The strain XNRB-3 belonged to $B$. licheniformis, which was identified based on carbon utilization (Table S10-11). The values of PROB, SIM, and DIST were $0.689,0.689$, and 4.698, respectively, indicating that reliable matching results were obtained.

Approximately 555-938 bases were sequenced for $r p o B$ and $g y r A, 1,455$ bases for $16 \mathrm{~S}$ rDNA, and 1,136 bases for gyrB. Congruency analysis revealed no conflict between the $16 \mathrm{~S}$ rDNA, gyrA, gyrB, and $r p o B$ sequences; the sequences were therefore combined. Maximum likelihood (ML) analysis of identities based on the four gene sequence alignments revealed that strain XNRB-3 had the highest homology with Bacillus licheniformis (Figure S3). In sum, strain XNRB-3 was identified as $B$. licheniformis.

\subsection{PGP activities}

The endophytic bacterium XNRB-3 possessed multiple PGP properties such as phosphate and potassium solubilization; nitrogen fixation; IAA, GA, and ABA production; ACC deaminase, ammonia, and amylase production; siderophore, cell wall-degrading enzyme (cellulase, pectinase, $\beta 1,3-g l u c a n a s e, ~ c h i t o s a n a s e$, and protease), and antifungal activity against phytopathogens (Table S4,12; Figure 2A-M).

An HPCE method was used to identify 20 PITC-derivatized amino acids, 17 of which were separated (Table S13), including Aspartic acid (Asp), Threonine (Thr), Serine (Ser), Glutamate (Glu), Proline (Pro), Glycine (Gly), Alanine (Ala), Cystine (Cys), Valine (Val), Methionine (Met), Isoleucine (lle), Leucine (Leu), Tyrosine (Tyr), Phenylalanine (Phe), Histidine (His), Lysine (Lys), and Arginine (Arg).

\subsection{Identification of antibiotic biosynthesis genes from XNRB-3}

To determine the mechanisms underlying the effects of the antagonistic strain, polymerase chain reaction (PCR) was used to screen XNRB-3 for genes involved in the biosynthesis of antibiotics. Amplicons of the expected sizes detected included $y n d J$ (involved in biosynthesis of Yndj protein), $q k$ (involved in subtilisin synthesis), bamC (involved in bacillomycin synthesis), ituD (involved in iturin A synthesis), fen and fenD (involved in fengycin synthesis), and srf and srfAB (involved in surfactin synthesis) (Figure S4).

\subsection{Optimization of liquid fermentation conditions}

The results of single-factor tests showed that the main carbon source affecting the growth of strain XNRB-3 was sucrose, the main nitrogen source was beef extract, and the inorganic salts were $\mathrm{MgSO}_{4}, \mathrm{KH}_{2} \mathrm{PO}_{4}$, and $\mathrm{KCl}$ (Figure S1 D,G,H). According to the orthogonal test results (Table S14), the organic salt that had the strongest effect on the growth of strain XNRB-3 was $\mathrm{MgSO}_{4}$, followed by $\mathrm{KH}_{2} \mathrm{PO}_{4}$ and $\mathrm{KCl}$. According to the $\mathrm{K}$ value, the optimal combination was $\mathrm{F} 4 \mathrm{I} \mathrm{E} 3$ $\left(\mathrm{MgSO}_{4} 1.0 \mathrm{~g} \mathrm{~L}^{-1}, \mathrm{~K}_{2} \mathrm{HPO}_{4} 1.5 \mathrm{~g} \mathrm{~L}^{-1}\right.$, and KCl $\left.1.0 \mathrm{~g} \mathrm{~L}^{-1}\right)$. According to the results of the single-factor experiment (Figure S1), the Plackett-Burman experiment was performed using the experimental factors and levels in Table S15, and Minitab 17 software was used for multiple regression analysis. The optimal equation with $\mathrm{OD}_{600}$ as the response value was $\mathrm{OD}_{600}=0.4472+0.004009 \mathrm{~A}-0.004149 \mathrm{~B}-0.01018 \mathrm{C}-0.01204 \mathrm{D}+0.00649 \mathrm{E}-0.01527 \mathrm{~F}$

$+0.00465 \mathrm{G}+0.001711 \mathrm{H}+0.000272$. According to the size of the $\mathrm{P}$ value, the key factor affecting $\mathrm{OD}_{600}$ was $\mathrm{A}$ (temperature), followed by $\mathrm{B}$ (rotating speed), $\mathrm{G}$ (sucrose), $\mathrm{H}$ (beef extract), $\mathrm{F}\left(\mathrm{MgSO}_{4}\right), \mathrm{I}\left(\mathrm{KH}_{2} \mathrm{PO}_{4}\right), \mathrm{D}(\mathrm{pH}), \mathrm{C}$ (liquid volume), and $\mathrm{E}(\mathrm{KCl})$ (Table S16-17). The effect of $\mathrm{A}-\mathrm{H}$ was highly significant ( $\left.\mathrm{P}<0.01\right)$, the effect of $F$ was significant $(P<0.05)$, and the effect of $I-E$ was not significant. A Box-Behnken test was conducted with four factors (sucrose, beef extract, temperature, and rotating speed) and three levels (Table S18). Design Expert 8.0.6 software was used to perform regression analysis and obtain the multiple quadratic regression equations: $Y=+22.054-0.1142 A-0.0875 B+0.4358 C-0.5942 D-0.1175 A B+1.6175 A C+0.1075 A D-0.4825 B C-0.0975 B D-0.6425 C D-0.8941 A^{2}-$ $0.4016 B^{2}-1.7641 C^{2}-2.1366 D^{2}$, where $Y$ was the inhibition zone diameter $(\mathrm{mm})$, A was sucrose, $B$ was beef extract, $C$ was temperature, and $D$ was rotating speed. Analysis of variance and significance test of the regression model were conducted (Table S19, Table 1), The F value of the regression model was 94.09 $(P<0.0001)$, which indicated that the regression model was robust. The coefficient of determination of the model was $R^{2}=0.9895$ and $R^{2}$ Adj $=0.9790$, indicating a good fit. Therefore, the regression model could be used to analyze and predict the abundance of the strain XNRB-3. In the regression model, the primary term 
$C, D$ and the secondary term $A C, C D$ significantly affected the diameter of the inhibition zone $(P<0.0001)$; the significance of $A, B, C, D$ was the same based on the results of the Plackett-Burman test.

Table 1

ANOVA for response surface quadratic model.

\begin{tabular}{|c|c|c|c|c|c|c|}
\hline Source & Degree of freedom & Sum of squares & Mean squares & F value & P value (Prob>F) & significance \\
\hline Model & 14 & 62.98152943 & 4.498680673 & 94.09309895 & $<0.0001$ & $\star *$ \\
\hline A-Sucrose & 1 & 0.156408333 & 0.156408333 & 3.271391293 & 0.092019216 & \\
\hline B-Beef extract & 1 & 0.091875 & 0.091875 & 1.921630828 & 0.187359213 & \\
\hline C-Temperature & 1 & 2.279408333 & 2.279408333 & 47.67544296 & $<0.0001$ & $\star \star$ \\
\hline D-Rotating speed & 1 & 4.236408333 & 4.236408333 & 88.60748683 & $<0.0001$ & $\star *$ \\
\hline$A B$ & 1 & 0.055225 & 0.055225 & 1.155070068 & 0.300664777 & \\
\hline$A C$ & 1 & 10.465225 & 10.465225 & 218.8876079 & $<0.0001$ & $\star \star$ \\
\hline$A D$ & 1 & 0.046225 & 0.046225 & 0.96682868 & 0.342160859 & \\
\hline $\mathrm{BC}$ & 1 & 0.931225 & 0.931225 & 19.47723176 & 0.000589533 & * \\
\hline $\mathrm{BD}$ & 1 & 0.038025 & 0.038025 & 0.795319861 & 0.387567486 & \\
\hline $\mathrm{CD}$ & 1 & 1.651225 & 1.651225 & 34.53654273 & $<0.0001$ & $\star *$ \\
\hline$A^{2}$ & 1 & 5.185200045 & 5.185200045 & 108.4521388 & $<0.0001$ & ** \\
\hline$B^{2}$ & 1 & 1.046070315 & 1.046070315 & 21.87930303 & 0.000356012 & * \\
\hline$c^{2}$ & 1 & 20.18588113 & 20.18588113 & 422.2020295 & $<0.0001$ & $\star *$ \\
\hline$D^{2}$ & 1 & 29.61073518 & 29.61073518 & 619.3295407 & $<0.0001$ & $\star *$ \\
\hline Residual & 14 & 0.669353333 & 0.047810952 & & & \\
\hline Lack of Fit & 10 & 0.472033333 & 0.047203333 & 0.956888979 & 0.568501936 & \\
\hline Pure Error & 4 & 0.19732 & 0.04933 & & & \\
\hline Cor Total & 28 & 63.65088276 & & & & \\
\hline
\end{tabular}

The shape of the response surface and the contour line can reflect the strength of interaction effects. Steeper response surfaces and greater proximity of the contour line to the ellipse are positively correlated with the significance of the effect (Figure 3). The interactions between temperature and sucrose, temperature and beef extract, and rotating speed and beef extract were the most significant; the interactions between rotating speed and sucrose, temperature and rotating speed, and the sucrose and beef extract on the diameter of the inhibition zone were relatively weak. The optimal fermentation conditions for strain XNRB-3 predicted by the regression model were sucrose $21.03 \mathrm{~g}$, beef extract $8.54 \mathrm{~g}$, temperature $32.73^{\circ} \mathrm{C}$, and rotating speed $191.46 \mathrm{rpm}$. The maximum theoretical value of the predicted inhibition zone diameter was $22.17 \mathrm{~mm}$. To further verify the predicted value, three parallel experiments were performed using the optimized fermentation conditions, and the diameter of the inhibition zone was $22.03 \pm 0.24 \mathrm{~mm}$; the error from the theoretically predicted value $(22.17 \mathrm{~mm})$ was only $0.63 \%$, indicating that the predicted value was a good fit with the measured value. Thus, the optimized model was reliable.

In sum, the optimal fermentation conditions for strain XNRB-3 were sucrose $21.03 \mathrm{~g}$, beef extract $8.54 \mathrm{~g}, \mathrm{MgSO}_{4} 1.0 \mathrm{~g}, \mathrm{~K}_{2} \mathrm{HPO} \mathrm{H}_{4} 1.5 \mathrm{~g}, \mathrm{KCl} 1.0,1 \mathrm{~L}, \mathrm{pH} 7.5$, temperature $32.73{ }^{\circ} \mathrm{C}$, rotating speed 191.46 , inoculation amount $5 \%$, and filling volume $40 \%$. Under optimal conditions, CK was used as a control to determine the $\mathrm{OD}_{600}$ absorbance value (after dilution) of the bacterial solution at different incubation times; to draw a growth curve, the $\mathrm{OD}_{600}$ absorbance value was used as the vertical axis, and the incubation time was used as the horizontal axis (Figure S1 B).

\subsection{Optimization of solid fermentation conditions}

A long and stable shelf life is one of the most important commercial characteristics of biocontrol products. Therefore, the population dynamics (an index of shelf life) of strain XNRB-3 using different candidate carriers were characterized in LB medium.

At the end of the storage period, the viable numbers of strain XNRB-3 in CDC and wheat straw were greater than 8.78 and 8.74 log CFU g $\mathrm{g}^{-1}$ dry carrier, respectively. CDC: wheat straw maintained the largest populations of strain XNRB-3 at a ratio of 1:2 (Figure 4M-0). Design Expert 8.0.6 software was used to perform regression analysis of the test data of Table $S 20-21$, and the multiple quadratic regression equation obtained was as follows: $Y=8.716$ -

$0.43 A+1.2608 B+0.6767 C+0.2692 D-0.52 A B-0.155 A C+0.145 A D+0.6125 B C+0.465 B D-0.1475 C D-0.9405-A^{2}-2.0218 B^{2}-0.7355 C^{2}-0.4243 D^{2}$, where $Y$ is population $(\mathrm{E}+08), \mathrm{A}$ is the inoculation amount; $\mathrm{B}$ is $\mathrm{pH}, \mathrm{C}$ is temperature, and $\mathrm{D}$ is rotating speed. The regression model was further analyzed by variance analysis and significance tests (Table 2). The $F$ value of the regression model was $102.13(P<0.0001)$, indicating that the regression model was robust. The coefficient of determination of the model was $\mathrm{R}^{2}=0.9903$ and $\mathrm{R}^{2} \mathrm{Adj}=0.9806$, indicating a good fit. Therefore, the regression model could be used to analyze and predict the abundance of $B$. licheniformis XNRB-3. In the regression model, the effects of the first term A, B, C and the second term BC on the diameter of the inhibition 
zone were significant $(\mathrm{P}<0.0001)$. The interactions between $\mathrm{pH}$ and inoculation amount, temperature and $\mathrm{pH}$, and rotating speed and $\mathrm{pH}$ had the most significant effect on the population of strain XNRB-3. The optimal solid fermentation conditions for $B$. licheniformis XNRB-3 were predicted by the regression model: inoculation amount $20.25 \%$, pH 8.25, temperature $39.23{ }^{\circ} \mathrm{C}$, and rotating speed $199.75 \mathrm{rpm}$. The predicted maximum theoretical value of the population of strain XNRB-3 was $8.91 \mathrm{E}+08$. To verify the predicted value, three parallel experiments were performed using the optimized fermentation conditions, and the diameter of the inhibition zone was $(22.03 \pm 0.24) \mathrm{mm}$; the error from the theoretically predicted value $(8.91 \mathrm{E}+08)$ was only $0.86 \%$, indicating that there was a good fit between the predicted value and the measured value and that the optimized model was robust.

Table 2

ANOVA for response surface quadratic model.

\begin{tabular}{|c|c|c|c|c|c|c|}
\hline Source & Degree of freedom & Sum of squares & Mean squares & F value & P value (Prob>F) & significance \\
\hline Model & 60.51220155 & 14 & 4.322300111 & 102.1311598 & $<0.0001$ & $\star *$ \\
\hline A-Inoculation amount & 2.2188 & 1 & 2.2188 & 52.4277842 & $<0.0001$ & ** \\
\hline B-pH & 19.07640833 & 1 & 19.07640833 & 450.7543805 & $<0.0001$ & ** \\
\hline C-Temperature & 5.494533333 & 1 & 5.494533333 & 129.8297313 & $<0.0001$ & $\star \star$ \\
\hline D-Rotating speed & 0.869408333 & 1 & 0.869408333 & 20.54315508 & 0.0005 & * \\
\hline$A B$ & 1.0816 & 1 & 1.0816 & 25.55700892 & 0.0002 & * \\
\hline$A C$ & 0.0961 & 1 & 0.0961 & 2.270736462 & 0.1541 & \\
\hline$A D$ & 0.0841 & 1 & 0.0841 & 1.987189765 & 0.1805 & \\
\hline $\mathrm{BC}$ & 1.500625 & 1 & 1.500625 & 35.45810513 & $<0.0001$ & ** \\
\hline $\mathrm{BD}$ & 0.8649 & 1 & 0.8649 & 20.43662816 & 0.0005 & * \\
\hline$C D$ & 0.087025 & 1 & 0.087025 & 2.056304273 & 0.1735 & \\
\hline$A^{\wedge} 2$ & 5.737558378 & 1 & 5.737558378 & 135.5721437 & $<0.0001$ & ** \\
\hline $\mathrm{B}^{\wedge} 2$ & 26.51333878 & 1 & 26.51333878 & 626.4808023 & $<0.0001$ & $\star *$ \\
\hline $\mathrm{C}^{\wedge} 2$ & 3.508931351 & 1 & 3.508931351 & 82.91215777 & $<0.0001$ & ** \\
\hline$D^{\wedge} 2$ & 1.167490135 & 1 & 1.167490135 & 27.58649759 & 0.0001 & * \\
\hline Residual & 0.592495 & 14 & 0.042321071 & & & \\
\hline Lack of Fit & 0.490975 & 10 & 0.0490975 & 1.934495666 & 0.2745 & \\
\hline Pure Error & 0.10152 & 4 & 0.02538 & & & \\
\hline Cor Total & 61.10469655 & 28 & & & & \\
\hline
\end{tabular}

In sum, the optimal solid fermentation component of $B$. licheniformis XNRB-3 was cow dung: wheat straw=1:2, and the optimal conditions were inoculation amount $20.25 \%, \mathrm{pH} 8.25$, temperature $39.23^{\circ} \mathrm{C}$, and rotating speed $199.75 \mathrm{rpm}$.

\subsection{Determination of antifungal activity}

Microscopic observations of hyphal and spore morphology revealed that the control Fusarium mycelium was uniform in thickness and slender with fewer branches; it was full of spores, its structure was complete, and its growth was strong (Figure 1A A-D). The mycelia treated with the cell-free culture filtrate were irregularly reticulated, uneven in thickness, shrunken (Figure 1A G-L), thinned (Figure 1A I, K), and broken (Figure 1A I, G, H); the spore cell wall was broken and deformed (Figure 1A E, I, K, H); the mycelia were dissolved; the cells had ruptured; and the cell contents had overflowed (Figure 1A G, K, H). Fermentation broth, cell-free culture filtrate, and crude extract significantly inhibited the spore germination of Fusarium spores, and the spore germination rate decreased by more than $60 \%$ (Figure 1A B, E). The antifungal metabolites produced by XNRB-3 were extracted from 3-day-old cell-free culture filtrates. As the concentration of extracellular metabolites increased, the inhibitory effect on the growth of Fusarium became more pronounced. At higher concentrations (25\%, $50 \%$, and $75 \%$ ), the inhibition rate reached more than $60 \%$ (Figure 1D).

\subsection{Identification of antifungal compounds}

Our results showed that a $25 \%$ concentration of bacterial cell-free culture filtrate of $B$. licheniformis XNRB-3 showed high activity against fungal pathogens.

After GC-MS chromatographic detection and analysis, the main antibacterial substances with Area\% $>0.62$ and retention index RI $>700$ were selected (Figure S5, Table S22). Most substances identified from the components were organic acids and esters, alcohols, ketones, alkanes, and phenols (Figure 5). Among the 42 identified compounds, 16 pure compounds were purchased for individual testing of antifungal properties (Figure S6). The 9 pure compounds showed antifungal activity against pathogenic fungi (Table 3). Among them, 2,4-di-tert-butylphenol and alpha-bisabolol had the strongest inhibitory effect on plant pathogenic fungi, especially Fusarium. At a concentration of $1000 \mu \mathrm{g} \mathrm{L}^{-1}$, the inhibition rate was higher than 50\% (Figure 6) $\square 0 \mathrm{Of}$ the 9 pure compounds, the fresh weight and root growth of Arabidopsis plants compared with the control treatment (water and ethanol) were significantly enhanced by butanedioic acid,

Page $12 / 40$ 
monomethyl ester $(500 \mu \mathrm{g})$, and dibutyl phthalate $(500 \mu \mathrm{g})$, followed by 2,4-di-tert-butylphenol $(500 \mu \mathrm{g})$, alpha-bisabolol ( $500 \mu \mathrm{g}), 3-\mathrm{nonen}-2$-one $(500 \mu \mathrm{g})$, benzoic acid, 3,4-dimethyl-, methyl ester $(100 \mu \mathrm{g})$, 2,3-butanediol $(100 \mu \mathrm{g})$, and acetoin $(500 \mu \mathrm{g})$ (Figure 7A-D). Compared with ethanol treatment, the fresh weight, root length, number of primary roots, and number of secondary roots of Arabidopsis seedlings were increased by approximately $2.56,1.42,0.91$, and 5.5 times, respectively, when treated with dibutyl phthalate; by $2.01,4.08,0.33$, and 4.5 times, respectively, when treated with butanedioic acid and monomethyl ester; and by $1.89,0.89,0.71$, and 10.5 times, respectively, when treated with 3-nonen-2-one. The above findings indicated that the main antifungal compounds produced by strain XNRB-3 play important roles in disease control and growth. 
Table 3

The inhibition of plant fungal pathogens mycelia growth by pure compounds identified from $B$. licheniformis XNRB3. Values in columns followed by the sam $\epsilon$ test at $\mathrm{P}<0.05$. Values are mean \pm SD. - , No inhibitory effect on fungi. *, the diameter of the fungus cannot be $r$

\begin{tabular}{|c|c|c|c|c|c|c|c|c|c|}
\hline Number & Ingredient name & Concentration $\left(\mu \mathrm{gL}^{-}\right)$ & $\begin{array}{l}F \\
\text { proliferatum }\end{array}$ & $\begin{array}{l}\text { F. } \\
\text { verticillioides }\end{array}$ & $\begin{array}{l}F \\
\text { oxysporum }\end{array}$ & F. solani & $\begin{array}{l}\text { Rhizoctonia } \\
\text { solani }\end{array}$ & $\begin{array}{l}\text { Alternaria } \\
\text { alternata }\end{array}$ & $\begin{array}{l}A / b i \\
\text { vert }\end{array}$ \\
\hline \multirow[t]{4}{*}{1} & \multirow[t]{4}{*}{ Harmaline } & 10 & - & - & - & - & - & - & - \\
\hline & & 100 & - & - & - & - & - & - & - \\
\hline & & 500 & - & - & - & - & - & - & - \\
\hline & & 1000 & - & - & - & - & - & - & - \\
\hline \multirow[t]{4}{*}{2} & \multirow[t]{4}{*}{$\mathrm{CH} 3 \mathrm{C}(\mathrm{O}) \mathrm{CH} 2 \mathrm{CH} 2 \mathrm{OH}$} & 10 & - & - & - & - & - & - & - \\
\hline & & 100 & - & - & - & - & - & - & - \\
\hline & & 500 & - & - & - & - & - & - & - \\
\hline & & 1000 & - & - & - & - & - & - & - \\
\hline \multirow[t]{4}{*}{3} & \multirow[t]{4}{*}{ Rhodanine } & 10 & - & - & - & - & - & - & - \\
\hline & & 100 & - & - & - & - & - & - & - \\
\hline & & 500 & - & - & - & - & - & - & - \\
\hline & & 1000 & - & - & - & - & - & - & - \\
\hline \multirow[t]{4}{*}{4} & \multirow[t]{4}{*}{ Triethyl citrate } & 10 & - & - & - & - & - & - & - \\
\hline & & 100 & - & - & - & - & - & - & - \\
\hline & & 500 & - & - & - & - & - & - & - \\
\hline & & 1000 & - & - & - & - & - & - & - \\
\hline \multirow[t]{4}{*}{5} & \multirow{4}{*}{$\begin{array}{l}\text { Benzeneacetic acid, } \\
\text { 4-hydroxy-, methyl } \\
\text { ester }\end{array}$} & 10 & - & - & - & - & - & - & - \\
\hline & & 100 & - & - & - & - & - & - & - \\
\hline & & 500 & - & - & - & - & - & - & - \\
\hline & & 1000 & - & - & - & - & - & - & - \\
\hline \multirow[t]{4}{*}{6} & \multirow[t]{4}{*}{ Duroquinone } & 10 & - & - & - & - & - & - & - \\
\hline & & 100 & - & - & - & - & - & - & - \\
\hline & & 500 & - & - & - & - & - & - & - \\
\hline & & 1000 & - & - & - & - & - & - & - \\
\hline \multirow[t]{4}{*}{7} & \multirow[t]{4}{*}{ 2-Coumaranone } & 10 & - & - & - & - & - & - & - \\
\hline & & 100 & - & - & - & - & - & - & - \\
\hline & & 500 & - & - & - & - & - & - & - \\
\hline & & 1000 & - & - & - & - & - & - & - \\
\hline \multirow[t]{4}{*}{8} & \multirow[t]{4}{*}{ 2,3-Butanediol } & 10 & $7.03 \pm 0.01 a$ & $7.02 \pm 0.00 \mathrm{a}$ & - & $7.01 \pm 0.00 \mathrm{a}$ & - & $7.01 \pm 0.01 a$ & $3.7 C$ \\
\hline & & 100 & $7.02 \pm 0.00 \mathrm{a}$ & $7.01 \pm 0.00 \mathrm{~b}$ & - & $6.81 \pm 0.00 \mathrm{~b}$ & - & $7.01 \pm 0.00 \mathrm{a}$ & $3.6 \mathrm{C}$ \\
\hline & & 500 & $7.01 \pm 0.01 \mathrm{a}$ & $6.9 \pm 0.01 \mathrm{c}$ & - & $6.80 \pm 0.00 \mathrm{bc}$ & - & $7.00 \pm 0.00 a$ & 3.41 \\
\hline & & 1000 & $6.80 \pm 0.00 \mathrm{~b}$ & $6.70 \pm 0.00 d$ & - & $6.80 \pm 0.00 c$ & - & $7.00 \pm 0.00 a$ & 2.31 \\
\hline \multirow[t]{4}{*}{9} & \multirow{4}{*}{$\begin{array}{l}\text { 2,4-Di-tert- } \\
\text { butylphenol }\end{array}$} & 10 & $4.50 \pm 0.00 a$ & $4.01 \pm 0.00 \mathrm{a}$ & $5.10 \pm 0.00 a$ & $4.80 \pm 0.00 a$ & $4.21 \pm 0.00 a$ & $3.80 \pm 0.00 a$ & $2.1 \mathrm{C}$ \\
\hline & & 100 & $4.01 \pm 0.00 \mathrm{~b}$ & $3.50 \pm 0.00 \mathrm{~b}$ & $4.50 \pm 0.00 \mathrm{~b}$ & $4.61 \pm 0.00 \mathrm{~b}$ & $2.01 \pm 0.01 b$ & $3.01 \pm 0.00 \mathrm{~b}$ & $2.0 \mathrm{C}$ \\
\hline & & 500 & $3.60 \pm 0.00 c$ & $3.40 \pm 0.00 c$ & $4.30 \pm 0.00 c$ & $4.40 \pm 0.00 c$ & $1.70 \pm 0.00 c$ & $2.90 \pm 0.00 \mathrm{c}$ & 1.81 \\
\hline & & 1000 & $2.30 \pm 0.00 \mathrm{~d}$ & $3.10 \pm 0.00 d$ & $3.50 \pm 0.00 \mathrm{~d}$ & $4.10 \pm 0.00 \mathrm{~d}$ & $1.50 \pm 0.00 \mathrm{~d}$ & $2.60 \pm 0.00 d$ & $1.1 \mathrm{C}$ \\
\hline \multirow[t]{4}{*}{10} & \multirow{4}{*}{$\begin{array}{l}\text { 1,2- } \\
\text { Benzenedicarboxylic } \\
\text { acid, bis(1- } \\
\text { methylethyl) ester }\end{array}$} & 10 & $6.50 \pm 0.00 a$ & $6.53 \pm 0.03 a$ & $7.50 \pm 0.00 a$ & $7.51 \pm 0.00 a$ & $5.50 \pm 0.00 a$ & $4.21 \pm 0.00 \mathrm{a}$ & 3.11 \\
\hline & & 100 & $5.20 \pm 0.00 \mathrm{~b}$ & $5.51 \pm 0.01 b$ & $7.01 \pm 0.00 \mathrm{~b}$ & $6.50 \pm 0.00 \mathrm{~b}$ & $4.80 \pm 0.00 \mathrm{~b}$ & $4.00 \pm 0.00 \mathrm{~b}$ & $3.1 \mathrm{C}$ \\
\hline & & 500 & $4.30 \pm 0.00 c$ & $4.50 \pm 0.00 c$ & $4.00 \pm 0.00 \mathrm{c}$ & $5.61 \pm 0.00 \mathrm{c}$ & $4.00 \pm 0.00 c$ & $3.41 \pm 0.00 \mathrm{c}$ & $2.6 \mathrm{C}$ \\
\hline & & 1000 & $2.00 \pm 0.00 \mathrm{~d}$ & $3.10 \pm 0.00 \mathrm{~d}$ & $2.80 \pm 0.00 \mathrm{~d}$ & $5.20 \pm 0.00 \mathrm{~d}$ & $2.30 \pm 0.00 d$ & $3.20 \pm 0.00 \mathrm{~d}$ & $1.7 C$ \\
\hline
\end{tabular}




\begin{tabular}{|c|c|c|c|c|c|c|c|c|c|}
\hline Number & Ingredient name & Concentration $\left(\mu \mathrm{gL}^{-}\right)$ & $\begin{array}{l}\text { F. } \\
\text { proliferatum }\end{array}$ & $\begin{array}{l}\text { F. } \\
\text { verticillioides }\end{array}$ & $\begin{array}{l}\text { F. } \\
\text { oxysporum }\end{array}$ & F. solani & $\begin{array}{l}\text { Rhizoctonia } \\
\text { solani }\end{array}$ & $\begin{array}{l}\text { Alternaria } \\
\text { alternata }\end{array}$ & $\begin{array}{l}\text { Albi } \\
\text { verr }\end{array}$ \\
\hline \multirow[t]{4}{*}{11} & \multirow{4}{*}{$\begin{array}{l}\text { Butanedioic acid, } \\
\text { monomethyl ester }\end{array}$} & 10 & $7.00 \pm 0.00 a$ & $7.61 \pm 0.00 \mathrm{a}$ & $7.80 \pm 0.00 \mathrm{a}$ & $7.50 \pm 0.00 a$ & - & $8.01 \pm 0.00 a$ & $3.5 \mathrm{C}$ \\
\hline & & 100 & $6.20 \pm 0.00 \mathrm{~b}$ & $7.50 \pm 0.00 \mathrm{~b}$ & $7.80 \pm 0.00 \mathrm{~b}$ & $7.20 \pm 0.00 a$ & - & $7.20 \pm 0.00 b$ & $3.5 \mathrm{C}$ \\
\hline & & 500 & $6.00 \pm 0.00 c$ & $7.30 \pm 0.00 c$ & $7.51 \pm 0.00 c$ & $6.53 \pm 0.00 \mathrm{~b}$ & - & $6.80 \pm 0.00 c$ & $3.4 \mathrm{C}$ \\
\hline & & 1000 & $5.83 \pm 0.03 d$ & $6.50 \pm 0.00 d$ & $7.00 \pm 0.00 \mathrm{~d}$ & $7.00 \pm 0.00 c$ & - & $6.61 \pm 0.03 d$ & $3.0 \mathrm{C}$ \\
\hline \multirow[t]{4}{*}{12} & \multirow[t]{4}{*}{.alpha.-Bisabolol } & 10 & $6.00 \pm 0.00 a$ & $7.31 \pm 0.00 \mathrm{a}$ & $7.01 \pm 0.00 \mathrm{a}$ & $7.00 \pm 0.00 a$ & $4.57 \pm 0.07 a$ & $5.10 \pm 0.00 a$ & $3.5 \mathrm{C}$ \\
\hline & & 100 & $4.70 \pm 0.00 \mathrm{~b}$ & $4.20 \pm 0.00 \mathrm{~b}$ & $5.00 \pm 0.00 b$ & $5.70 \pm 0.00 \mathrm{~b}$ & $4.00 \pm 0.00 b$ & $4.20 \pm 0.00 b$ & $2.5 \mathrm{C}$ \\
\hline & & 500 & $4.27 \pm 0.03 c$ & $3.50 \pm 0.00 c$ & $3.40 \pm 0.00 c$ & $4.90 \pm 0.00 c$ & $3.10 \pm 0.00 c$ & $3.30 \pm 0.00 c$ & $1.8 \mathrm{C}$ \\
\hline & & 1000 & $2.00 \pm 0.00 d$ & $3.20 \pm 0.00 d$ & $2.83 \pm 0.03 d$ & $4.20 \pm 0.00 d$ & $2.93 \pm 0.03 d$ & $2.93 \pm 0.03 d$ & $1.5 \mathrm{C}$ \\
\hline \multirow[t]{4}{*}{13} & \multirow[t]{4}{*}{ Acetoin } & 10 & $7.20 \pm 0.00 \mathrm{a}$ & $7.10 \pm 0.00 a$ & $9.00 \pm 0.00 \mathrm{a}$ & $7.40 \pm 0.00 a$ & - & $7.80 \pm 0.00 a$ & $3.8 \mathrm{C}$ \\
\hline & & 100 & $6.80 \pm 0.00 \mathrm{~b}$ & $6.80 \pm 0.00 \mathrm{~b}$ & $7.50 \pm 0.00 \mathrm{~b}$ & $7.00 \pm 0.00 \mathrm{~b}$ & - & $6.70 \pm 0.00 b$ & $3.7 \mathrm{C}$ \\
\hline & & 500 & $6.70 \pm 0.00 c$ & $6.80 \pm 0.00 \mathrm{~b}$ & $6.61 \pm 0.00 c$ & $6.60 \pm 0.00 c$ & - & $6.30 \pm 0.00 c$ & $3.7 c$ \\
\hline & & 1000 & $6.40 \pm 0.00 d$ & $6.70 \pm 0.00 c$ & $6.30 \pm 0.00 \mathrm{~d}$ & $6.3 \pm 0.00 \mathrm{~d}$ & - & $6.00 \pm 0.00 d$ & $3.5 \mathrm{C}$ \\
\hline \multirow[t]{4}{*}{14} & \multirow[t]{4}{*}{ Dibutyl phthalate } & 10 & $6.31 \pm 0.01 a$ & $6.41 \pm 0.00 \mathrm{a}$ & $7.01 \pm 0.00 a$ & $4.71 \pm 0.00 \mathrm{a}$ & $7.07 \pm 0.07 a$ & $4.50 \pm 0.00 a$ & 3.27 \\
\hline & & 100 & $6.31 \pm 0.00 \mathrm{a}$ & $6.20 \pm 0.00 \mathrm{~b}$ & $6.90 \pm 0.00 \mathrm{~b}$ & $4.70 \pm 0.00 a$ & $6.50 \pm 0.00 \mathrm{~b}$ & $4.40 \pm 0.00 \mathrm{~b}$ & $3.2 \mathrm{C}$ \\
\hline & & 500 & $6.30 \pm 0.00 a$ & $5.90 \pm 0.00 c$ & $6.80 \pm 0.00 c$ & $4.70 \pm 0.00 a$ & $5.00 \pm 0.15 c$ & $4.30 \pm 0.00 c$ & $3.2 \mathrm{C}$ \\
\hline & & 1000 & $6.30 \pm 0.00 a$ & $5.60 \pm 0.00 d$ & $6.40 \pm 0.00 \mathrm{~d}$ & $4.10 \pm 0.00 \mathrm{~b}$ & $4.10 \pm 0.26 d$ & $4.20 \pm 0.00 d$ & $3.0 \mathrm{C}$ \\
\hline \multirow[t]{4}{*}{15} & \multirow[t]{4}{*}{ 3-Nonen-2-one } & 10 & $6.80 \pm 0.00 a$ & $7.30 \pm 0.00 a$ & $7.50 \pm 0.00 a$ & $6.50 \pm 0.00 a$ & - & $7.10 \pm 0.00 a$ & 3.77 \\
\hline & & 100 & $6.40 \pm 0.00 \mathrm{~b}$ & $7.30 \pm 0.00 a$ & $7.50 \pm 0.00 a$ & $6.50 \pm 0.00 a$ & - & $6.80 \pm 0.00 \mathrm{~b}$ & $3.6 \mathrm{C}$ \\
\hline & & 500 & $4.60 \pm 0.00 c$ & $6.80 \pm 0.00 \mathrm{~b}$ & $7.00 \pm 0.00 \mathrm{~b}$ & $6.50 \pm 0.00 a$ & - & $6.50 \pm 0.00 c$ & $3.5 \mathrm{C}$ \\
\hline & & 1000 & $2.70 \pm 0.00 \mathrm{~d}$ & $6.80 \pm 0.00 \mathrm{~b}$ & $7.00 \pm 0.00 \mathrm{~b}$ & $6.00 \pm 0.00 b$ & - & $6.50 \pm 0.00 c$ & $3.4 \mathrm{C}$ \\
\hline \multirow[t]{4}{*}{16} & \multirow{4}{*}{$\begin{array}{l}\text { Benzoic acid, 3,4- } \\
\text { dimethyl-, methyl } \\
\text { ester }\end{array}$} & 10 & $7.00 \pm 0.00 a$ & $7.80 \pm 0.00 a$ & $6.00 \pm 0.00 \mathrm{a}$ & $7.20 \pm 0.00 a$ & - & $7.30 \pm 0.00 a$ & $3.0 \mathrm{C}$ \\
\hline & & 100 & $6.80 \pm 0.00 \mathrm{~b}$ & $7.30 \pm 0.00 \mathrm{~b}$ & $6.01 \pm 0.01 a$ & $6.80 \pm 0.00 \mathrm{bc}$ & - & $6.70 \pm 0.00 \mathrm{~b}$ & $2.9 \mathrm{C}$ \\
\hline & & 500 & $6.70 \pm 0.00 \mathrm{c}$ & $7.00 \pm 0.00 \mathrm{c}$ & $6.00 \pm 0.00 a$ & $6.30 \pm 0.00 c$ & - & $6.00 \pm 0.00 c$ & $2.8 \mathrm{C}$ \\
\hline & & 1000 & $6.50 \pm 0.00 d$ & $6.50 \pm 0.00 d$ & $6.00 \pm 0.00 a$ & $6.00 \pm 0.00 d$ & - & $5.80 \pm 0.00 d$ & $2.6 \mathrm{C}$ \\
\hline
\end{tabular}

\subsection{Phloridin degradation ability of strain XNRB-3}

The phloridzin utilization efficiency by strain XNRB-3 in MSM solution was high (Figure 2Q). After culture for 60 h, the degradation rate was $60.75 \%$ when the amount of inoculum added was $1 \%$, and the degradation rate was $68.83 \%$ when the amount of inoculum added was $2 \%$. The ability of strain XNRB- 3 to degrade phloridin increased as the amount of inoculum added increased. Strain XNRB-3 could effectively utilize CA, BA, FA, and PHBA (Table S23), and the degradation rates ranged from 45.65-69.20\%. Strain XNRB-3 could efficiently degrade phloridzin, CA, BA, FA, and PHBA in soil (Table 4). The content of

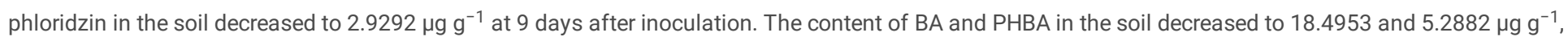
respectively, at 9 days after inoculation. FA and CA concentrations in the soil decreased to 13.3669 and $0.3785 \mu g^{-1}$ at 9 days after treatment, respectively, which was only $13.31 \%$ and $3.63 \%$ of the control concentration. 
Table 4

Phenolic acids degradation of strain XNRB-3 in soil. The soil samples were added with Phloridzin, Cinnamic acid (CA), Ferulic acid (FA), Benzoic acid (BA), and P-hydroxybenzoic acid (PHBA) $\left(\mu_{\mathrm{g} \mathrm{g}}{ }^{-1}\right)$. Lowercase letters above the columns indicate a significant difference

\begin{tabular}{|lllllll|}
\hline Treatment & Time & CA & Phloridzin & BA & FA & PHBA \\
\hline CK & Od & $10.4321 \pm 0.1703 \mathrm{a}$ & $30.0569 \pm 0.0228 \mathrm{a}$ & $90.4921 \pm 0.0536 \mathrm{a}$ & $100.4403 \pm 0.1695 \mathrm{a}$ & $20.6373 \pm 0.1954 \mathrm{a}$ \\
& 3d & $6.6133 \pm 0.0349 \mathrm{~b}$ & $23.8619 \pm 0.5910 \mathrm{c}$ & $83.8100 \pm 0.2810 \mathrm{~b}$ & $83.8655 \pm 0.7399 \mathrm{~b}$ & $18.3768 \pm 0.2350 \mathrm{~b}$ \\
& 6d & $5.7945 \pm 0.0349 \mathrm{c}$ & $24.9330 \pm 0.0137 \mathrm{~b}$ & $77.0167 \pm 0.4360 \mathrm{c}$ & $71.1995 \pm 0.3209 \mathrm{c}$ & $12.2645 \pm 0.1751 \mathrm{c}$ \\
& 9d & $5.6424 \pm 0.3036 \mathrm{~cd}$ & $24.1495 \pm 0.5873 \mathrm{bc}$ & $67.5674 \pm 0.6518 \mathrm{~d}$ & $62.6178 \pm 0.2685 \mathrm{~d}$ & $10.3960 \pm 0.2109 \mathrm{~d}$ \\
\hline Strain XNRB-3 & Od & $10.4321 \pm 0.1703 \mathrm{a}$ & $30.0569 \pm 0.0228 \mathrm{a}$ & $90.4921 \pm 0.0536 \mathrm{a}$ & $100.4403 \pm 0.1695 \mathrm{a}$ & $20.6373 \pm 0.1954 \mathrm{a}$ \\
& 3d & $5.2219 \pm 0.1101 \mathrm{e}$ & $14.4323 \pm 0.2139 \mathrm{~d}$ & $44.6154 \pm 0.0853 \mathrm{e}$ & $48.1822 \pm 0.6503 \mathrm{e}$ & $12.5532 \pm 0.0382 \mathrm{c}$ \\
& 6d & $1.6232 \pm 0.0377 \mathrm{f}$ & $9.4797 \pm 0.1108 \mathrm{e}$ & $35.6996 \pm 0.1247 \mathrm{f}$ & $31.8586 \pm 0.0451 \mathrm{f}$ & $8.9623 \pm 0.0035 \mathrm{e}$ \\
& 9d & $0.3785 \pm 0.0045 \mathrm{~g}$ & $2.9292 \pm 0.0120 \mathrm{f}$ & $18.4953 \pm 0.0370 \mathrm{~g}$ & $13.3669 \pm 0.0380 \mathrm{~g}$ & $5.2882 \pm 0.0404 \mathrm{f}$ \\
\hline
\end{tabular}

\subsection{The protective effect of strain XNRB-3 on plant roots}

Strain XNRB-3 can form a thick biofilm in a static medium. After 14 days of planting, the population of strain XNRB-3 colonized on root tissue was approximately $7.30 \times 10^{6} \mathrm{CFU} \mathrm{g}^{-1}$. The population sharply decreased to $6.47 \times 10^{4} \mathrm{CFU} \mathrm{g}^{-1}$ after 35 days (Figure S7 B). The total number of strain XNRB-3 cells measured on the LB medium with antibiotics was significantly higher than that on the roots of the control plants. Observation of plant root sections revealed that the root system was mainly composed of three parts from outside to inside: the epidermis, the cortex (the outer cortex, the cortical parenchyma, and the Kjeldahl belt), and the vascular column (the central sheath, phloem, and xylem). Root epidermal cells infected by Fusarium were deformed, broken, detached, and/or irregularly arranged. Fungal hyphae invaded the cortical cells through the intercellular layer and then entered the vascular column. New hyphae were visible close to the cell wall, and mature hyphae were scattered in the cells. There was also a large amount of cell contents (viscous substances and starch granules) in the cortical cells and vascular column (Figure 8, Figure S7A). The epidermal and cortical cells treated with both strain XNRB-3 and Fusarium appeared slightly shrunken and ruptured, and the conidia and hyphae of Fusarium were attached only to the root epidermal cells (Figure 8A-D). The root systems from the control treatment were complete and neatly arranged (Figure 8, Mock).

\subsection{Disease severity assessment}

In the greenhouse test, the symptoms of Fusarium wilt appeared 7 days after the plant seedlings were transplanted into the infected soil. The incidence of Fusarium wilt increased rapidly over the next 28 days, and the disease severity index increased progressively over the experimental period and ultimately reached 4.00 \pm 0.00 ; a reduction in disease progress was noted in plants treated with strain XNRB-3 (Table 5). In the fifth week, the disease index and relative control effect of plant seedlings inoculated with strain XNRB-3 were both stable at 33 and $50 \%$, respectively. During the test period, plants inoculated with sterile distilled water remained healthy. The disease symptoms were the result of artificial infection with Fusarium, which was successfully re-isolated from inoculated plants at the end of the experiment. According to RT-PCR, the size of the Fusarium populations of the two treatments significantly increased after 21 days of planting in the infected soil. Compared with the CK treatment (5.50 $\times 10^{5} \mathrm{copies} / \mathrm{g}$ soil), the size of the Fusarium population treated with strain XNRB-3 $\left(2.37 \times 10^{5}\right.$ copies/g soil) was significantly reduced (Figure S7 C). These results are consistent with the incidence of the aforementioned diseases. 
Table 5

PDP, FMS and AUDPC of Malus hupehensis Rehd. seedlings after inoculation strain XNRB-3. Values are mean \pm SD.

\begin{tabular}{|c|c|c|c|c|c|c|c|c|}
\hline \multicolumn{2}{|c|}{ Treatment } & $\begin{array}{l}\text { Investigation } \\
\text { time }\end{array}$ & $\mathrm{DI}(\%)$ & $\begin{array}{l}\text { Relative control } \\
\text { effect }(\%)\end{array}$ & Incidence(\%) & PDP(\%) & FMS & AUDPC \\
\hline \multicolumn{2}{|c|}{ Negative control } & Week 1-5 & $0.00 \pm 0.00$ & - & $0.00 \pm 0.00$ & $0.00 \pm 0.00$ & $0.00 \pm 0.00$ & $0.00 \pm 0.00$ \\
\hline \multirow{20}{*}{$\begin{array}{l}\text { Positive } \\
\text { control }\end{array}$} & \multirow{5}{*}{$\begin{array}{l}\text { Fusarium } \\
\text { proliferatum }\end{array}$} & Week 1 & $34.45 \pm 3.64 a$ & - & $64.44 \pm 8.01 a$ & $0.00 \pm 0.00 c$ & $2.15 \pm 0.05 a$ & $30.14 \pm 3.19 a$ \\
\hline & & Week 2 & $67.22 \pm 0.55 b$ & - & $100 \pm 0.00 \mathrm{a}$ & $55.55 \pm 2.22 \mathrm{a}$ & $2.69 \pm 0.02 a$ & $88.96 \pm 3.67 a$ \\
\hline & & Week 3 & $87.78 \pm 1.47 a$ & - & $100 \pm 0.00 a$ & $68.89 \pm 2.22 b$ & $3.51 \pm 0.06 a$ & $135.62 \pm 1.46 a$ \\
\hline & & Week 4 & $100 \pm 0.00 \mathrm{a}$ & - & $100 \pm 0.00 \mathrm{a}$ & $100 \pm 0.00 \mathrm{a}$ & $4.00 \pm 0.00 \mathrm{a}$ & $149.97 \pm 1.35 a$ \\
\hline & & Week 5 & $100 \pm 0.00 a$ & - & $100 \pm 0.00 a$ & $100 \pm 0.00 \mathrm{a}$ & $4.00 \pm 0.00 a$ & $284.96 \pm 1.62 a$ \\
\hline & \multirow{5}{*}{$\begin{array}{l}\text { Fusarium } \\
\text { verticillioides }\end{array}$} & Week 1 & $33.89 \pm 0.65 a$ & - & $68.89 \pm 2.22 a$ & $0.00 \pm 0.00$ & $1.97 \pm 0.03 a$ & $29.65 \pm 0.49 a$ \\
\hline & & Week 2 & $70.00 \pm 1.67 a b$ & - & $100 \pm 0.00 a$ & $48.89 \pm 2.22 a b$ & $2.80 \pm 0.07 a$ & $90.90 \pm 1.94 a$ \\
\hline & & Week 3 & $87.78 \pm 0.55 a$ & - & $100 \pm 0.00 \mathrm{a}$ & $68.89 \pm 2.22 b$ & $3.51 \pm 0.02 a$ & $138.06 \pm 1.75 a$ \\
\hline & & Week 4 & $100 \pm 0.00 \mathrm{a}$ & - & $100 \pm 0.00 \mathrm{a}$ & $100 \pm 0.00 a$ & $4.00 \pm 0.00 \mathrm{a}$ & $151.18 \pm 1.06 a$ \\
\hline & & Week 5 & $100 \pm 0.00 \mathrm{a}$ & - & $100 \pm 0.00 \mathrm{a}$ & $100 \pm 0.00 \mathrm{a}$ & $4.00 \pm 0.00 \mathrm{a}$ & $286.42 \pm 1.27 a$ \\
\hline & \multirow{5}{*}{$\begin{array}{l}\text { Fusarium } \\
\text { oxysporum }\end{array}$} & Week 1 & $30.56 \pm 1.11 \mathrm{a}$ & - & $64.44 \pm 5.88 a$ & $0.00 \pm 0.00$ & $1.92 \pm 0.12 a$ & $26.74 \pm 0.97 a$ \\
\hline & & Week 2 & $70.00 \pm 1.92 a b$ & - & $100 \pm 0.00 \mathrm{a}$ & $48.89 \pm 2.22 a b$ & $2.80 \pm 0.08 a$ & $87.99 \pm 2.57 a$ \\
\hline & & Week 3 & $91.67 \pm 0.96 a$ & - & $100 \pm 0.00 a$ & $80.00 \pm 0.00 a$ & $3.67 \pm 0.04 a$ & $141.46 \pm 1.46 a$ \\
\hline & & Week 4 & $100 \pm 0.00 a$ & - & $100 \pm 0.00 \mathrm{a}$ & $100 \pm 0.00 a$ & $4.00 \pm 0.00 \mathrm{a}$ & $154.59 \pm 0.84 a$ \\
\hline & & Week 5 & $100 \pm 0.00 \mathrm{a}$ & - & $100 \pm 0.00 \mathrm{a}$ & $100 \pm 0.00 \mathrm{a}$ & $4.00 \pm 0.00 \mathrm{a}$ & $290.50 \pm 1.01 a$ \\
\hline & \multirow[t]{5}{*}{ Fusarium solani } & Week 1 & $35.00 \pm 0.00 a$ & - & $64.44 \pm 4.44 a$ & $0.00 \pm 0.00$ & $2.19 \pm 0.14 a$ & $30.63 \pm 0.00 a$ \\
\hline & & Week 2 & $72.22 \pm 2.00 \mathrm{a}$ & - & $100 \pm 0.00 \mathrm{a}$ & $42.22 \pm 5.88 b$ & $2.89 \pm 0.08 a$ & $93.82 \pm 1.75 a$ \\
\hline & & Week 3 & $88.33 \pm 1.67 a$ & - & $100 \pm 0.00 a$ & $71.11 \pm 2.22 b$ & $3.53 \pm 0.07 a$ & $140.49 \pm 3.19 a$ \\
\hline & & Week 4 & $100 \pm 0.00 \mathrm{a}$ & - & $100 \pm 0.00 \mathrm{a}$ & $100 \pm 0.00 \mathrm{a}$ & $4.00 \pm 0.00 \mathrm{a}$ & $152.64 \pm 2.32 a$ \\
\hline & & Week 5 & $100 \pm 0.00 \mathrm{a}$ & - & $100 \pm 0.00 \mathrm{a}$ & $100 \pm 0.00 a$ & $4.00 \pm 0.00 \mathrm{a}$ & $288.17 \pm 2.78 \mathrm{a}$ \\
\hline \multirow{18}{*}{$\begin{array}{l}\text { Strain } \\
\text { XNRB-3 }\end{array}$} & \multirow{5}{*}{$\begin{array}{l}\text { Fusarium } \\
\text { proliferatum }\end{array}$} & Week 1 & $1.11 \pm 0.56 b$ & $96.39 \pm 1.81 \mathrm{ab}$ & $4.44 \pm 2.22 \mathrm{c}$ & $0.00 \pm 0.00$ & $0.67 \pm 0.33 b$ & $0.97 \pm 0.49 b$ \\
\hline & & Week 2 & $8.33 \pm 0.00 \mathrm{~cd}$ & $87.60 \pm 0.10 \mathrm{~b}$ & $26.67 \pm 3.85 c$ & $0.00 \pm 0.00 c$ & $1.31 \pm 0.19 b$ & $8.26 \pm 0.49 b$ \\
\hline & & Week 3 & $12.22 \pm 1.11 b$ & $86.11 \pm 1.07 a$ & $33.33 \pm 3.85 b$ & $0.00 \pm 0.00 c$ & $1.48 \pm 0.08 \mathrm{bc}$ & $17.99 \pm 0.97 b$ \\
\hline & & Week 4 & $23.89 \pm 0.56 d$ & $76.11 \pm 0.56 a$ & $42.22 \pm 8.01 b$ & $6.67 \pm 0.00 \mathrm{~b}$ & $2.46 \pm 0.52 b$ & $24.79 \pm 0.73 b$ \\
\hline & & Week 5 & $35.56 \pm 0.56 d$ & $64.44 \pm 0.56 a$ & $68.89 \pm 2.22 b$ & $6.67 \pm 0.00 c$ & $2.07 \pm 0.03 d$ & $60.96 \pm 0.77 d$ \\
\hline & \multirow{5}{*}{$\begin{array}{l}\text { Fusarium } \\
\text { verticillioides }\end{array}$} & Week 1 & $4.44 \pm 0.56 b$ & $86.83 \pm 1.83 c$ & $17.78 \pm 2.22 b$ & $0.00 \pm 0.00$ & $0.67 \pm 0.33 b$ & $3.89 \pm 0.49 \mathrm{~b}$ \\
\hline & & Week 2 & $7.22 \pm 0.55 d$ & $89.71 \pm 0.53 a$ & $24.45 \pm 2.22 \mathrm{c}$ & $0.00 \pm 0.00 c$ & $1.19 \pm 0.10 \mathrm{~b}$ & $10.21 \pm 0.00 b$ \\
\hline & & Week 3 & $14.44 \pm 3.09 \mathrm{~b}$ & $83.59 \pm 3.44 a$ & $40.00 \pm 6.67 b$ & $0.00 \pm 0.00 \mathrm{c}$ & $1.42 \pm 0.09 \mathrm{c}$ & $18.96 \pm 3.03 b$ \\
\hline & & Week 4 & $30.56 \pm 0.56 b$ & $69.44 \pm 0.56 b$ & $53.33 \pm 3.85 b$ & $0.00 \pm 0.00 \mathrm{c}$ & $2.31 \pm 0.14 b$ & $29.17 \pm 2.95 b$ \\
\hline & & Week 5 & $48.33 \pm 0.96 b$ & $51.67 \pm 0.96 c$ & $66.67 \pm 3.85 b$ & $20.00 \pm 0.00 \mathrm{~b}$ & $2.91 \pm 0.11 \mathrm{~b}$ & $76.42 \pm 3.66 b$ \\
\hline & \multirow{5}{*}{$\begin{array}{l}\text { Fusarium } \\
\text { oxysporum }\end{array}$} & Week 1 & $2.78 \pm 0.55 b$ & $90.82 \pm 1.99 b c$ & $11.11 \pm 2.22 \mathrm{bc}$ & $0.00 \pm 0.00$ & $0.67 \pm 0.33 b$ & $2.43 \pm 0.49 b$ \\
\hline & & Week 2 & $6.67 \pm 0.00 \mathrm{~d}$ & $90.46 \pm 0.26 a$ & $22.22 \pm 2.22 \mathrm{c}$ & $0.00 \pm 0.00 \mathrm{c}$ & $1.22 \pm 0.11 \mathrm{~b}$ & $8.26 \pm 0.49 b$ \\
\hline & & Week 3 & $12.78 \pm 0.55 b$ & $86.07 \pm 0.49 a$ & $31.11 \pm 2.22 b$ & $0.00 \pm 0.00 \mathrm{c}$ & $1.65 \pm 0.05 b$ & $17.01 \pm 0.49 b$ \\
\hline & & Week 4 & $26.11 \pm 0.56 c$ & $73.89 \pm 0.56 a$ & $44.44 \pm 5.88 b$ & $6.67 \pm 0.00 \mathrm{~b}$ & $2.45 \pm 0.38 b$ & $25.52 \pm 0.42 b$ \\
\hline & & Week 5 & $33.89 \pm 1.11 d$ & $66.11 \pm 1.11 \mathrm{a}$ & $62.22 \pm 4.44 b$ & $6.67 \pm 0.00 \mathrm{c}$ & $2.19 \pm 0.09 d$ & $62.13 \pm 0.00 d$ \\
\hline & \multirow[t]{3}{*}{ Fusarium solani } & Week 1 & $0.56 \pm 0.56 b$ & $98.41 \pm 1.59 a$ & $2.22 \pm 2.22 \mathrm{c}$ & $0.00 \pm 0.00$ & $0.33 \pm 0.33 b$ & $0.94 \pm 1.94 \mathrm{~b}$ \\
\hline & & Week 2 & $11.11 \pm 0.56 c$ & $84.56 \pm 1.11 \mathrm{c}$ & $37.78 \pm 2.22 b$ & $0.00 \pm 0.00 \mathrm{c}$ & $1.18 \pm 0.01 \mathrm{~b}$ & $10.21 \pm 0.84 b$ \\
\hline & & Week 3 & $13.89 \pm 1.11 b$ & $84.24 \pm 1.43 a$ & $40.00 \pm 0.00 \mathrm{~b}$ & $0.00 \pm 0.00 \mathrm{c}$ & $1.39 \pm 0.11 \mathrm{c}$ & $21.88 \pm 0.84 b$ \\
\hline
\end{tabular}

Note: DI: disease intensity, Incidence: percentage of diseased plants, PDP: percentage of dead plants, FMS: final mean severity of symptoms and AUDPC: area under the disease progress curve. Values in columns followed by the same letter are not significantly different according to Duncan test at $P<0.05$. The test was repeated three times. 


\begin{tabular}{|llllllll|}
\hline Treatment & $\begin{array}{l}\text { Investigation } \\
\text { time }\end{array}$ & DI(\%) & $\begin{array}{l}\text { Relative control } \\
\text { effect (\%) }\end{array}$ & Incidence(\%) & PDP(\%) & FMS & AUDPC \\
\hline & Week 4 & $25.00 \pm 0.96 \mathrm{~cd}$ & $75.00 \pm 0.96 \mathrm{a}$ & $46.67 \pm 3.85 \mathrm{~b}$ & $0.00 \pm 0.00 \mathrm{c}$ & $2.18 \pm 0.25 \mathrm{~b}$ & $27.95 \pm 1.06 \mathrm{~b}$ \\
\cline { 2 - 7 } & Week 5 & $41.11 \pm 1.47 \mathrm{c}$ & $58.89 \pm 1.47 \mathrm{~b}$ & $64.44 \pm 5.88 \mathrm{~b}$ & $6.67 \pm 0.00 \mathrm{c}$ & $2.58 \pm 0.15 \mathrm{c}$ & $68.25 \pm 1.82 \mathrm{c}$ \\
\hline
\end{tabular}

Note: DI: disease intensity, Incidence: percentage of diseased plants, PDP: percentage of dead plants, FMS: final mean severity of symptoms and AUDPC: area under the disease progress curve. Values in columns followed by the same letter are not significantly different according to Duncan test at $P<0.05$. The test was repeated three times.

The same results were obtained in the outdoor pot experiment. The biomass of apple plants treated with strain XNRB-3 (T2) in September was significantly higher than the biomass of apple plants in CK1, and the plant height, ground diameter, fresh weight, and dry weight were increased by $88.07 \%, 61.28 \%$, $181.35 \%$, and $140.44 \%$, respectively, which were second only to the methyl bromide fumigation treatment. (Figure S8). Treatment with strain XNRB-3 also significantly enhanced the root growth of apple plants (Figure 7E, I, J, L, M). In September, the plants had grown considerably, and the root length, surface area, number of tips, and number of forks were significantly lower in CK1 than in CK2 and T2. The length, surface area, number of tips, and number of forks were $1.73,2.62,5.67$, and 2.65 times higher in T2 than in CK1. The root respiration rate and the SOD, POD, and CAT activity increased from July to September in T2 and CK2 (Figure 7E-H, K, N). In September, the root respiration rate in $\mathrm{T} 2$ was $1037.98 \mu \mathrm{mol} \mathrm{O}_{2} \cdot \mathrm{g}^{-1} \mathrm{FW} \cdot \mathrm{min}^{-1}$, which was 1.49 and 1.32 times higher compared with that observed in CK1 and T1. The activity of SOD, POD, and CAT was 1.50, 2.93, and 1.72 times higher in T2 than in CK1. The MDA content showed the opposite trend: the MDA content was $29.96 \%, 60.35 \%$, and $78.13 \%$ lower in July, August, and September, respectively, in T2 compared with CK1.

\subsection{Effect of strain XNRB-3 on the biomass of young apple trees}

The XNRB-3 bacterial fertilizer treatment (T2) significantly promoted the growth of young apple trees, and this difference became significant in October 2021 (Figure 9A-B). In July and October 2020, 2021, the biomass indicators were significantly lower in CK1 and T1 than in CK2 and T2. In October 2021, the plant height, ground diameter, number of branches, and average branch length increased by $38.10 \%, 62.79 \%, 49.17 \%$, and $176.00 \%$ in $\mathrm{T} 2$ relative to $\mathrm{CK} 1$, respectively, and the plant height, ground diameter, number of branches, and average branch length were 1.27, 1.25, 1.37, 1.77, 2.45, and 2.21-fold higher in T2 than in T1, respectively (Figure 9C-D).

\subsection{Effect of strain XNRB-3 on the soil environment}

In October 2020, 2021, the soil phenolic acid content was highest in CK1 and T1 and lowest in CK2 and T2 (Figure 10A-B). The total soil phenolic acid content was significantly lower in T2 than in CK1. In October 2020, the soil content of cinnamic acid, phlorizin, benzoic acid, ferulic acid, and p-hydroxybenzoic acid was $54.38 \%, 74.02 \%, 77.29 \%, 54.70 \%$, and $71.83 \%$ lower, respectively, in T2 than in CK1. In October 2021, the soil content of cinnamic acid, phlorizin, benzoic acid, ferulic acid, and p-hydroxybenzoic acid was $87.23 \%, 91.95 \%, 89.80 \%, 84.11 \%$, and $91.98 \%$ lower, respectively, in T2 than in CK1.

The activity of urease, phosphatase, sucrase, and catalase increased steadily in T1 and T2 in July and October 2020, 2021 relative to CK1. The soil enzyme activity decreased in the first year of the fumigation treatment; it then continued to increase and increased most significantly in T2 (Figure $10 \mathrm{G}-\mathrm{J}$ ).In October 2020,2021 , the urease activity was 1.65 -fold and 1.64-fold higher, the phosphatase activity was 1.56 -fold and 1.93 -fold higher, the sucrase activity was $2.03-$ fold and 2.34-fold higher, and the catalase activity was 1.69-fold and 1.87-fold higher in T2 than in CK1, respectively. After two years of applying strain XNRB3 , the physical and chemical properties of plant rhizosphere soil were significantly improved. Compared with CK1, organic matter, total nitrogen, total phosphorus, total potassium, available potassium, available phosphorus, $\mathrm{NH}_{4}{ }^{+} \mathrm{N}$, nitrate nitrogen, and soil pH increased by $228.54 \%, 245.25 \%, 242.29 \%$, $30.53 \%, 327.89 \%, 128.64 \%, 56.05 \%, 239.61 \%$, and $7.43 \%$ respectively, in T1. Various nutrient indexes of the soil were also increased in $\mathrm{T} 1$, indicating that the addition of organic amendments could enhance the nutrient conditions of the soil.

In July and October 2020, 2021, the number of soil bacteria in the XNRB-3 bacterial fertilizer treatment (T2) increased significantly, and compared with CK1, the number of soil bacteria was increased by $107.21 \%, 45.13 \%, 100.79 \%$, and $113.08 \%$ in T2, respectively (Figure 10C). There were significant differences in the number of soil fungi between different treatments. Compared with CK1, the number of soil fungi in CK2, T1, and T2 was significantly reduced, the number of soil fungi in T1 was significantly higher than that in T2, and the effect of T2 was similar to the fumigation treatment. In October 2020, 2021, the number of soil fungi in CK2 and T2 was reduced by 58.55\%, 50.26\% and 62.74\%, 52.83\% compared with CK1, respectively (Figure 10D). The number of actinomycetes and the ratio of bacteria/fungi in the soil were significantly higher in T2 than in CK1 (Figure 10E-F).

The qPCR results showed that the abundance of Fusarium was significantly reduced in July and October 2020, 2021 in CK2 and T2 compared with CK1 and T1 (Figure 10K-N).In October 2020, 2021, the abundance of F. proliferatum, F. solani, F. verticillioides, and F. oxysporum was 50.43\%, 40.74\%, $25.96 \%$, and $22.20 \%$, and $60.43 \%, 57.97 \%, 28.69 \%$, and $40.31 \%$ lower in T2 relative to $\mathrm{T} 1$, respectively.

\subsection{Effect of strain XNRB-3 on the soil microbial community}

AWCD was used as an indicator of soil microbial activity. Variation in AWCD with incubation time is shown in Figure 11 (I, L). AWCD increased as the incubation time extended for all treatments in October 2020, 2021. Soil with strain XNRB-3 (T2) had a higher AWCD value than soil in other treatments, which indicated that the addition of strain XNRB-3 increased the activity of microorganisms. After $120 \mathrm{~h}$, the AWCD values of T1 and CK1 were similar, and the AWCD value was lower in CK2, indicating that fumigation can inhibit the activity of microorganisms for a longer period. 
Biolog-ECO plates have six categories of carbon sources: carbohydrates, carboxylic acids, amino acids, polymers, phenolic compounds, and amines (Guo et al., 2015). In October 2020 (Figure 11 J-K), the OD value of three types of carbon sources (polymers, miscellaneous, and amino acids) increased significantly in T1 and CK1 relative to CK1. In contrast, amines/amines and carbohydrates were significantly reduced in T2. The effect of strain XNRB-3 treatment (T2) on the utilization rate of the four substrate groups (polymers, miscellaneous, carboxylic acids, and amino acids) was stronger compared with the other treatments. The utilization rate of these four substrate groups was $6.11 \%, 0.97 \%, 15.41 \%$, and $10.24 \%$ higher in T2 than in T1, respectively. In October 2021 (Figure $11 \mathrm{M}-\mathrm{N}$ ), the changes in the utilization rate of microbial substrates under different soil treatments varied starting in 2020. Compared with CK1, the OD values of the six types of carbon sources increased significantly in T2. With the exception of miscellaneous, the OD values of amines/amines, carboxylic acids, carbohydrates, polymers, and amino acids increased by $40.79 \%, 42.17 \%, 24.45 \%, 10.56 \%$, and $7.91 \%$ in 2021 , respectively, compared with 2020 . These findings indicated that the soil microorganisms treated by strain XNRB-3 mainly use polymers, carboxylic acids, and amino acids. The utilization rate of the six types of carbon sources in CK2 was significantly lower compared with the other treatments; this showed that fumigation greatly affected the soil microbial community.

Principal component analysis and cluster analysis showed that the soil microbial community structure in T2 and CK2 significantly differed from that in CK1 (Figure 11 A-H). The soil bacterial community structure in T2 differed significantly from that in other treatments (Figure 11G-H), and the soil fungal and bacterial communities of T1 and CK1 were similar (Figure 11C-D, G-H). The Margalef, Mc intosh, Brillouin, Simpson and Shannon Index reflect the richness and diversity of soil microbial communities (Table S24-25). The Margalef index reflects the abundance of soil microbial communities; the Mc intosh index reflects the number of different types of carbon sources utilized, which can be used to distinguish different carbon source utilization levels; and the Brillouin, Simpson, and Shannon Index reflects the diversity of soil microbial communities. The abundance of soil fungi and bacterial communities was significantly increased after adding strain XNRB-3. The diversity of soil fungi communities was significantly increased, the dominance index and carbon source utilization were significantly reduced, and the bacterial community showed the opposite pattern. The functional diversity of the microbial community was analyzed based on the data of 96-hour Biolog Eco plates; in 2020 and 2021, the functional diversity of the microbial community in T1 and T2 showed similar changes. The diversity of soil microbial communities was significantly increased in T1 and T2 than in CK1, which was consistent with the results of the T-RFLP analysis.

These results indicated that XNRB-3 bacterial fertilizer can improve the soil microbial environment.

\section{Discussion}

ARD, which is mainly caused by soil-borne plant diseases, has severely restricted the sustainable development of China's apple industry. Given the environmental pollution and pathogen resistance caused by the overuse or misuse of chemical fungicides, there is an urgent need to develop effective and environmentally friendly methods to replace the use of chemical control methods to suppress the spread of this disease(Yin et al., 2017; Wang et al., 2018; Sheng et al., 2020; Xiang et al., 2021). In recent years, the introduction of beneficial microorganisms into soil has been shown to be an attractive alternative for controlling plant diseases, especially endophytic strains with antibacterial effects or strains that promote plant growth; however, these microorganisms have been rarely used to control ARD (Nan et al., 2011; Deketelaere et al., 2017). Cao et al. (2011) found that $B$. subtilis SQR 9 isolated from a healthy cucumber root in a field with a high incidence of Fusarium wilt disease can control cucumber wilt by colonizing plant roots. An endogenous $B$. licheniformis XNRB-3 was isolated from the root tissues of healthy fruit trees in orchards where the incidence of ARD was high; this strain could stably colonize the roots of apple seedlings, and it showed high phloridin-degrading activity and multiple PGP properties. It could also significantly inhibit the mycelial growth and spore germination of Fusarium by producing antifungal compounds. Inhibition of spore germination can protect plant roots from fungal infection and is essential for the development of fungal disease during the early stage (Miyara et al., 2010). This reveals that the strain XNRB-3 has the potential to be used as a biological control agent to control ARD.

Some BCAs that can colonize root tissues without causing harmful effects are known as beneficial endophytes (Cao et al., 2011; Santoyo et al., 2016) they exhibit several disease suppression mechanisms and promote plant growth, including preventing vascular pathogens from colonizing ecological niches; producing hydrolytic enzymes, broad-spectrum antibiotics, PGP hormones, and VOCs; and promoting induced systemic resistance (Santoyo et al., 2012; Chowdhury et al., 2015; Eljounaidi et al., 2016; Afzal et al., 2019). Previous studies indicate that many Bacillus spp. have PGP traits such as IAA production, phosphate solubilization, potassium solubilization, nitrogen fixation, ACC deaminase, and biocontrol attributes such as the production of siderophores, hydrolytic enzymes, HCN, and antibiotics (Penrose and Glick, 2003; Senthilkumar et al., 2009; Kumar et al., 2012; Vacheron et al., 2013). The endogenous B. licheniformis XNRB-3 isolated in this study also has several of the aforementioned PGP properties and antagonistic traits. For example, IAA, CTK, and GA can significantly increase the root length, root tip, and branch number of apple seedlings, The production of IAA can also promote the establishment of a symbiotic relationship between plants and arbuscular mycorrhizal (AM) fungi to improve their adaptability to the external environment (Wahyudi et al., 2011; Liao et al., 2015; Afzal et al., 2017); nitrogen fixation, ACC deaminase, and ammonia production can induce plant resistance and promote plant growth (Penrose and Glick, 2003; Senthilkumar et al., 2009); and phosphate and potassium solubilization can effectively increase the absorption of phosphorus and potassium by plants and promote root development (Richardson, 2001), Therefore, adding the strain XNRB-3 under potted and field conditions can improve the ability of plants to resist pathogens and promote the growth of apple plants. Ryu et al. (2003) found that the bacterial volatile 2,3-butanediol can significantly increase the biomass of Arabidopsis thaliana. Similar results were obtained in our study. Strain XNRB-3 produced butanedioic acid, monomethyl ester, and dibutyl phthalate and had a strong growth-promoting effect on the root system of Arabidopsis. This revealed that strain XNRB-3 can promote root elongation and lateral root development by secreting volatile compounds.

Yu et al. (2011) found that the siderophore-producing bacterium B. subtilis CAS15 has a biocontrol effect on Fusarium wilt. The strain XNRB-3 in this study also has a siderophore-producing function, can directly stimulate the biosynthesis of other antibacterial compounds by increasing the availability of minerals to bacteria, inhibit the growth of pathogenic bacteria, and induce the activity of plant root protection enzymes. The increase in root protection enzyme activity indicates that the root system's defense response against pathogens has been initiated (Ramamoorthy et al., 2001; Joseph et al., 2007; Wahyudi et al., 2011). Strain XNRB-3 can also produce enzymes that dissolve fungal cell walls (cellulose, pectinase, $\beta 1,3-$ glucanase, chitosanase, and protease), antifungal compounds (2,4-di-tert-butylphenol and alpha-bisabolol), and low molecular weight metabolites (HCN), which limits the growth of pathogens and protects 
plants from phytopathogenic fungi. Among them, cellulases and pectinases are important for the intracellular root colonization of PGP bacteria, as these are hydrolytic enzymes with the ability to degrade cellulose/pectin material of the plant cell wall (Verma et al., 2001). This feature helps strain XNRB-3 better colonize the root system and continue to produce substances that are beneficial to plant growth to promote the development of the root system, which enhances the growth of the aboveground parts of plants. The above results indicate that the endophytic bacterium XNRB-3 has high potential to be used as a biofertilizer and biopesticide and could aid the development of a sustainable, safe, and effective agriculture system.

The production and transportation of BCAs are essential for successful biological control under field conditions (Thangavelu et al., 2004). An appropriate carrier can support the survival of BCAs while inhibiting the growth of target pathogens, thereby improving the performance of BCAs for plant disease control (Ling et al., 2010; Wei et al., 2015). The selection of a suitable vector for strain XNRB-3 is thus necessary for the successful application of BCAs (Malusá et al., 2012). A carrier ideally possesses the following properties: high water-holding capacity, ease of processing, free of lump-forming materials, near-sterile or easy to sterilize by autoclaving or by other methods (e.g., gamma irradiation), high pH buffering capacity, low cost, available in adequate amounts, no toxicity, and environmental safety (Stephens and Rask, 2000; Ferreira and Castro, 2005).Smith (1992) found that dry inoculants can be produced using different types of soil materials (peat, coal, clays, and inorganic soil), organic materials (composts, soybean meal, wheat bran, and sawdust), or inert materials (e.g., vermiculite, perlite, kaolin, bentonite, and silicates). In this experiment, dry inoculants in Table S7 were used to optimize the fermentation conditions of strain XNRB-3 using response surface analysis (RSM), which significantly increased the survival rate and shelf life of strain XNRB-3 and complies with the Chinese bio-organic fertilizer production standard stipulating that the functional microorganism content should be greater than $2.0 \times 10^{7} \mathrm{CFU} \mathrm{g}^{-1}$ dry formulation after storage for 6 months at room temperature (Emmert and Handelsman, 1999). The raw materials (cow dung compost and wheat straw) in the formula are cheap and easy to obtain, and the fermentation level is high, which provides a good foundation for its large-scale industrial production. We verified the results under field conditions and found that the addition of optimized XNRB-3 bacterial fertilizer can significantly promote the growth of replanted young apple trees and inhibit the growth of Fusarium in the soil. The abundance of Fusarium in the soil was significantly lower after treatment with the optimized XNRB-3 bacterial fertilizer compared with CK1. This ability to promote plant growth might also stem from the ability of XNRB-3 to enhance the soluble mineral nutrient content and produce indole-3-acetic acid (IAA), as well as its multiple PGP properties and antagonistic traits (Pii et al., 2015) .To improve the effectiveness of the application of XNRB-3 bacterial fertilizer, fertilizer application should be repeated 3-4 times during the growing season with an interval of 2-4 weeks each time (Wei et al., 2015).

The optimized strain XNRB-3 fermentation broth can significantly inhibit the mycelial growth and spore germination of Fusarium, and an abnormal structure of the mycelia (mycelia and conidia breakage, deformity, and dissolution) from the edge of the inhibition zone was observed using scanning electron microscopy (SEM) in vitro assays. This antagonism may be caused by the secreted antifungal compounds (lipopeptides, polyketides, and bacteriocins) (Cawoy et al., 2014; Harwood et al., 2018). Among these compounds, lipopeptides (surfactin, iturin, and fengycin families) show potent antimicrobial activity against a wide variety of microorganisms in vitro, especially filamentous fungi (Bonmatin et al., 2003; Hofemeister et al., 2004; Moyne et al., 2001; FrikhaGargouri et al., 2017). Aside from their antimicrobial activity, lipopeptides are involved in the attachment to plant surfaces, the formation of biofilms, and the induction of resistance against phytopathogens (Hofemeister et al., 2004; Chen et al., 2013). In our study, non-ribosomal peptide synthetase genes involved in the synthesis of antibiotics were detected in strain XNRB-3 using PCR-based assays, and the antibiotics that can be synthesized include Yndj protein, subtilisin, bacillomycin, iturin A, fengycin, and surfactin, which confer broad-spectrum resistance to plant pathogenic fungi. These findings are similar to the results of Cao et al. (2012). The antibiotics (surfactin, fengycin, iturin, bacillomycin, and subtilosin) produced by B. subtilis SQR 9 significantly inhibit the growth of F. oxysporum, Verticillium dahliae, Phytophthora capsici, and Phytophthora nicotianae. The production of lipopeptides substances might also be one of the important reasons why strain XNRB-3 can form a biofilm on the surface of roots. Besson et al. (1990) found that asparagine appeared to be the optimal precursor among the a-amino acids in the peptidic part of iturin, indicating that the production of amino acids also affects the biosynthesis of peptide antibiotics. In this experiment, capillary electrophoresis was used to detect the content of free amino acids during fermentation by strain XNRB-3. The concentration of four free amino acids (aspartic acid, glutamic acid, proline, and tyrosine) in the extracellular matrix was the highest. This finding is consistent with the results of Ren et al. (2012). This indicates that the production of amino acids might be involved in the biosynthesis of peptide antibiotics.

Recently, Bacillus spp. belonging to PGPR have been shown to promote plant growth and mediate the biocontrol of various pathogens (Cao et al., 2011; Cawoy et al., 2014; Chowdhury et al., 2015; Harwood et al., 2018). However, when applied in the field, they are usually unable to impart these beneficial effects, which might be closely related to the formation of bacterial biofilm and their ability to colonize the rhizosphere and/or roots (Compant et al., 2010;

Bhattacharyya et al., 2012). Mendis et al. (2018) found that B. firmus I-1582 and B. amyloliquefaciens QST713 can colonize plant roots, promote plant growth, and provide protection against pathogens/pests, such as F. oxysporum, Pythium aphanidermatum, and Rhizoctonia solani. Nan et al. (2011) found that B. subtilis N11 mainly colonizes the roots by forming a biofilm along the elongation zone and differentiation zone of the roots, thereby protecting the plants from fungal infection. Some studies have found that the presence of lipopeptide biosynthetic genes or the co-production of multiple lipopeptides are important for the colonization of Bacillus and the formation of biofilms (Bais et al., 2004; Frikha-Gargouri et al., 2017). There is thus a need to evaluate the colonization ability of strain XNRB-3 in the root system. Given that strain XNRB-3 has a variety of lipopeptide biosynthetic genes and forms a thick biofilm in a static medium, we also evaluated the colonization ability of the root system by dilution-plate counting in a greenhouse and in the field in non-sterile soil (Mendis et al., 2018). Strain XNRB-3 could colonize plant roots, and its fresh weight ranged from $10^{5}$ to $10^{7} \mathrm{cfu} / \mathrm{g}$ within 21 days. This is consistent with the results of Hallmann (2001) indicating that strain XNRB-3 can colonize the roots of apple seedlings, which is critical for its ability to become established in the soil environment after applying it in the field. We also found that watering the strain XNRB-3 in soil pre-infected with Fusarium can significantly reduce the abundance of Fusarium in rhizosphere soil. After 5 weeks, the relative control effect was as high as $51 \%$. These findings are consistent with the results of Cao et al. (2011) showing that the pathogen density in the rhizosphere of cucumber seedlings inoculated with Bacillus subtilis SQR9 was significantly reduced. This result indicated that strain XNRB-3 can stably colonize the rhizosphere of apple seedlings and provide protection to plants. Similar results were obtained in the PAS staining test. The roots treated with the fermentation broth of strain XNRB-3 did not show symptoms of Fusarium infection, which demonstrated that strain XNRB-3 can colonize the roots of the plant and grow root epidermis, forming a biofilm that prevents Fusarium infection and improves the resistance of plants to infection (Duan et al., 2021), Similar results were obtained by Benhamou et al. (1998): seed treatment of tomato with the endophytic bacterium B.

Page $20 / 40$ 
pumilus SE 34 prevents the entry of the vascular wilt fungus F. oxysporum $\mathrm{f}$. sp. radicis-lycopersici into the vascular stele, and the mycelial growth is restricted to the epidermis and outer root cortex. Infected roots can also produce a large amount of sticky substances and result in the deposition of formed callose and starch granules to form a mechanical barrier that inhibits the invasion of pathogens (Lagopodi et al., 2002; Grunewaldt-Stöcker et al., 2020). A similar structure was also observed in this experiment.

Soil enzyme activity is often used to monitor changes in soil microbial activity and soil fertility because it is involved in all soil biochemical processes (e.g., soil organic matter formation and degradation; $\mathrm{C}, \mathrm{N}$, and $\mathrm{P}$ cycling; and plant nutrient transformation); it is also sensitive to changes in soil management (Kandeler et al., 2006; Song et al., 2012). Changes in soil attributes (e.g., SOC, TN, TP, AN, and AP concentrations) are also important indicators of changes in soil fertility and long-term ecosystem sustainability (Pan et al., 2013). Therefore, we evaluated soil microbial activity and fertility status by measuring the activity of soil-related enzymes and soil nutrient attributes after adding strain XNRB-3. The application of strain XNRB-3 significantly increased the activity of soil-related enzymes, and it increased after the second year of applying strain XNRB-3. This is consistent with the results of several previous studies. For example, the addition of PGPR can significantly improve the physical and chemical properties of soil and soil enzyme activity (Ren et al., 2019). PGPR strains can induce the production of lytic enzymes by utilizing carbon from the cell wall of microorganisms, thereby increasing soil urease activity (Karthik et al., 2017). The increase in urease activity indicated that the application of XNRB-3 may increase the gross $\mathrm{N}$ mineralization rate because urease can catalyze the hydrolysis of urea into $\mathrm{CO}_{2}$ and $\mathrm{NH}_{4}{ }^{+}$and promote the soil nitrogen cycle (Xu et al., 2015). The increase in invertase activity can promote the conversion of carbohydrates and increase the concentration of soil nutrients (e.g. N, P, K) under the action of microorganisms and improve soil fertility (Han et al., 2017). Phosphorus $(\mathrm{P})$ plays a key role in crop productivity, and its availability depends on $\mathrm{P}$ mineralization from soil organic matter. This enzymatic process is performed by a group of phosphatases, such as AP, which provide inorganic P to the soil solution (Krämer, 2000). Strain XNRB-3 can increase AP activity, which increases the availability of soluble $\mathrm{P}$ and promotes plant growth. Many studies have shown that soil phosphatase and urease activity is significantly positively correlated with TN, TP, and SOC, and soil pH is significantly negatively correlated with the activity of soil enzymes (Xie et al., 2017; Ren et al., 2019). Soil sucrase activity is significantly positively correlated with soil available nitrogen (Fu et al., 2018). This finding is consistent with the results of this study; after adding strain XNRB-3, changes in the content of N, P, K, and SOC in the soil and soil pH were similar to changes in the activity of soil-related enzymes. The increase in the nutrient concentration in the soil might also be related to the characteristics of strain XNRB-3 such as nitrogen fixation, phosphorus dissolution, and potassium dissolution. Some soil environmental factors (such as soil temperature, $\mathrm{pH}$, soil aggregate, organic matter, nitrogen, phosphorus, and other nutrients) affect the number and activity of microorganisms and thus affects the activity of soil enzymes (Floch et al., 2009; Qi et al., 2016). The increase in CAT activity after the addition of strain XNRB-3 might be closely related to soil microbial activity (Kabiri et al., 2016). This indicates that the application of strain XNRB-3 can increase the number and activity of soil microorganisms by enhancing soil environmental factors and soil enzyme activity and promoting the growth of young apple trees.

Soil microorganisms play an important role in agroecosystems because they participate in nutrient cycling, the decomposition of organic matter, and the development of soil-borne diseases (Lambers et al., 2009), The functional diversity and overall activity of microbial communities in soil can reflect soil quality (Islam et al., 2011). Biological methods are some of the main methods used to measure the functional diversity and overall activity of microbial communities for their simple operation, high sensitivity and resolution, and rich data (Dang et al., 2015; Guo et al., 2015). Therefore, biological methods were used in this study to investigate the functional diversity and carbon source utilization of the rhizosphere soil microbial community after treatment with strain XNRB-3, as well as evaluate the safety of its use in the soil environment. The AWCD value of rhizosphere soil was significantly higher after the addition of strain XNRB-3 compared with other treatments; the addition of strain XNRB-3 also significantly enhanced the use of carbon sources such as polymers, carboxylic acids, and amino acids, which might be related to the increase in the number of soil bacteria and actinomycetes after the addition of strain XNRB-3. Biolog GEN III microplate identification revealed that strain XNRB-3 can use a wide range of carbon sources, which permits this strain to grow and reproduce in environments with different nutrient levels (Schutter and Dick, 2001).

Previous studies have shown that the occurrence of ARD is closely related to the structure and diversity of soil microbial communities. Increases in the number of rhizosphere soil pathogens and decreases in the number of beneficial microorganisms are also important factors leading to disease outbreaks (Mazzola and Manici, 2012; Kelderer et al., 2012). The T-RFLP data from this study showed that strain XNRB-3 can significantly alter the structure of the rhizosphere soil fungal and bacterial communities after treatment; compared with the treatment with strain XNRB-3 addition, the community structure observed in CK1 and T1 differed, but the community structure observed in the fumigation treatment was similar. Application of this strain also significantly increased the abundance and diversity of rhizosphere soil bacteria and fungi, reduced the relative abundance of Fusarium, provided a stable and beneficial rhizosphere ecosystem for plants, and promoted plant growth. These results were consistent with the conclusion of Liu (2011), who indicated that adjustment of soil microbial community structure and the abundance of soil microbes can reduce disease caused by continuous soil cropping. The addition of strain XNRB-3 may improve the soil microbial environment by promoting the aggregation of some beneficial microorganisms or the secretion of some VOCs (Romoli et al., 2014; Liu et al., 2021). Soil microbial VOCs have been shown to promote plant growth (Ryu et al.2003) and inhibit bacterial and fungal growth (Fernando et al., 2005). This finding is consistent with the results of our research. The volatile antibacterial compounds in the fermentation broth of strain XNRB-3 can not only strongly inhibit the growth of pathogenic fungi but can also promote root growth. Bacterial VOCs can also decrease soil fungal biomass and increase soil bacterial biomass (Yuan et al.,2017), The same pattern was observed in this study: after the addition of strain XNRB-3, the number of soil bacteria significantly increased, and the number of fungi significantly decreased. Strain XNRB-3 can also reduce the damage of ARD to the replanted young apple trees by improving the soil microbial environment.

Imbalances in soil physical and chemical properties and the allelopathy of root exudates and residues are considered the main causes of soil sickness (Pant et al., 2013; Zhang Y et al., 2010). Yin et al. (2017) found that the roots of apple plants under continuous cropping can secrete the same substances (such as phenolic acid autotoxic substances) for a long time, and these substances significantly affect the composition and distribution of the rhizosphere microflora, increasing the number of pathogenic fungi and inhibiting plant growth (Liu H et al., 2019; Xu et al., 2020). Phenolic substances related to ARD currently known mainly include 2,4-di-tert-butylphenol, vanillic acid, benzoic acid, p-hydroxybenzoic acid, ferulic acid, cinnamic acid, and phloridzin (Ye et al., 2006; Qu and

Page $21 / 40$ 
Wang, 2008; Yin et al., 2013, 2017; Chen et al., 2021). Phlorizin is a unique phenolic acid substance of apples that mainly exists in the roots, stems, bark, tender leaves, and fruits of apples. The high concentration of phlorizin can significantly inhibit the growth of apple seedlings and reduce the rate of plant photosynthesis and transpiration (Ehrenkranz et al., 2005; Zhang Y et al., 2010). Ye et al. (2006) found that ROS-induced membrane damage caused by cinnamic acid can facilitate the attack and colonization of the vascular bundle system of roots by pathogenic Fusarium. The use of microbial degradation methods to degrade phenolic acids in the environment is becoming increasingly popular because of its various advantages, including low cost, high degradation efficiency, lack of secondary pollution, and environmental safety (Ma et al., 2017; Wang et al., 2021), Use of the medium containing phloridzin as the sole carbon source revealed that strain XNRB-3 can efficiently degrade phloridzin; this strain can also effectively degrade phloridzin, cinnamic acid, ferulic acid, benzoic acid, and p-hydroxybenzoic acid in soil and culture fluid, thereby promoting the growth of apple seedlings. This finding is similar to the results of Zhang $Y$ et al. (2010), which used a screening medium containing p-coumaric acid as the sole carbon source. Four microbes were isolated from plant soils, and these microbes could effectively degrade ferulic acid, p-hydroxybenzoic acid, and p-hydroxybenzaldehyde and promote seedling growth. Phloridin is degraded in the soil in two main ways. The first is through the hydrolysis of phloretin into phloroglucinol and p-hydroxyphenylpropionic acid by secreting a phloretin hydrolase, followed by decomposition to phloretin and glucose by $\beta$-glucosidase, which is then used by bacteria (Chatterjee et al., 1969), Alternatively, it can be degraded to pyruvic acid by the protocatechuic acid pathway in Pseudomonas (Mohan and Phale, 2017), and pyruvic acid can be converted to acetyl CoA and enter the tricarboxylic acid cycle, which produces organic acids, such as citric acid, succinic acid, malic acid, and oxaloacetic acid (Priefert et al., 2001; Zhang $Y$ et al., 2010), These substances play an important role in promoting the absorption and transportation of certain nutrients and improving the photosynthetic efficiency of plants and the accumulation of nitrogen, phosphorus, and potassium (Liu et al., 2005). Therefore, the method of phloridin degradation in the soil environment by the strain XNRB-3 is thought to be an effective approach for overcoming the obstacles of continuous apple cropping.

\section{Conclusions}

The phloridin-degrading bacterium B. licheniformis XNRB-3 was isolated from the roots of apple plants grown in a replanted orchard. Strain XNRB-3 features a variety of PGP characteristics and antagonistic traits, which confers it with high potential for practical use, including its ability to produce some antifungal substances and significantly inhibit the spore germination of Fusarium. XNRB-3 could effectively colonize the root surface of plant seedlings and even enter roots after it was inoculated on the roots of plant seedlings. The addition of strain XNRB-3 under potted and field conditions can significantly promote the growth of apple plants; reduce the abundance of Fusarium and the content of phenolic acids in the rhizosphere soil; improve the structure of the soil microbial community; increase the available nitrogen, phosphate, and potassium in soil; and improve soil health(Figure 12). This study provided new insight as well as a strain resource that could be used to aid the prevention and control of ARD.

\section{Declarations}

\section{Acknowledgements}

We thank all the colleagues that helped with the development of different parts of this manuscript.

\section{Authors'contributions}

Yanan Duan: performed all experiments. Yanan Duan and Lei Zhao: designed the study and wrote the majority of the manuscript. Yanan Duan and Weitao Jiang, and Ran Chen: analyzed the data. Yanan Duan, Lei Zhao, Weitao Jiang, Ran Chen, Rong Zhang, Xuesen Chen, Chengmiao Yin, and Zhiquan Mao: participated in the design of the study, provided comments, and edited the manuscript. All authors read and approved the final manuscript.

\section{Funding}

This work was supported by Supported by China Agriculture Research System of MOF and MARA (CARS-27), the National Natural Science Foundation of China (32072510), Shandong Agricultural Major Applied Technology Innovation Project (SD2019ZZ008); Taishan Scholar Funded Project (NO.ts20190923); Qingchuang Science and Technology Support Project of Shandong Colleges and Universities (2019KJF020) and Natural Science Foundation of Shandong Province (ZR2020MC131).

\section{Availability of data and materials}

Te datasets generated and analysed during the current study are available from the corresponding author on reasonable request. The datasets presented in this study can be found in online repositories. The 16S rDNA, gyrA, gyrB, and rpoB sequences of bacterial strains in this research were deposited in the GenBank nucleotide database under accession numbers MN726439.1, MT703801.1,MT713119.1,MT713122.1.

The strain XNRB-3 was deposited at China General Microbiological Culture Collection Center (CGMCC) under the accession number CGMCC No.15308.

\section{Ethics approval and consent to participate}

Not applicable.

\section{Consent for publication}

Not applicable.

\section{Competing interests}


The authors declare that they have no competing interests.

\section{Supplementary Information}

The online version contains supplementary material available at

\section{References}

1. Abdelmoteleb A, Troncoso-Rojas R, Gonzalez-Soto T, González-Mendoza D. Antifungical activity of autochthonous Bacillus subtilis isolated from Prosopis juliflora against phytopathogenic fungi. Mycobiology. 2017;45(4):385-391. https://doi.org/10.5941/MYC0.2017.45.4.385.

2. Adinarayana K, Ellaiah P, Prasad DS. Purification and partial characterization of thermostable serine alkaline protease from a newly isolated Bacillus subtilis PE-11. Aaps Pharmscitech. 2003;4(4):440-448. https://doi.org/10.1208/pt040456.

3. Afzal I, Iqrar I, Shinwari ZK, Yasmin A. Plant growth-promoting potential of endophytic bacteria isolated from roots of wild Dodonaea viscosa L. Plant Growth Regulation. 2017;81(3):399-408. https://doi.org/10.1007/s10725-016-0216-5.

4. Afzal I, Shinwari ZK, Sikandar S, Shahzad S. Plant beneficial endophytic bacteria: mechanisms, diversity, host range and genetic determinants. Microbiological research. 2019;221:36-49. https://doi.org/10.1016/j.micres.2019.02.001.

5. Ahemad M, Khan MS. Functional aspects of plant growth promoting rhizobacteria: recent advancements. Insight Microbiol. 2011;1(3):39-54. https://doi.org/10.5567/ IMICRO-IK.2011.39.54.

6. Ahmad F, Ahmad I, Khan M. Screening of free-living rhizospheric bacteria for their multiple plant growth promoting activities. Microbiological research. 2008;163(2):173-181. https://doi.org/10.1016/j.micres.2006.04.001.

7. Anthony T, Rajesh T, Kayalvizhi N, Gunasekaran P. Influence of medium components and fermentation conditions on the production of bacteriocin (s) by Bacillus licheniformis AnBa9. Bioresource technology. 2009;100(2):872-877. https://doi.org/10.1016/j.biortech.2008.07.027.

8. Avery B. Soil classification in the Soil Survey of England and Wales. Journal of Soil Science. 1973;24(3):324-338.

9. Azabou MC, Gharbi Y, Medhioub I, Ennouri K, Barham H, Tounsi S, et al. The endophytic strain Bacillus velezensis OEE1: An efficient biocontrol agent against Verticillium wilt of olive and a potential plant growth promoting bacteria. Biological Control. 2020;142:104168. https://doi.org/10.1016/j.biocontrol.2019.104168.

10. Bais HP, Fall R, Vivanco JM. Biocontrol of Bacillus subtilis against infection of Arabidopsis roots by Pseudomonas syringae is facilitated by biofilm formation and surfactin production. Plant physiology. 2004;134(1):307-319. https://doi.org/10.3724/SP.J.1037.2013.00537.

11. Balbín-Suárez A, Jacquiod S, Rohr A-D, Liu B, Flachowsky H, Winkelmann T, et al. Root exposure to apple replant disease soil triggers local defense response and rhizoplane microbiome dysbiosis. FEMS Microbiology Ecology. 2021;97(4):fiab031. https://doi.org/10.1093/femsec/fiab031.

12. Benhamou N, Kloepper JW, Tuzun S. Induction of resistance against Fusarium wilt of tomato by combination of chitosan with an endophytic bacterial strain: ultrastructure and cytochemistry of the host response. Planta. 1998;204(2):153-168. https://doi.org/10.1007/s004250050242.

13. Besson F, Hourdou ML, Michel G. Studies on the biosynthesis of iturin, an antibiotic of Bacillus subtilis, and alipopeptide containing $\beta$-hydroxy fatty acids. Biochimica et Biophysica Acta (BBA)-General Subjects. 1990;1036(2):101-106. https://doi.org/10.1016/0304-4165(90)90020-W.

14. Bhattacharyya PN, Jha DK. Plant growth-promoting rhizobacteria (PGPR): emergence in agriculture. World Journal of Microbiology and Biotechnology. 2012;28(4):1327-1350. https://doi.org/10.1007/s11274-011-0979-9.

15. Bibi F, Yasir M, Song G-C, Lee S-Y, Chung Y-R. Diversity and characterization of endophytic bacteria associated with tidal flat plants and their antagonistic effects on oomycetous plant pathogens. The Plant Pathology Journal. 2012;28(1):20-31. https://doi.org/10.5423/ppj.0a.06.2011.0123.

16. Bochner B. "Breathprints" at the microbial level. ASM news. 1989;55:536-539.

17. Bonmatin JM, Laprévote O, Peypoux F. Diversity among microbial cyclic lipopeptides: iturins and surfactins. Activity-structure relationships to design new bioactive agents. Combinatorial chemistry \& high throughput screening. 2003;6(6):541-556. https://doi.org/10.2174/138620703106298716.

18. Bremner J. Determination of nitrogen in soil by the Kjeldahl method. The Journal of Agricultural Science. 1960;55(1):11-33. https://doi.org/10.1017/S0021859600021572.

19. Cachinero J, Hervas A, Jiménez-Díaz R, Tena M. Plant defence reactions against fusarium wilt in chickpea induced by incompatible race of Fusarium oxysporum f. sp. ciceris and nonhost isolates of F. oxysporum. Plant pathology. 2002;51(6):765-776. https://doi.org/10.1046/j.1365-3059.2002.00760.x.

20. Cao Y, Zhang Z, Ling N, Yuan Y, Zheng X, Shen B, et al. Bacillus subtilis SQR 9 can control Fusarium wilt in cucumber by colonizing plant roots. Biology and fertility of soils. 2011;47(5):495-506. https://doi.org/10.1007/s00374-011-0556-2.

21. Cao Y, Xu Z, Ling N, Yuan Y, Yang X, Chen L, et al. Isolation and identification of lipopeptides produced by B. subtilis SQR 9 for suppressing Fusarium wilt of cucumber. Scientia horticulturae. 2012;135:32-39. https://doi.org/10.1016/ j.scienta.2011.12.002.

22. Cawoy H, Debois D, Franzil L, De Pauw E, Thonart P, Ongena M. Lipopeptides as main ingredients for inhibition of fungal phytopathogens by Bacillus subtilis/amyloliquefaciens. Microbial biotechnology. 2015;8(2):281-295. https://doi.org/10.1111/1751-7915.12238.

23. Chatterjee A, Gibbins L. Metabolism of phloridzin by Erwinia herbicola: nature of the degradation products, and the purification and properties of phloretin hydrolase. Journal of bacteriology. 1969;100(2):594-600. https://doi.org/0.1128/JB.100.2.594 -600.1969.

24. Chen Y, Yan F, Chai Y, Liu H, Kolter R, Losick R, et al. Biocontrol of tomato wilt disease by Bacillus subtilis isolates from natural environments depends on conserved genes mediating biofilm formation. Environmental microbiology. 2013;15(3):848-864. https://doi.org/10.1111/j.1462-2920.2012.02860.x.

25. Chen R, Jiang W, Liu Y, Wang Y, Fan H, Chen X, et al. Amygdalin and Benzoic Acid on the Influences of the Soil Environment and Growth of Malus hupehensis Rehd. Seedlings. ACS omega. 2021;6(19):12522-12529. https://doi.org/10.1021/acsomega. 1. c00206.

Page $23 / 40$ 
26. Cheng CY, Li YK. An Aspergillus chitosanase with potential for large-scale preparation of chitosan oligosaccharides. Biotechnology and Applied Biochemistry. 2000;32(3):197-203. https://doi.org/10.1042/BA20000063.

27. Chowdhury SP, Hartmann A, Gao X, Borriss R. Biocontrol mechanism by root-associated Bacillus amyloliquefaciens FZB42-a review. Frontiers in microbiology. 2015;6:780. https://doi.org/10.3389/fmicb.2015.00780.

28. Chowdhury SK, Majumdar S, Mandal V. Application of Bacillus sp. LBF-01 in Capsicum annuum plant reduces the fungicide use against Fusarium oxysporum. Biocatalysis and Agricultural Biotechnology. 2020;27:101714. https://doi.org/10.1016/j.bcab.2020.101714.

29. Chun J, Bae KS. Phylogenetic analysis of Bacillus subtilis and related taxa based on partial gyrA gene sequences. Antonie van Leeuwenhoek. 2000;78(2):123-127. https://doi.org/10.1023/A:1026555830014.

30. Classen AT, Boyle SI, Haskins KE, Overby ST, Hart SC. Community-level physiological profiles of bacteria and fungi: plate type and incubation temperature influences on contrasting soils. FEMS Microbiology Ecology. 2003;44(3):319-328. https://doi.org/10.1016/S0168-6496(03)00068-0.

31. Compant S, Clément C, Sessitsch A. Plant growth-promoting bacteria in the rhizo-and endosphere of plants: their role, colonization, mechanisms involved and prospects for utilization. Soil Biology and Biochemistry. 2010;42(5):669-678. https://doi.org/10.1016/j.soilbio.2009.11.024.

32. Cui W, He P, Munir S, He P, Li X, Li Y, et al. Efficacy of plant growth promoting bacteria Bacillus amyloliquefaciens B9601-Y2 for biocontrol of southern corn leaf blight. Biological Control. 2019;139:104080. https://doi.org/10.1016/j.biocontrol. 2019. 104080.

33. Dandurand LM, Zasada IA, Wang X, Mimee B, Kuhl JC. Current Status of Potato Cyst Nematodes in North America. Annual Review of Phytopathology. 2019;57(1):1-17. https://doi.org/10.1146/annurev-phyto-082718-100254.

34. Dang W, Gao CH, Zhang Q, Li JH, Lu CD, Jin DS, et al. Screening of Preprocessing Method of Biolog for Soil Microbial Community Functional Diversity. Agricultural Science \& Technology. 2015;16(10). https://doi.org/10.16175/j.cnki.1009-4229.2015.10.038.

35. Deketelaere S, Tyvaert L, França SC, Höfte M. Desirable traits of a good biocontrol agent against Verticillium wilt. Frontiers in microbiology. $2017 ; 8: 1186$. https://doi.org/10.3389/fmicb.2017.01186.

36. Dixit R, Singh RB, Singh HB. Screening of antagonistic potential and plant growth promotion activities of Trichoderma spp. and fluorescent Pseudomonas spp. isolates against Sclerotinia sclerotiorum causing stem rot of French bean. Legume Research- An International Journal. 2015;38(3):375381. https://doi.org/10.5958/0976-0571.2015.00121.6.

37. Dong X, Cai M. Handbook of common bacteria systematic identify. Beijing: Science press; 2001.

38. Duan YN, Chen R, Zhang R, Jiang WT, Chen XS, Yin CM, et al. Isolation, identification, and antibacterial mechanisms of Bacillus amyloliquefaciens QSB-6 and its effect on plant roots. Frontiers in microbiology. 2021;12. https://doi.org/10.3389/ FMICB.2021.746799.

39. Ehrenkranz JR, Lewis NG, Ronald Kahn C, Roth J. Phlorizin: a review. Diabetes/ metabolism research and reviews. 2005;21(1):3138.https://doi.org/10.1002/dmrr.532.

40. Eljounaidi K, Lee SK, Bae H. Bacterial endophytes as potential biocontrol agents of vascular wilt diseases-review and future prospects. Biological Control. 2016;103: 62. -68. https://doi.org/10.1016/j.biocontrol.2016.07.013.

41. Emmert EA, Handelsman J. Biocontrol of plant disease: a (Gram-) positive perspective. FEMS Microbiology letters. 1999;171(1):1-9. https://doi.org/10.1111/j.1574-6968.1999.tb13405.x.

42. Fernando WD, Ramarathnam R, Krishnamoorthy AS, Savchuk SC. Identification and use of potential bacterial organic antifungal volatiles in biocontrol. Soil Biology and Biochemistry. 2005;37(5):955-964. https://doi.org/10.1016/j.soilbio.2004.10.021.

43. Ferreira EM. Residues of the cork industry as carriers for the production of legume inoculants. Silva Lusitana. 2005;13(2):159-167.

44. Filippi MCC, Da Silva GB, Silva-Lobo VL, Côrtes MVC, Moraes AJG, Prabhu AS. Leaf blast (Magnaporthe oryzae) suppression and growth promotion by rhizobacteria on aerobic rice in Brazil. Biological Control. 2011;58(2):160-166. https://doi.org/10.1016/j.biocontrol.2011.04.016.

45. Floch C, Capowiez Y, Criquet S. Enzyme activities in apple orchard agroecosystems: How are they affected by management strategy and soil properties. Soil Biology and Biochemistry. 2009;41(1):61-68. https://doi.org/10.1016/j.soilbio.2008.09.018.

46. Frikha-Gargouri O, Ben Abdallah D, Bhar I, Tounsi S. Antibiosis and bmyB gene presence as prevalent traits for the selection of efficient Bacillus biocontrol agents against crown gall disease. Frontiers in plant science. 2017;8:1363. https://doi.org/10.3389/fpls.2017.01363.

47. Fu D, Yang H, Wang L, Yang S, Li R, Zhang W, et al. Vegetation and soil nutrient restoration of cut slopes using outside soil spray seeding in the plateau region of southwestern China. Journal of environmental management. 2018;228:47-54. https://doi.org/10.1016/j.jenvman.2018.08.108.

48. Gao XB, Zhao FX, Xiang S, Hu YL, Hao YH, Yang SQ, et al. Effects of cinnamon acid on respiratory rate and its related enzymes activity in roots of seedlings of Malus hupehensis Rehd. Agricultural Sciences in China. 2010;9(6):833-839. https://doi.org/10.1016/S1671-2927(09)60161-9.

49. Gao Z, Zhang B, Liu H, Han J, Zhang Y. Identification of endophytic Bacillus velezensis ZSY-1 strain and antifungal activity of its volatile compounds against Alternaria solani and Botrytis cinerea. Biological Control. 2017;105:27-39. https://doi.org/10.1016/j.biocontrol.2016.11.007.

50. Gardes M, Bruns TD. ITS primers with enhanced specificity for basidiomycetes -application to the identification of mycorrhizae and rusts. Molecular ecology. 1993;2(2):113-118. https://doi.org/10.1111/j.1365-294X.1993.tb00005.x.

51. Guo P, Zhu L, Wang J, Wang J, Liu T. Effects of alkyl-imidazolium ionic liquid [Omim] Cl on the functional diversity of soil microbial communities. Environmental Science and Pollution Research. 2015;22(12): 9059-9066.https://doi.org/10.1007/ s11356-014-4052-8.

52. Garrity G, Boone DR, Castenholtz RW. Bergey's manual of systematic bacteriology: Volume 3: The Firmicutes: Bergey's manual of systematic bacteriology. 2009. ISBN: 978-0-387-95041-9.

53. Ge Z, Du H, Gao Y, Qiu W. Analysis on metabolic functions of stored rice microbial communities by BIOLOG ECO microplates. Frontiers in microbiology. 2018;9:1375. https://doi.org/CNKI:SUN:HJKB.0.2018-05-027. 
54. Grunewaldt-Stöcker G, Popp C, Baumann A, Fricke S, Menssen M, Winkelmann T, et al. Observations on early fungal infections with relevance for replant disease in fine roots of the rose rootstock Rosa corymbifera 'Laxa'. Scientific reports. 2020;10(1): 1. -17. https://doi.org/10.1038/s41598-020-79878-8.

55. Guan SY. Soil Enzymes and Its Research Methods. Beijing: China Agriculture Press.1986.

56. Garland JL. Analytical approaches to the characterization of samples of microbial communities using patterns of potential $\mathrm{C}$ source utilization. Soil Biology and Biochemistry. 1996;28(2), 213-221. https://doi.org/10.1016/0038-0717(95)00112-3.

57. Hallmann J. Plant interactions with endophytic bacteria. Biotic interactions in plant-pathogen associations. 2001:87-119. ISBN: 9780851995120.

58. Han L, Su D, Lv S, Luo Y, Li X, Jiao J, et al. Responses of biogeochemical characteristics and enzyme activities in sediment to climate warming under a simulation experiment in geographically isolated wetlands of the Hulunbuir Grassland, China. International journal of environmental research and public health. 2017;14(9):968. https://doi.org/10.3390/ijerph14090968.

59. Hankin L, Anagnostakis S. The use of solid media for detection of enzyme production by fungi. Mycologia. 1975;67(3):597-607. https://doi.org/10.1007/BF02891700.

60. Harwood CR, Mouillon J-M, Pohl S, Arnau J. Secondary metabolite production and the safety of industrially important members of the Bacillus subtilis group. FEMS microbiology reviews. 2018;42(6):721-738. https://doi.org/10.1093/femsre/fuy028.

61. Hendricks CW, Doyle JD, Hugley B. A new solid medium for enumerating cellulose-utilizing bacteria in soil. Applied and environmental microbiology. 1995;61(5):2016-2019. https://doi.org/10.1128/AEM.61.5.2016-2019.1995.

62. Hewavitharana SS, Mazzola M. Carbon source-dependent effects of anaerobic soil disinfestation on soil microbiome and suppression of Rhizoctonia solani AG-5 and Pratylenchus penetrans. Phytopathology. 2016;106(9):1015-1028. https://doi.org/10.1094/PHYT0-12-15-0329-R.

63. Hofemeister J, Conrad B, Adler B, Hofemeister B, Feesche J, Kucheryava N, et al. Genetic analysis of the biosynthesis of non-ribosomal peptide-and polyketide-like antibiotics, iron uptake and biofilm formation by Bacillus subtilis A1/3. Molecular Genetics and Genomics. 2004;272(4):363-378. https://doi.org/10.1007/s00438 -004-1056-y.

64. Hofmann A, Wittenmayer L, Arnold G, Schieber A, Merbach W. Root exudation of phloridzin by apple seedlings (Malus× domestica Borkh.) with symptoms of apple replant disease. Journal of Applied Botany and Food Quality. 2009;82(2):193-198. https://doi.org/10.1614/IPSM-08-126.1.

65. Hong TY, Meng M. Biochemical characterization and antifungal activity of an endo-1, 3- $\beta$-glucanase of Paenibacillus sp. isolated from garden soil. Applied microbiology and biotechnology. 2003;61(5):472-478. https://doi.org/10.1007/s00253-003-1249-z.

66. Hsieh FC, Li MC, Lin TC, Kao SS. Rapid detection and characterization of surfactin -producing Bacillus subtilis and closely related species based on PCR. Current microbiology. 2004;49(3):186-191. https://doi.org/10.1134/S1061934807110159.

67. Hu M, Shi Z, Zhang Z, Zhang Y, Li H. Effects of exogenous glucose on seed germination and antioxidant capacity in wheat seedlings under salt stress. Plant growth regulation. 2012;68(2):177-188. https://doi.org/10.1007/s10725-012-9705-3.

68. Hussein W, Fahim S. Detection of synthetases genes involved in non ribosomal lipopeptides (NRLPs) biosynthesis from Bacillus species by bioinformatics and PCR degenerated primers and estimation of their production. Int J Pharma Bio Sci. 2017;8(2):116-125. https://doi.org/10.22376/ijpbs.2017.8.2.b116-125.

69. Islam MR, Chauhan PS, Kim Y, Kim M, Sa T. Community level functional diversity and enzyme activities in paddy soils under different long-term fertilizer management practices. Biology and Fertility of Soils. 2011;47(5):599-604. https://doi.org/10.1007/ s00374-010-0524-2.

70. Ji SH, Gururani MA, Chun S-C. Isolation and characterization of plant growth promoting endophytic diazotrophic bacteria from Korean rice cultivars. Microbiological research. 2014;169(1):83-98. https://doi.org/10.1016/j.micres. 2013. 06.003.

71. Joseph B, Ranjan Patra R, Lawrence R. Characterization of plant growth promoting rhizobacteria associated with chickpea (Cicer arietinum L.). International Journal of Plant Production. 2012;1(2):141-152. https://doi.org/10.1111/j.1365-2494.2007. 00593. x.

72. Kabiri V, Raiesi F, Ghazavi MA. Tillage effects on soil microbial biomass, SOM mineralization and enzyme activity in a semi-arid Calcixerepts. Agriculture, Ecosystems \& Environment. 2016;232:73-84. https://doi.org/10.1016/j.agee. 2016. 07.022.

73. Kandeler E, Mosier AR, Morgan JA, Milchunas DG, King JY, Rudolph S, et al. Response of soil microbial biomass and enzyme activities to the transient elevation of carbon dioxide in a semi-arid grassland. Soil Biology and Biochemistry. 2006;38(8):2448-2460. https://doi.org/10.1016/j.soilbio.2006.02.021.

74. Karthik C, Elangovan N, Kumar TS, Govindharaju S, Barathi S, Oves M, et al. Characterization of multifarious plant growth promoting traits of rhizobacterial strain AR6 under Chromium (VI) stress. Microbiological research. 2017;204:65-71. https://doi.org/10.1016/j.micres.2017.07.008.

75. Kelderer M, Manici LM, Caputo F, Thalheimer M. Planting in the 'inter-row'to overcome replant disease in apple orchards: a study on the effectiveness of the practice based on microbial indicators. Plant and Soil. 2012;357(1):381-393. https://doi.org/10.1007/s11104-012-1172-0.

76. Kloepper JW, Beauchamp CJ. A review of issues related to measuring colonization of plant roots by bacteria. Canadian journal of Microbiology. 1992;38(12):1219-1232. https://doi.org/10.1139/m92-202.

77. Krämer S, Green DM. Acid and alkaline phosphatase dynamics and their relationship to soil microclimate in a semiarid woodland. Soil biology and biochemistry. 2000;32(2):179-188. https://doi.org/10.1016/S0038-0717(99)00140-6.

78. Kumar P, Dubey R, Maheshwari D. Bacillus strains isolated from rhizosphere showed plant growth promoting and antagonistic activity against phytopathogens. Microbiological research. 2012;167(8):493-499. https://doi.org/10.1016/j.micres. 2012. 05.002.

79. Lagopodi AL, Ram AF, Lamers GE, Punt PJ, Van den Hondel CA, Lugtenberg BJ, et al. Novel aspects of tomato root colonization and infection by Fusarium oxysporum f. sp. radicis-lycopersici revealed by confocal laser scanning microscopic analysis using the green fluorescent protein as a marker. Molecular Plant-Microbe Interactions. 2002;15(2):172-179. https://doi.org/10.1094/MPMI.2002.15.2.172.

80. Lambers H, Mougel C, Jaillard B, Hinsinger P. Plant-microbe-soil interactions in the rhizosphere: an evolutionary perspective. Plant and soil. 2009;321(1):83-115. https://doi.org/0.1007/s11104-009-0042-x.

Page 25/40 
81. Laurent AS, Merwin IA, Fazio G, Thies JE, Brown MG. Rootstock genotype succession influences apple replant disease and root-zone microbial community composition in an orchard soil. Plant and soil. 2010;337(1):259-272. https://doi.org/10.1007/s11104-010-0522-z.

82. Li Y, Feng X, Wang X, Zheng L, Liu H. Inhibitory effects of Bacillus licheniformis BL06 on Phytophthora capsici in pepper by multiple modes of action. Biological Control. 2020;144:104210. https://doi.org/10.1016/j.biocontrol.2020.104210.

83. Ling N, Xue C, Huang Q, Yang X, Xu Y, Shen Q. Development of a mode of application of bioorganic fertilizer for improving the biocontrol efficacy to Fusarium wilt. Biocontrol. 2010;55(5):673-683. https://doi.org/10.1007/s10526-010-9290-1.

84. Liu H, Pan F, Han X, Song F, Zhang Z, Yan J, et al. Response of soil fungal community structure to long-term continuous soybean cropping. Frontiers in microbiology. 2019;9:3316. https://doi.org/10.3389/fmicb.2018.03316.

85. Liu H, Li J, Carvalhais LC, Percy CD, Prakash Verma J, Schenk PM, et al. Evidence for the plant recruitment of beneficial microbes to suppress soil-borne pathogens. New Phytologist. 2021;229(5):2873-2885. https://doi.org/10.1111/nph.17057.

86. Liu L, Chen S, Zhao J, Zhou X, Wang B, Li Y, et al. Watermelon planting is capable to restructure the soil microbiome that regulated by reductive soil disinfestation. Applied Soil Ecology. 2018;129:52-60. https://doi.org/10.1016/j.apsoil.2018.05.004.

87. Liu S, Xia X, Chen G, Mao D, Che S, Li Y. Study progress on functions and affecting factors of soil enzymes. Chinese Agricultural Science Bulletin. 2011;27(21):1-7. https://doi.org/10.1007/s11783-010-0264-4.

88. Liao D, Chen X, Chen A, Wang H, Liu J, Liu J, et al. The characterization of six auxin-induced tomato GH3 genes uncovers a member, SIGH3. 4, strongly responsive to arbuscular mycorrhizal symbiosis. Plant and Cell Physiology, 2015;56(4): 674-687. https://doi.org/10.1093/pcp/pcu212.

89. Liu SL, Yang ZM, Hua DL, Jie XL. and Li YT. Effect of different organic acids on growth, physiological and biochemical characteristics of flue-cured tobacco. Chin Agric Sci Bull. 2005;21(5):248-252.

90. Liu X, Jiang X, He X, Zhao W, Cao Y, Guo T, et al. Phosphate-solubilizing Pseudomonas sp. strain P34-L promotes wheat growth by colonizing the wheat rhizosphere and improving the wheat root system and soil phosphorus nutritional status. Journal of Plant Growth Regulation. 2019;38(4):1314-1324. https://doi.org/ 10. 1007/s00344-019-09935-8.

91. Ma L, Zhang HY, Zhou XK, Yang CG, Zheng SC, Duo JL, et al. Biological control tobacco bacterial wilt and black shank and root colonization by bioorganic fertilizer containing bacterium Pseudomonas aeruginosa NXHG29. Applied Soil Ecology. 2018;129:136-144. https://doi.org/10.1016/j.apsoil.2018.05.011.

92. Ma Y, Chen X, Li M, Wang J, Zhang X, Yang G. Degradation of cinnamic acid by Exiguobacterium sp. strain. Microbiology China. 2017;44(9):2079-2088. https://doi.org/10.13344/j.microbiol.china.160840.

93. Malusá E, Sas-Paszt L, Ciesielska J. Technologies for beneficial microorganisms inocula used as biofertilizers. The scientific world journal. 2012. https://doi.org/ 10. 1100/2012/491206.

94. Marques AP, Pires C, Moreira H, Rangel AO, Castro PM. Assessment of the plant growth promotion abilities of six bacterial isolates using Zea mays as indicator plant. Soil Biology and Biochemistry. 2010;42(8):1229-1235. https://doi.org/10.1016/j.soilbio.2010.04.014.

95. Mazzola M, Manici LM. Apple replant disease: role of microbial ecology in cause and control. Annual Review of Phytopathology. 2012;50:45-65. https://doi.org/10.1146/ annurev-phyto-081211-173005.

96. Mendis HC, Thomas VP, Schwientek P, Salamzade R, Chien JT, Waidyarathne P, et al. Strain-specific quantification of root colonization by plant growth promoting rhizobacteria Bacillus firmus I-1582 and Bacillus amyloliquefaciens QST713 in non-sterile soil and field conditions. PLoS One. 2018;13(2):e0193119. https://doi.org/10.1371/journal.pone.0193119.

97. Miyara I, Shafran H, Davidzon M, Sherman A, Prusky D. pH regulation of ammonia secretion by Colletotrichum gloeosporioides and its effect on appressorium formation and pathogenicity. Molecular plant-microbe interactions. 2010;23(3):304-316. https://doi.org/10.1094/MPMI-23-3-0304.

98. Mohan K, Phale PS. Carbon source-dependent inducible metabolism of veratryl alcohol and ferulic acid in Pseudomonas putida CSV86. Applied and environmental microbiology. 2017;83(8):e03326-03316. https://doi.org/10.1128/AEM.03326-16.

99. Moyne AL, Shelby R, Cleveland T, Tuzun S. Bacillomycin D: an iturin with antifungal activity against Aspergillus flavus. Journal of applied microbiology. 2001;90(4):622-629. https://doi.org/10.1007/s12583-010-0245-3.

100. Nan Z, Kai W, He X, Li SQ, Zhang ZH, Shen B, et al. A new bioorganic fertilizer can effectively control banana wilt by strong colonization with Bacillus subtilis N11. Plant \& Soil. 2011;344(1-2):87-97. https://doi.org/10.1007/s11104-011-0729-7.

101. Omran RG. Peroxide levels and the activities of catalase, peroxidase, and indoleacetic acid oxidase during and after chilling cucumber seedlings. Plant physiology. 1980;65(2):407-408. https://doi.org/10.1104/pp.65.2.407.

102. Pan C, Liu C, Zhao H, Wang Y. Changes of soil physico-chemical properties and enzyme activities in relation to grassland salinization. European Journal of Soil Biology. 2013;55:13-19. https://doi.org/10.1016/j.ejsobi.2012.09.009.

103. Pant G, Mistry SK, Sibi G. Isolation, Identification and Characterization of p, p'-DDT Degrading Bacteria from Soil. Journal of Environmental Science \& Technology. 2013;6(3). https://doi.org/10.3923/jest.2013.130.137.

104. Penrose DM, Glick BR. Methods for isolating and characterizing ACC deaminase-containing plant growth-promoting rhizobacteria. Physiologia plantarum. 2003;118(1):10-15. https://doi.org/10.1034/j.1399-3054.2003.00086.x.

105. Pérez-García A, Romero D, De Vicente A. Plant protection and growth stimulation by microorganisms: biotechnological applications of Bacilli in agriculture. Current opinion in biotechnology. 2011;22(2):187-193. https://doi.org/10.1016/j.copbio. 2010. 12.003.

106. Pii Y, Mimmo T, Tomasi N, Terzano R, Cesco S, Crecchio C. Microbial interactions in the rhizosphere: beneficial influences of plant growth-promoting rhizobacteria on nutrient acquisition process. A review. Biology and fertility of soils. 2015;51(4) :403-415. https://doi.org/10.1007/s00374-015-0996-1. 
107. Priefert H, Rabenhorst J, Steinbüchel A. Biotechnological production of vanillin. Applied Microbiology and Biotechnology. 2001;56(3):296-314. ISBN: 9781118354063.

108. Qi R, Li J, Lin Z, Li Z, Li Y, Yang X, et al. Temperature effects on soil organic carbon, soil labile organic carbon fractions, and soil enzyme activities under long-term fertilization regimes. Applied Soil Ecology. 2016;102:36-45. https://doi.org/10.1016/j.apsoil.2016.02.004.

109. Qiao JJ, Xu YL, Wang LJ. Optimizationrme of the Ratio of Fentation Medium of Bacillus Probiotic Strain J-4 Based on the Model of BP Neural Network. Advances in Technology and Management: Springer; 2012: 807-812. ISBN: 978-3-642-29636-9.

110. Qu XH, Wang J. Effect of amendments with different phenolic acids on soil microbial biomass, activity, and community diversity. Applied Soil Ecology. 2008;39(2):172 -179. https://doi.org/10.1016/j.apsoil.2007.12.007.

111. Quéric N-V, Soltwedel T. Benthic prokaryotic community dynamics along the Ardencaple Canyon, Western Greenland Sea. Sedimentary Geology. 2012;263:36-44. https://doi.org/10.1016/j.sedgeo.2011.10.004.

112. Ramamoorthy V, Viswanathan R, Raguchander T, Prakasam V, Samiyappan R. Induction of systemic resistance by plant growth promoting rhizobacteria in crop plants against pests and diseases. Crop protection. 2001;20(1):1-11. https://doi.org/ 10. 1016/S0261-2194(00)00056-9.

113. Rashid S, Charles TC, Glick BR. Isolation and characterization of new plant growth-promoting bacterial endophytes. Applied soil ecology. 2012;61:217224. https://doi.org/10.1016/j.apsoil.2011.09.011.

114. Raymaekers K, Ponet L, Holtappels D, Berckmans B, Cammue BP. Screening for novel biocontrol agents applicable in plant disease management-a review. Biological Control. 2020;144:104240. https://doi.org/10.1016/j.biocontrol.2020.104240.

115. Rehman HU, Siddique NN, Aman A, Nawaz MA, Baloch AH, Qader SAU. Morphological and molecular based identification of pectinase producing Bacillus licheniformis from rotten vegetable. Journal of Genetic Engineering and Biotechnology. 2015;13(2):139-144. https://doi.org/10.1016/j.jgeb.2015.07.004.

116. Ren H, Lv C, Fernández-García V, Huang B, Yao J, Ding W. Biochar and PGPR amendments influence soil enzyme activities and nutrient concentrations in a eucalyptus seedling plantation. Biomass Conversion and Biorefinery. 2019:1-10. https://doi.org/10.1007/s13399-019-00571-6.

117. Ren Y, Zhou J, Zhang X, Li Z, Zhong J, Yang J, et al. Analysis of free amino acids during fermentation by Bacillus subtilis using capillary electrophoresis. Biotechnology and Bioprocess Engineering. 2012;17(6):1244-1251. https://doi.org/10.1007/s12257-012-0292-y.

118. Richardson AE. Prospects for using soil microorganisms to improve the acquisition of phosphorus by plants. Functional Plant Biology. 2001;28(9):897906. https://doi.org/ 10. 1071/PP01093.

119. Romoli R, Papaleo M, De Pascale D, Tutino M, Michaud L, LoGiudice A, et al. GC-MS volatolomic approach to study the antimicrobial activity of the antarctic bacterium Pseudoalteromonas sp. TB41. Metabolomics. 2014;10(1):42-51. https://doi.org/10.1007/s11306-013-0549-2.

120. Ryu CM, Farag MA, Hu CH, Reddy MS, Wei HX, Paré PW, et al. Bacterial volatiles promote growth in Arabidopsis. Proceedings of the National Academy of Sciences. 2003;100(8):4927-4932. https://doi.org/10.1073/pnas.0730845100.

121. Sambrook J, Russel D. Molecular cloning: A laboratory Manual. 3rd edn, 2001. cold spring harbor laboratory press, cold spring harbor, NY. ISBN: 0-87969136-0.

122. Sanei S, Razavi S. Suppression of Verticillium wilt in olive planting stocks by root-associated fluorescent Pseudomonas spp. Journal of Experimental Agriculture International. 2011:294-305. https://doi.org/10.1016/j.biocontrol.2004.02.002.

123. Santoyo G, Moreno-Hagelsieb G, del Carmen Orozco-Mosqueda M, Glick BR. Plant growth-promoting bacterial endophytes. Microbiological research. 2016;183:92-99. https://doi.org/10.1016/j.micres.2015.11.008.

124. Santoyo G, Orozco-Mosqueda MDC, Govindappa M. Mechanisms of biocontrol and plant growth-promoting activity in soil bacterial species of Bacillus and Pseudomonas: a review. Biocontrol Science and Technology. 2012;22(8):855-872. https://doi.org/ 10. 1080/09583157.2012.694413.

125. Schutter M, Dick R. Shifts in substrate utilization potential and structure of soil microbial communities in response to carbon substrates. Soil Biology and Biochemistry. 2001;33(11):1481-1491. https://doi.org/10.1016/S0038-0717 01. 00057-8.

126. Schwyn B, Neilands J. Universal chemical assay for the detection and determination of siderophores. Analytical biochemistry. 1987;160(1):47-56. https://doi.org/10.1007/ BF00011696.

127. Senthilkumar M, Swarnalakshmi K, Govindasamy V, Lee YK, Annapurna K. Biocontrol Potential of Soybean Bacterial Endophytes Against Charcoal Rot Fungus, Rhizoctonia bataticola. Current Microbiology. 2009;58(4):288-293. https://doi.org/ 10. 1007/s00284-008-9329-z.

128. Shahzad R, Khan AL, Waqas M, Ullah I, Lee IJ. Metabolic and proteomic alteration in phytohormone-producing endophytic Bacillus amyloliquefaciens RWL-1 during methanol utilization. Metabolomics. 2019;15(2):16. https://doi.org/10.1007/s11306 -018-1467-0.

129. Shao J, Song Y, Zhou Y, Wan Z, Li R, Yu J. Diagnostic value of fluorescein-labeled chitinase staining in formalin-fixed and paraffin-embedded tissues of fungal disease. Medical mycology: official publication of the International Society for Human and Animal Mycology. $2019(1): 1$. https://doi.org/10.1093/mmy/myz035.

130. Sheng YF, Wang H, Wang M, Li H, Xiang L, Pan FB, et al. Effects of Soil Texture on the Growth of Young Apple Trees and Soil Microbial Community Structure Under Replanted Conditions. Horticultural Plant Journal. 2020;6(3):123-131. https://doi.org/ 10. 1016/j.hpj.2020.04.003.

131. Singh BK, Sharma SR, Singh B. Antioxidant enzymes in cabbage: Variability and inheritance of superoxide dismutase, peroxidase and catalase. Scientia Horticulturae. 2010;124(1):9-13. https://doi.org/10.1016/j.scienta.2009.12.011.

132. Smith, R. S. Legume inoculant formulation and application. Canadian Journal of Microbiology. 1992;38(6):485-492. https://doi.org/10.1139/m92-080.

133. Somerville TF, Corless CE, Sueke H, Neal T, Kaye SB. 16S Ribosomal RNA PCR Versus Conventional Diagnostic Culture in the Investigation of Suspected Bacterial Keratitis. Translational Vision Science \& Technology. 2020;9(13):2. https://doi.org/ 10. 1167/tvst.9.13.2.

134. Song Y, Song C, Yang G, Miao Y, Wang J, Guo Y. Changes in Labile Organic Carbon Fractions and Soil Enzyme Activities after Marshland Reclamation and Restoration in the Sanjiang Plain in Northeast China. Environmental Management. 2012;50(3):418-426. https://doi.org/10.1007/s00267-012-9890-x.

Page 27/40 
135. Stamatakis, A. RAxML version 8: a tool for phylogenetic analysis and post-analysis of large phylogenies. Bioinformatics. 2014(9):1312-1313. https://doi.org/10.1093/ bioinformatics/btu033.

136. Stephens J, Rask HM. Inoculant production and formulation. Field Crops Research. 2000;65(2-3):249-258. https://doi.org/10.1016/S03784290(99)00090-8.

137. Tewoldemedhin YT, Mazzola M, Labuschagne I, Mcleod A. A multi-phasic approach reveals that apple replant disease is caused by multiple biological agents, with some agents acting synergistically. Soil Biology \& Biochemistry. 2011;43(9):1917-1927. https://doi.org/10.1016/j.soilbio.2011.05.014.

138. Thangavelu R, Palaniswami A, Velazhahan R. Mass production of Trichoderma harzianum for managing fusarium wilt of banana. Agriculture, Ecosystems \& Environment. 2004;24:261-274. https://doi.org/10.1016/j.agee.2003.09.026.

139. Tilston EL, Deakin G, Bennett J, Passey T, Xu X. Effect of fungal, oomycete and nematode interactions on apple root development in replant soil. CABI Agriculture and Bioscience. 2020;1(1): 1-18. https://doi.org/10.1186/s43170-020-00014-7.

140. Tjurin I. Agrochemical Methods of Soil Analysis. 1965.

141. Vacheron J, Desbrosses G, Bouffaud ML, Touraine B, Moënne-Loccoz Y, Muller D, et al. Plant growth-promoting rhizobacteria and root system functioning. Frontiers in Plant Science. 2013;4(September):356. https://doi.org/10.3389/fpls.2013.00356.

142. Van Schoor L, Denman S, Cook, NC. Characterisation of apple replant disease under South African conditions and potential biological management strategies. Scientia Horticulturae. 2009;119(2):153-162. https://doi.org/10.1016/j.scienta.2008.07.032.

143. Verma SC, Ladha JK, Tripathi AK. Evaluation of plant growth promoting and colonization ability of endophytic diazotrophs from deep water rice. Journal of Biotechnology. 2001;91(2-3):127-141. https://doi.org/10.1016/s0168 -1656(01)00333-9.

144. Wahyudi AT, Astuti RP, Widyawati A, Meryandini A, Nawangsih AA. Characterization of Bacillus sp. strains isolated from rhizosphere of soybean plants for their use as potential plant growth for promoting Rhizobacteria. journal of microbiology \& antimicrobials. 2011;3(2): 34-40.

145. Wang G, Yin C, Pan F, Wang X, Xiang L, Wang Y, et al. Analysis of the Fungal Community in Apple Replanted Soil Around Bohai Gulf. Horticultural Plant Journal. 2018(5):7. https://doi.org/10.1016/j.hpj.2018.05.003.

146. Wang Y, Zhang W, Zhang Z, Wang W, Xu S, He X. Isolation, identification and characterization of phenolic acid-degrading bacteria from soil. Journal of Applied Microbiology. 2021;131(1):208-220. https://doi.org/10.1016/j.scienta.2014.05.029.

147. Weerakoon DMN, Reardon CL, Paulitz TC, Izzo AD, Mazzola M. Long-term suppression of Pythium abappressorium induced by Brassica juncea seed meal amendment is biologically mediated. Soil Biology \& Biochemistry. 2012;51 (none):44-52. https://doi.org/10.1016/j.soilbio.2012.03.027.

148. Wei Z, Huang J, Yang C, Xu Y, Shen Q, Chen W, et al. Screening of suitable carriers for Bacillus amyloliquefaciens strain QL-18 to enhance the biocontrol of tomato bacterial wilt. Crop Protection. 2015,75:96-103. https://doi.org/10.1016/j.cropro.2015.05.010.

149. Whelan JA, Russell NB, Whelan MA. A method for the absolute quantification of cDNA using real-time PCR. Journal Of Immunological Methods. 2003. https://doi.org/10.1016/S0022-1759(03)00223-0.

150. Wu Y, Zhou J, Li C, Ma Y. Antifungal and plant growth promotion activity of volatile organic compounds produced by Bacillus amyloliquefaciens. MicrobiologyOpen. 2019. https://doi.org/10.1002/mbo3.813.

151. Xiang L, Wang M, Jiang WT, Wang YF, Chen XS, Yin CM, et al. Key indicators for renewal and reconstruction of perennial trees soil: Microorganisms and phloridzin. Ecotoxicology and Environmental Safety.225. https://doi.org/10.1016/ j.ecoenv.2021.112723.

152. Xie X, Pu L, Wang Q, Zhu M, Xu Y, Zhang M. Response of soil physicochemical properties and enzyme activities to long-term reclamation of coastal saline soil, Eastern China. The Science of the Total Environment. 2017;607-608(dec.31): 1419. -1427. https://doi.org/10.1016/j.scitotenv.2017.05.185.

153. Xu HJ, Bai J, Li WY, Zhao LX, Li YT. Removal of persistent DDT residues from soils by earthworms: A mechanistic study. Journal of Hazardous Materials. 2019;365(MAR.5):622-631. https://doi.org/10.1016/j.jhazmat.2018.11.043.

154. Xu W, Wang Z, Wu F. The effect of D123 wheat as a companion crop on soil enzyme activities, microbial biomass and microbial communities in the rhizosphere of watermelon. Frontiers in Microbiology. 2015;6:899. https://doi.org/10.3389/ fmicb.2015.00899.

155. Xu F, Chen Y, Cai Y, Gu F, An K. Distinct Roles for Bacterial and Fungal Communities During the Curing of Vanilla. Frontiers in Microbiology. 2020;11:552388. https://doi.org/10.3389/fmicb.2020.552388.

156. Yamamoto, Harayama. PCR amplification and direct sequencing of gyrB genes with universal primers and their application to the detection and taxonomic analysis of Pseudomonas putida strains. Applied and environmental microbiology. 1995;61(3):1104-1109. https://doi.org/10.1016/j.ijms.2010.08.029.

157. Ye SF, Zhou YH, Sun Y, Zou LY, Yu J Q. Cinnamic acid causes oxidative stress in cucumber roots, and promotes incidence of Fusarium wilt. Environmental \& Experimental Botany. 2006;56(3):255-262. https://doi.org/10.1016/ j.envexpbot.2005.02.010.

158. Yim B, Baumann A, Grunewaldt-Stcker G, Liu B, Winkelmann T. Rhizosphere microbial communities associated to rose replant disease: links to plant growth and root metabolites. Horticulture Research. 2020;71:1-16. https://doi.org/10.1038/ s41438-020-00365-2.

159. Yin C, Xiang L, Wang G, Wang Y, Shen X, Chen X, et al. Phloridzin promotes the growth of Fusarium moniliforme (Fusarium verticillioides). Scientia Horticulturae. 2017;214:187-194. https://doi.org/10.1016/j.scienta.2016.11.035.

160. Yin CM, Wang GS, Li YY, Che JS, Shen X, Chen XS, et al. A new method for analysis of phenolic acids in the soil-soil from replanted apple orchards was investigated. Scientia Agricultura Sinica. 2013.

161. Yu HY, Wang YK, Chen PC, Li FB, Chen MJ, Hu M. The effect of ammonium chloride and urea application on soil bacterial communities closely related to the reductive transformation of pentachlorophenol. Journal of Hazardous Materials. 2014;272(may 15):10-19.

https://doi.org/10.1016/j.jhazmat.2014.02.037. 
162. Yu X, Ai C, Li X, Zhou G. The siderophore-producing bacterium, Bacillus subtilis CAS15, has a biocontrol effect on Fusarium wilt and promotes the growth of pepper. European Journal of Soil Biology. 2011;47(2):138-145. https://doi.org/10.1016/j.ejsobi.2010.11.001.

163. Yuan J, Raza W, Shen Q, Huang Q. Antifungal Activity of Bacillus amyloliquefaciens NJN-6 Volatile Compounds against Fusarium oxysporum f. sp. cubense. Applied \& Environmental Microbiology. 2012;78(16):5942-5944. https://doi.org/10.1128/aem.01357-12.

164. Yuan J, Zhao M, Li R, Huang Q, Raza W, Rensing C, et al. Microbial volatile compounds alter the soil microbial community. Environmental Science \& Pollution Research International. 2017. https://doi.org/10.1007/s11356-017-9839-y.

165. Zalila-Kolsi I, Mahmoud AB, Ali H, Sellami S, Jamoussi K. Antagonist effects of Bacillus spp. strains against Fusarium graminearum for protection of durum wheat (Triticum turgidum L. subsp. durum). Microbiological Research. 2016;192:148-158. https://doi.org/10.1016/j.micres.2016.06.012.

166. Zhang C, Wang J, Zhu L, Du Z, Wang J, Sun X, et al. Effects of 1-octyl-3-methylimidazolium nitrate on the microbes in brown soil. Journal of Environmental Sciences. 2018. https://doi.org/CNKI:SUN:HJKB.0.2018-05-027.

167. Zhang X, Gao J, Zhao F, Zhao Y, Li Z. Characterization of a salt-tolerant bacterium Bacillus sp. from a membrane bioreactor for saline wastewater treatment. Journal of Environmental Sciences. 2014. https://doi.org/10.1016/S1001-0742(13)60613-0.

168. Zhang Y, Han X, Chen X, Jin H, Cui X. Exogenous nitric oxide on antioxidative system and ATPase activities from tomato seedlings under copper stress. Scientia Horticulturae. 2009;123(2):217-223. https://doi.org/0.1016/j.scienta.2009.08.015.

169. Zhang Y, Li R, Cheng R. Developmental changes of carbohydrates, organic acids, amino acids, and phenolic compounds in 'Honeycrisp' apple flesh. Food Chemistry. 2010;123(4):1013-1018. https://doi.org/10.1016/j.foodchem.2010.05.053.

170. Zhang ZY, Pan LP, Li HH. Isolation, identification and characterization of soil microbes which degrade phenolic allelochemicals. Journal of Applied Microbiology. 2010;108(5). https://doi.org/10.1111/j.1365-2672.2009.04589.x.

171. Zhao $D$, Zhao $H$, Zhao D, Zhu X, Wang Y, Duan, $Y$, et al. Isolation and identification of bacteria from rhizosphere soil and their effect on plant growth promotion and root-knot nematode disease. Biological Control: Theory and Application in Pest Management. 2018.

https://doi.org/10.1016/j.biocontrol.2018.01.004.

\section{Figures}

A
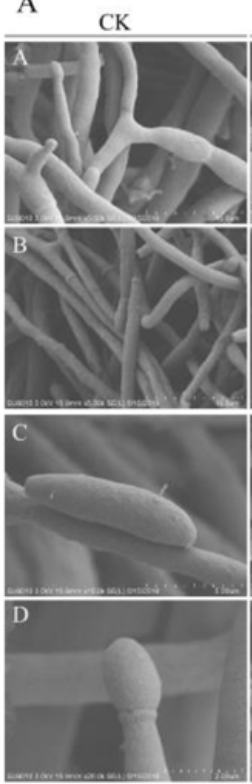

C

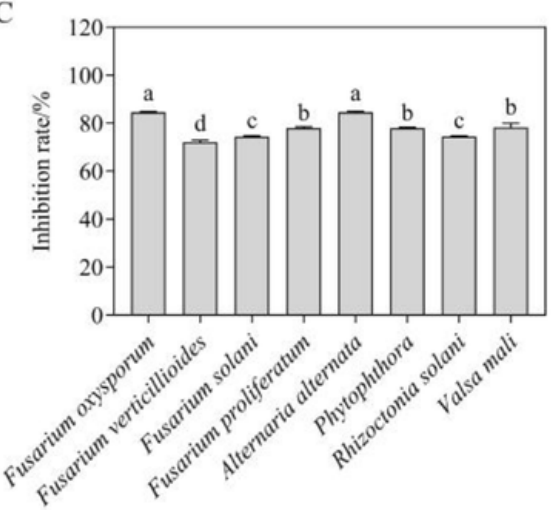

B

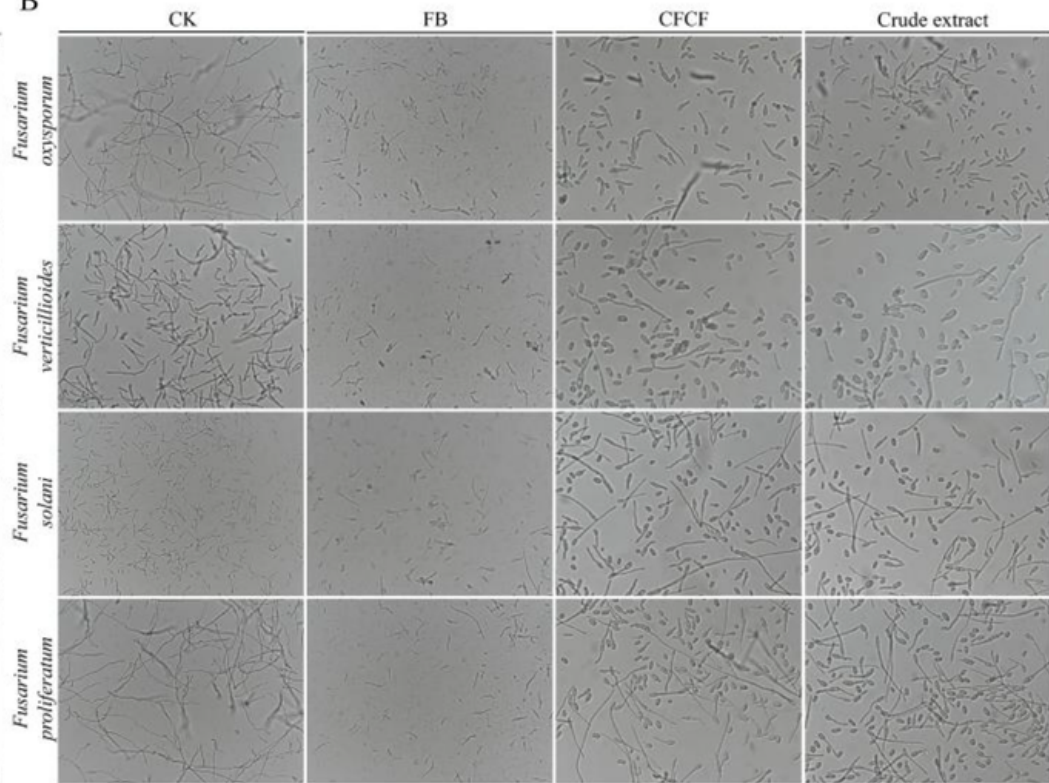

D

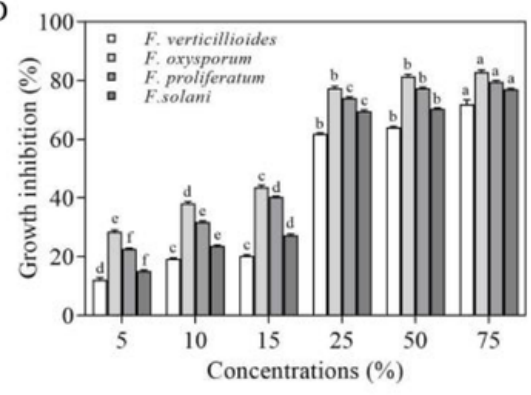

E

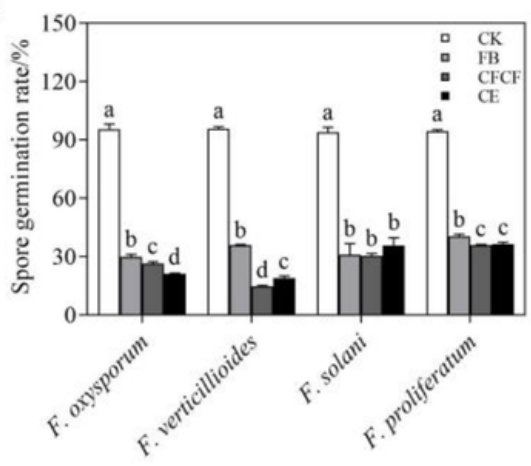

Figure 1 
Antifungal activity of strain XNRB-3 against plant fungal pathogen. (A): The mycelia and spore morphology of Fusarium oxysporum under the scanning electron microscope. A-D was the normal mycelium and spore, E-L was the mycelium treated with fermentation broth. (B): Effects of different treatments on spore germination of Fusarium. CK: Fusarium spore suspension was mixed with sterile water at 1:1, FB: Fusarium spore suspension was mixed with fermentation broth at 1:1, CFCF: Fusarium spore suspension was mixed with cell-free culture filtrate at 1:1. Crude extract (CE): Fusarium spore suspension was mixed with extracellular metabolites at 1:1. (C): Inhibition rate of strain XNRB-3 against plant fungal pathogen. (D): Effects of different concentrations of CFCF on the Fusarium mycelial growth. (E): Germination rate of Fusarium spores after different treatments. Lowercase letters above the columns indicate a significant difference at $p<0.05$. Values are mean \pm SD.
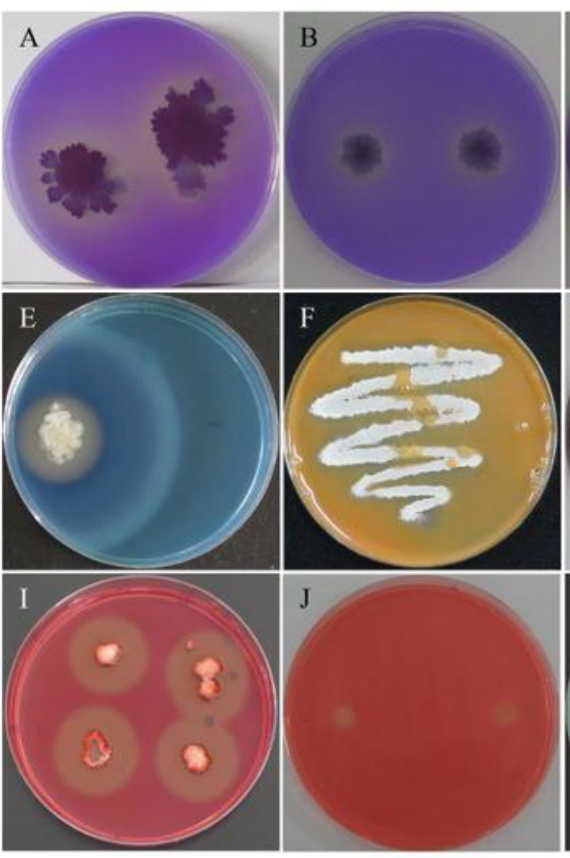

$\mathrm{O}$

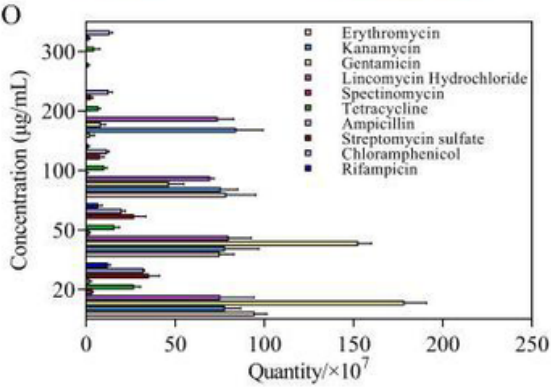

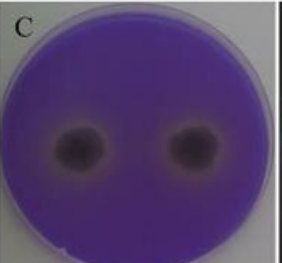
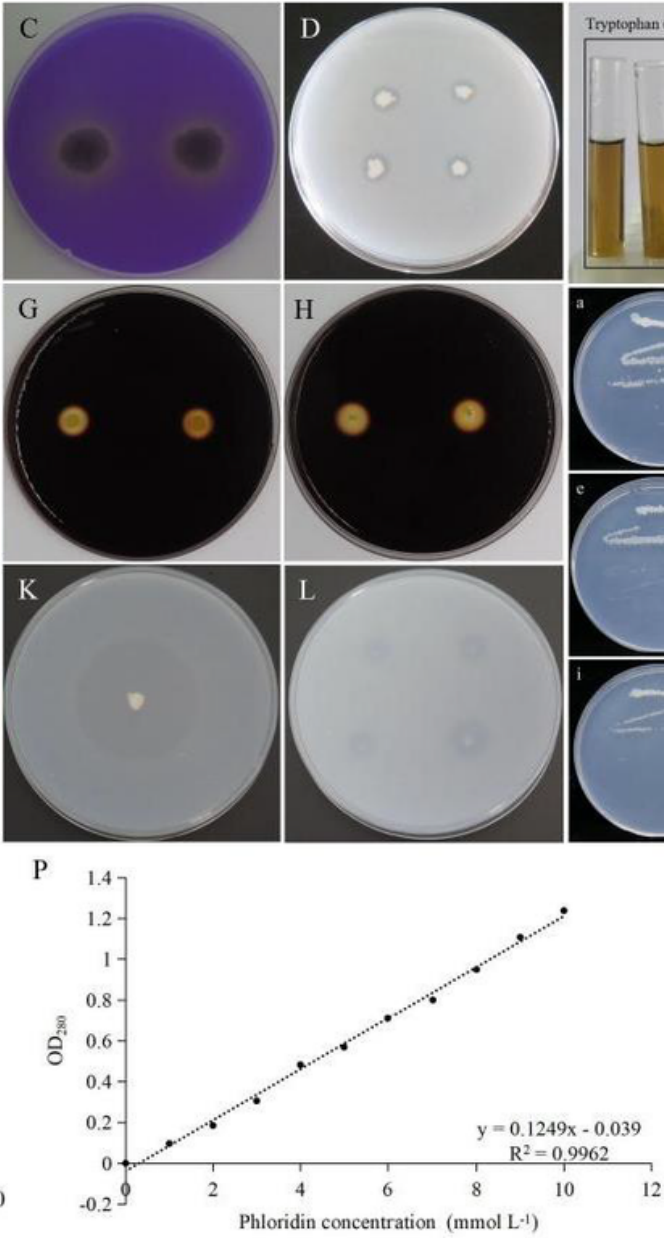
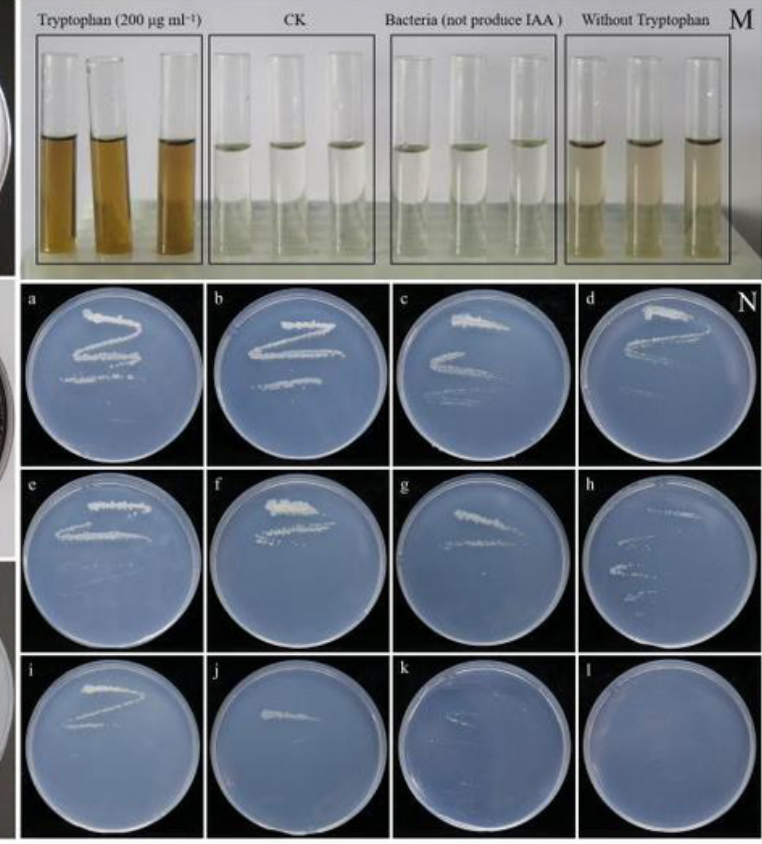

Q

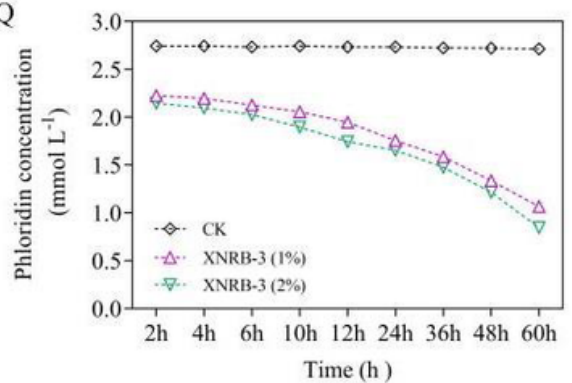

Figure 2

Strain XNRB-3 has a variety of plant growth promoting activities. A: Phosphate solubilization, B: Potassium solubilization, C: Nitrogenfixation, D: Chitinolytic activity, E: Siderophore production, F: Ammonia production, G: Pectinase activity, H: Amylase production, I: Cellulose activity, J: $\beta 1$,3-glucanase activity, K: Protease activity, L: Chitosanase activity, M: Indole-3-acetic acid (IAA) production, N: The growth of strain XNRB-3 on different concentrations of phloridin inorganic salt medium. a Control, b-d 1 mmol L-1, e-g 2 mmol L-1, h-j 3 mmol L-1, k 4 mmol L-1, I 5 mmol L-1. O: Sensitivity of strain XNRB-3 to antibiotics. The ordinate is the concentration of antibiotics, and the abscissa is the number of strains. P: Standard curve of phloridin. The ordinate is the absorbance value, and the abscissa is the concentration of phlorizin. Q: Degradation of phloridin under different treatments. The ordinate is the concentration of phloridin, and the abscissa is the days of inoculation. 

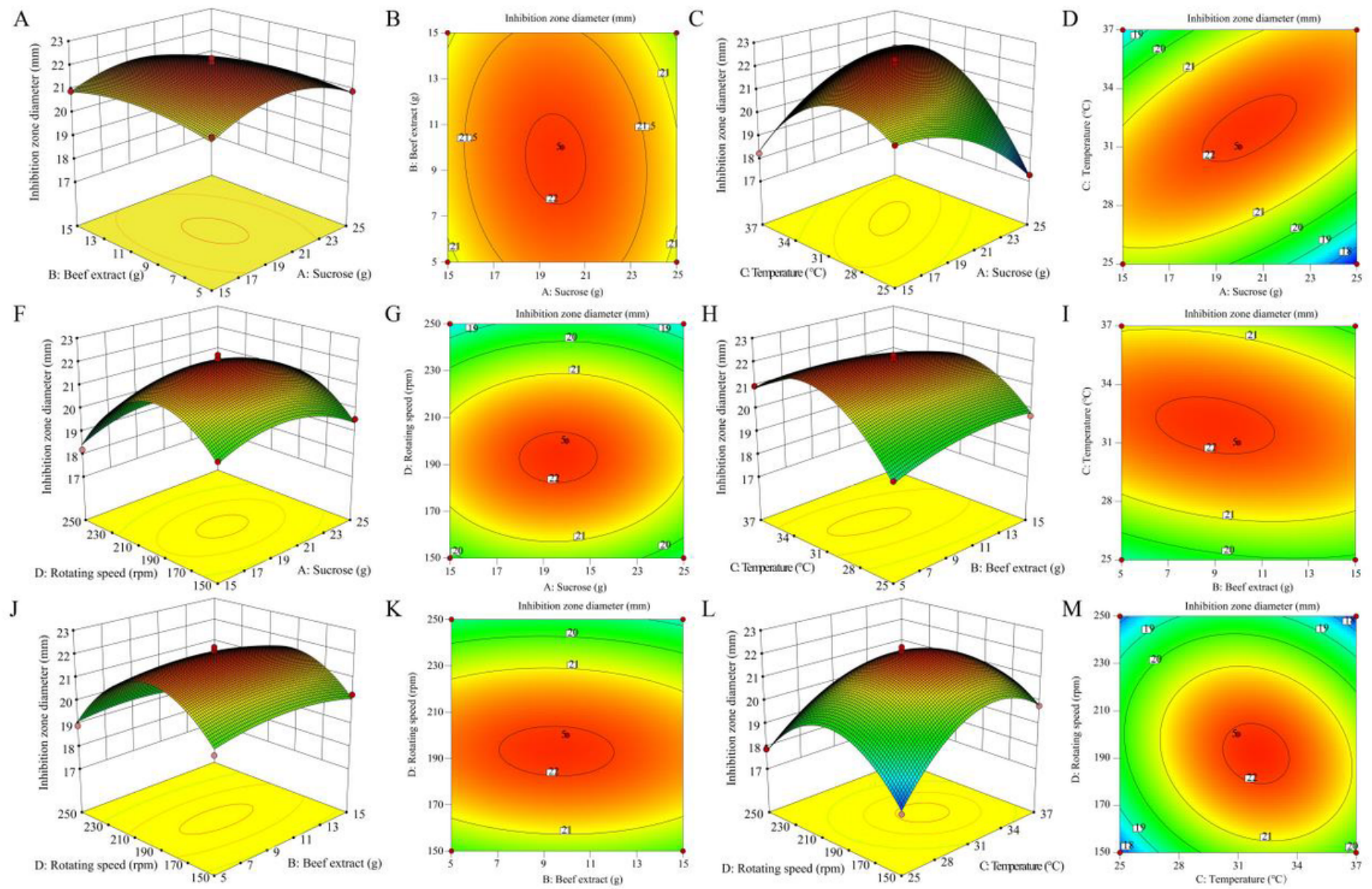

\section{Figure 3}

Response surface analysis three-dimensional and contour plot for inhibition zone diameter interaction. 

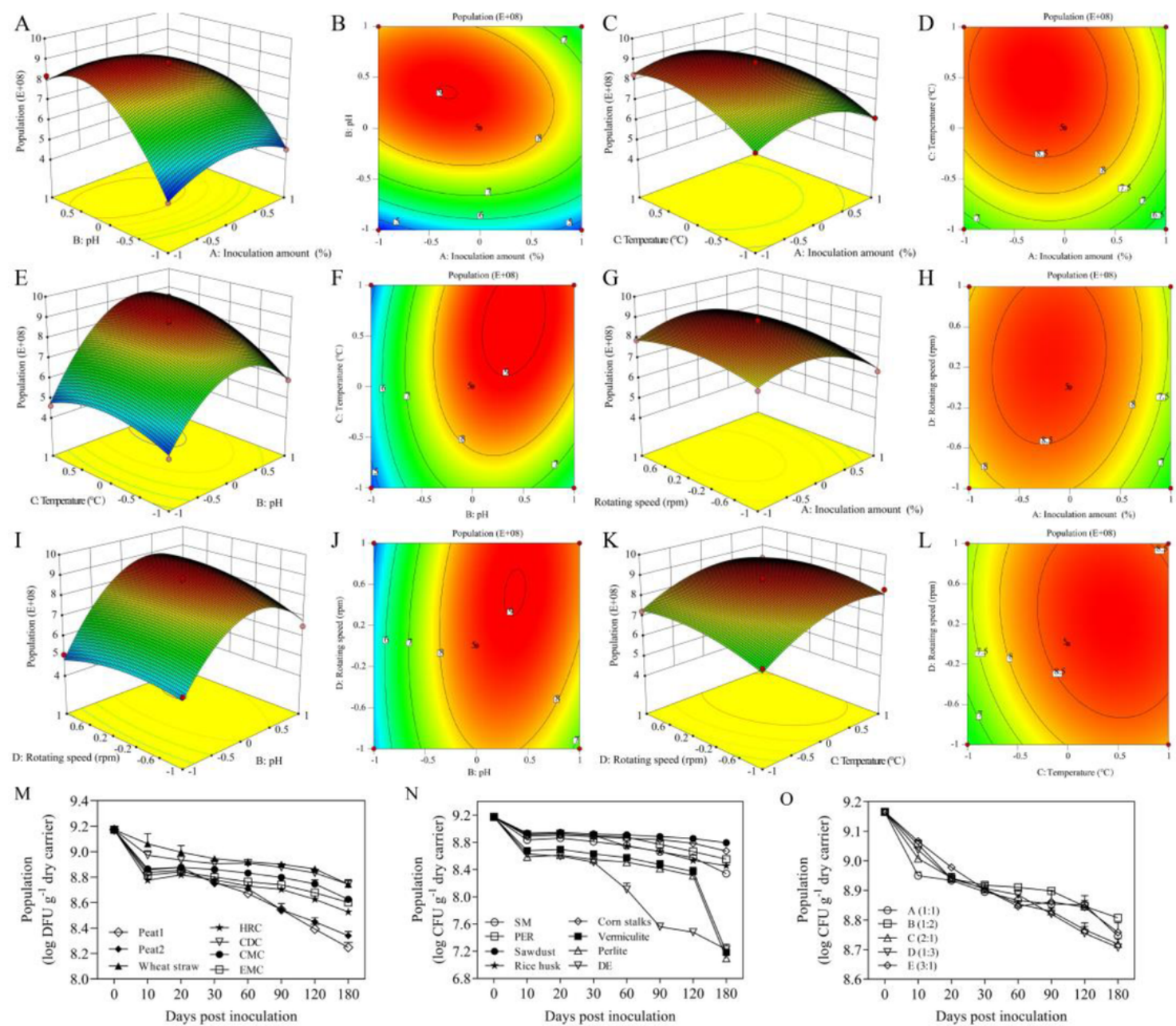

\section{Figure 4}

Response surface analysis three-dimensional and contour plot for population (A-L). Shelf life of B. licheniformis XNRB-3 in different carrier formulations (MN). Plate counts on V8-salt medium from Earthworm manure compost (EMC), Pleurotus eryngii residue (PER), Chicken manure compost (CMC), Herb residue compost (HRC), cow dung compost (CDC), Diatomite earths (DE), Soybean meal(SM), peat1, and peat2 carriers inoculated with aseptic fermentation broth or B. licheniformis XNRB-3 were determined on different days post-inoculation. O: Shelf life of B. licheniformis XNRB-3 under different carrier ratios. A: CDC: wheat straw=1:1, B: CDC: wheat straw=1:2, C: CDC: wheat straw=2:1, D: CDC: wheat straw=1:3, E: CDC: wheat straw=3:1. 


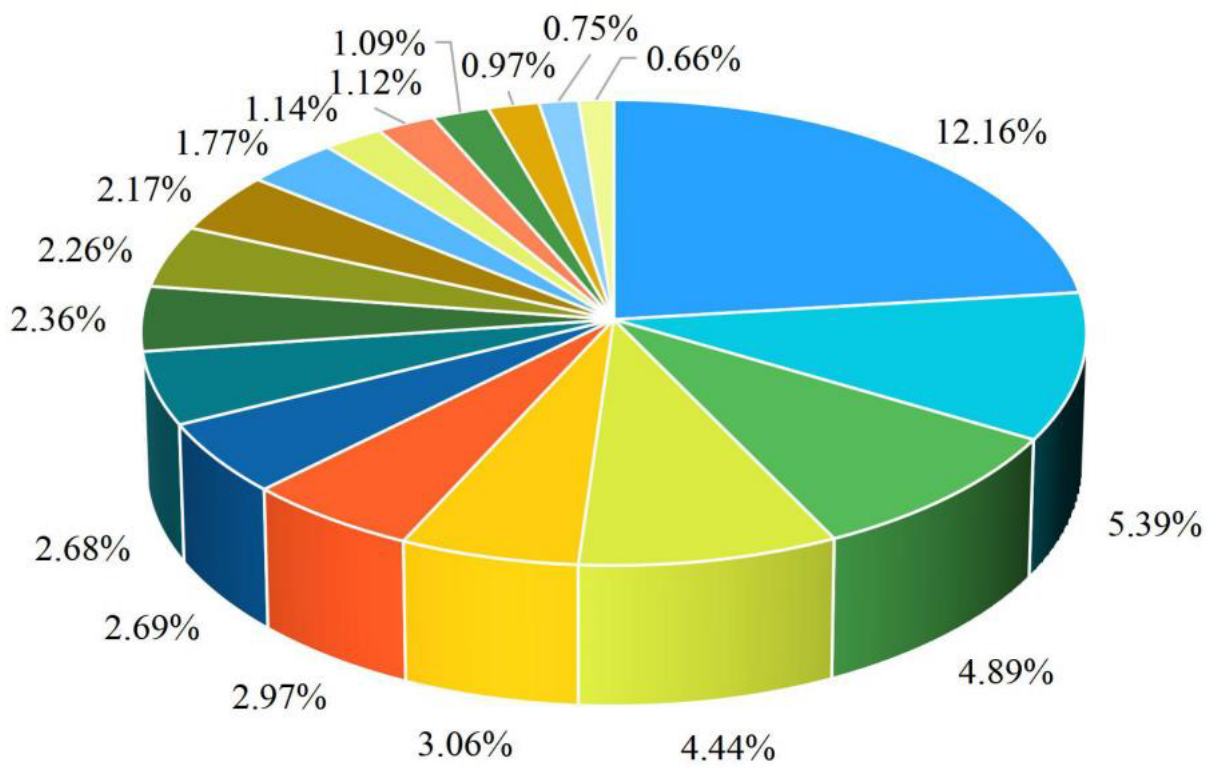

- 2,3-Butanediol

- Benzoic acid, 3,4-dimethyl-, methyl ester

= $\mathrm{CH} 3 \mathrm{C}(\mathrm{O}) \mathrm{CH} 2 \mathrm{CH} 2 \mathrm{OH}$

- alpha.-Bisabolol

- 2-Coumaranone

- Benzeneacetic acid, 4-hydroxy-, methyl ester

- Thiophene, 2,3-dihydro-

- Butanedioic acid, monomethyl ester

- $(6 \mathrm{Z}, 9 \mathrm{Z}, 12 \mathrm{Z}, 15 \mathrm{Z})$-Methyl octadeca-6,9,12,15-tetraenoate

3-Nonen-2-one

- Sesquicineole

- Dibutyl phthalate

- Acetoin

- Ledol

- Hexestrol dimethyl ether

(2E,4S,7E)-4-Isopropyl-1,7-dimethylcyclodeca-2,7-dienol

Duroquinone

- 4-Nonanol, 4-methyl-

- Harmaline

- 2,4-Di-tert-butylphenol

- Triethyl citrate

I 1,2-Benzenedicarboxylic acid, bis(1-methylethyl) ester

- 1,2-Benzenedicarboxylic acid

= 1,4,5,8,9,10-Hexahydroanthracene

- 1,2-Bis(trimethylsilyl)benzene

Benzeneacetic acid

- Docosahexaenoic acid, 1,2,3-propanetriyl ester

Rhodanine

\section{Figure 5}

GC-MS identification result of extracellular metabolites. 

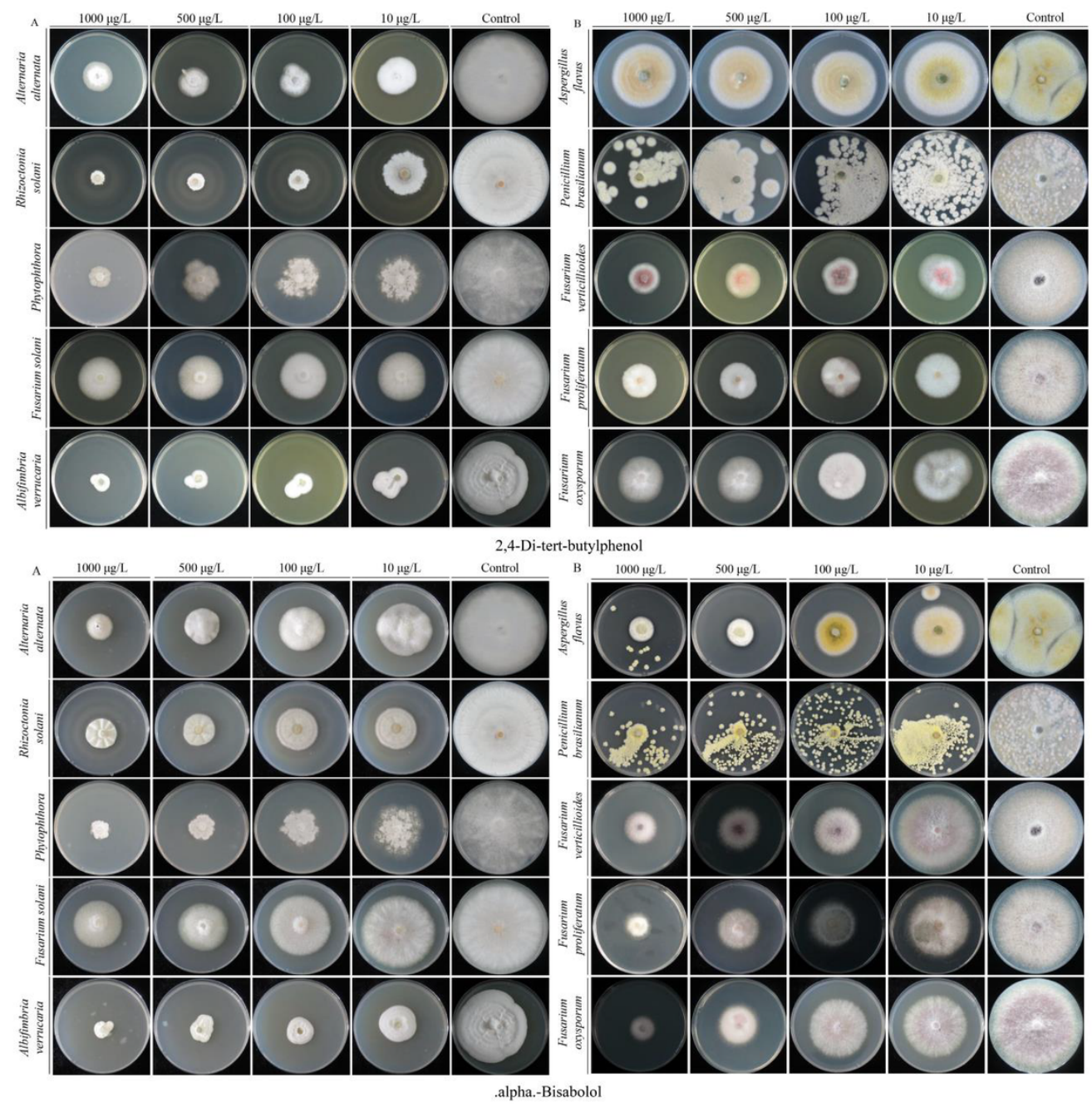

Figure 6

Growth inhibition of plant fungal pathogens on the PDA medium after treated with different different gradient 2,4-Di-tert-butylphenol and .alpha.-Bisabolol. 

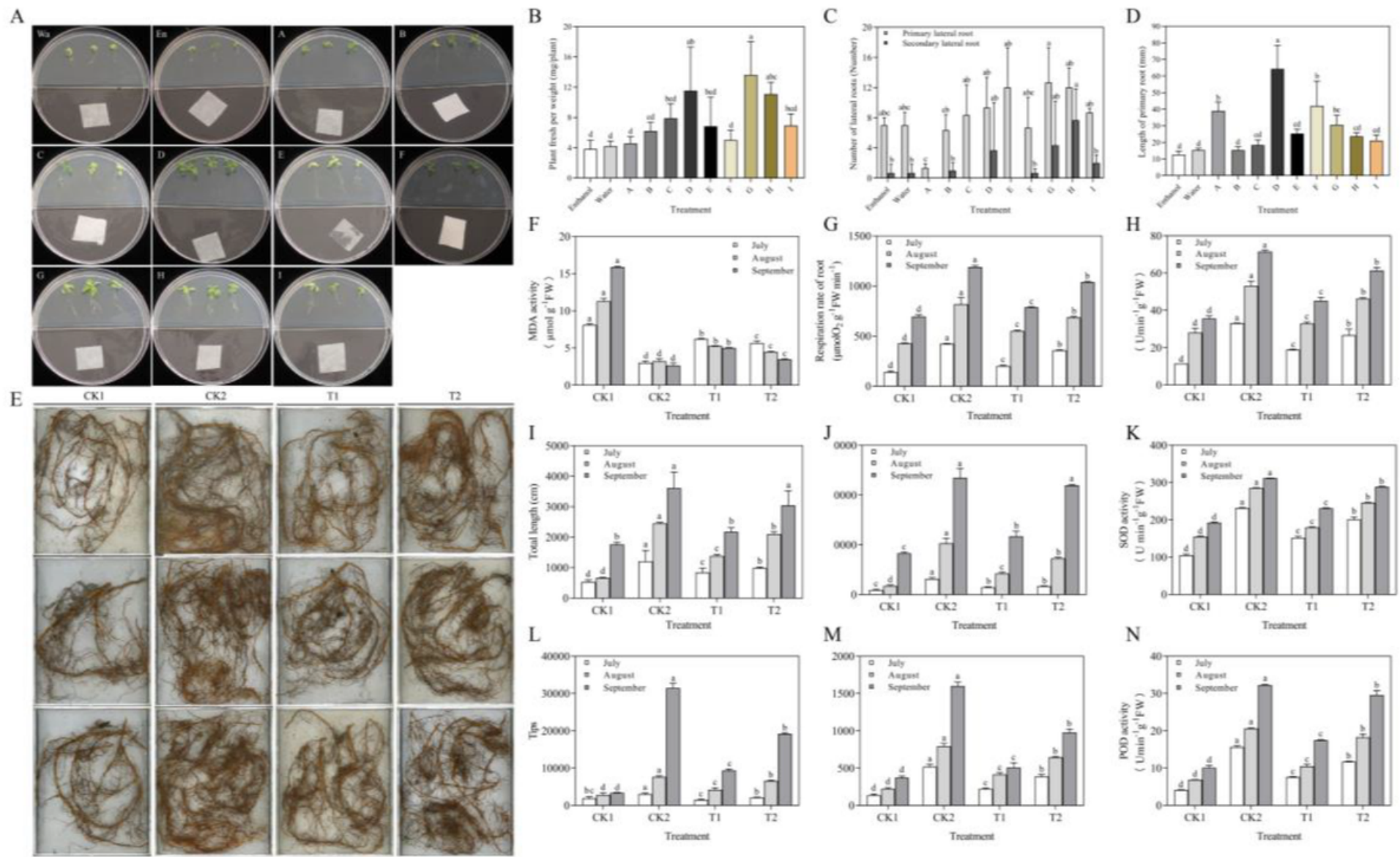

Figure 7

A: Growth promotion of Arabidopsis thaliana Col-0 with exposure to pure compounds. (a) Wa: Water, En: Enthanol, A: 2,3-Butanediol (100 $\mu$ g), B: 1,2Benzenedicarboxylic acid, bis(1-methylethyl) ester $(100 \mu \mathrm{g})$, C: 2,4-Di-tert-butylphenol $(500 \mu \mathrm{g})$, D: Butanedioic acid, monomethyl ester $(500 \mu \mathrm{g})$, E: .alpha.Bisabolol $(500 \mu \mathrm{g})$, F: Acetoin $(500 \mu \mathrm{g})$, G: Dibutyl phthalate $(500 \mu \mathrm{g}), \mathrm{H}$ : 3-Nonen-2-one $(500 \mu \mathrm{g})$, I: Benzoic acid, 3,4-dimethyl-, methyl ester (100 $\mu \mathrm{g})$. (b) Plant fresh per weight, (c) Length of primary root, (d) Number of lateral roots. Lowercase letters above the columns indicate a significant difference at $p<0.05$. Values are mean \pm SD. 


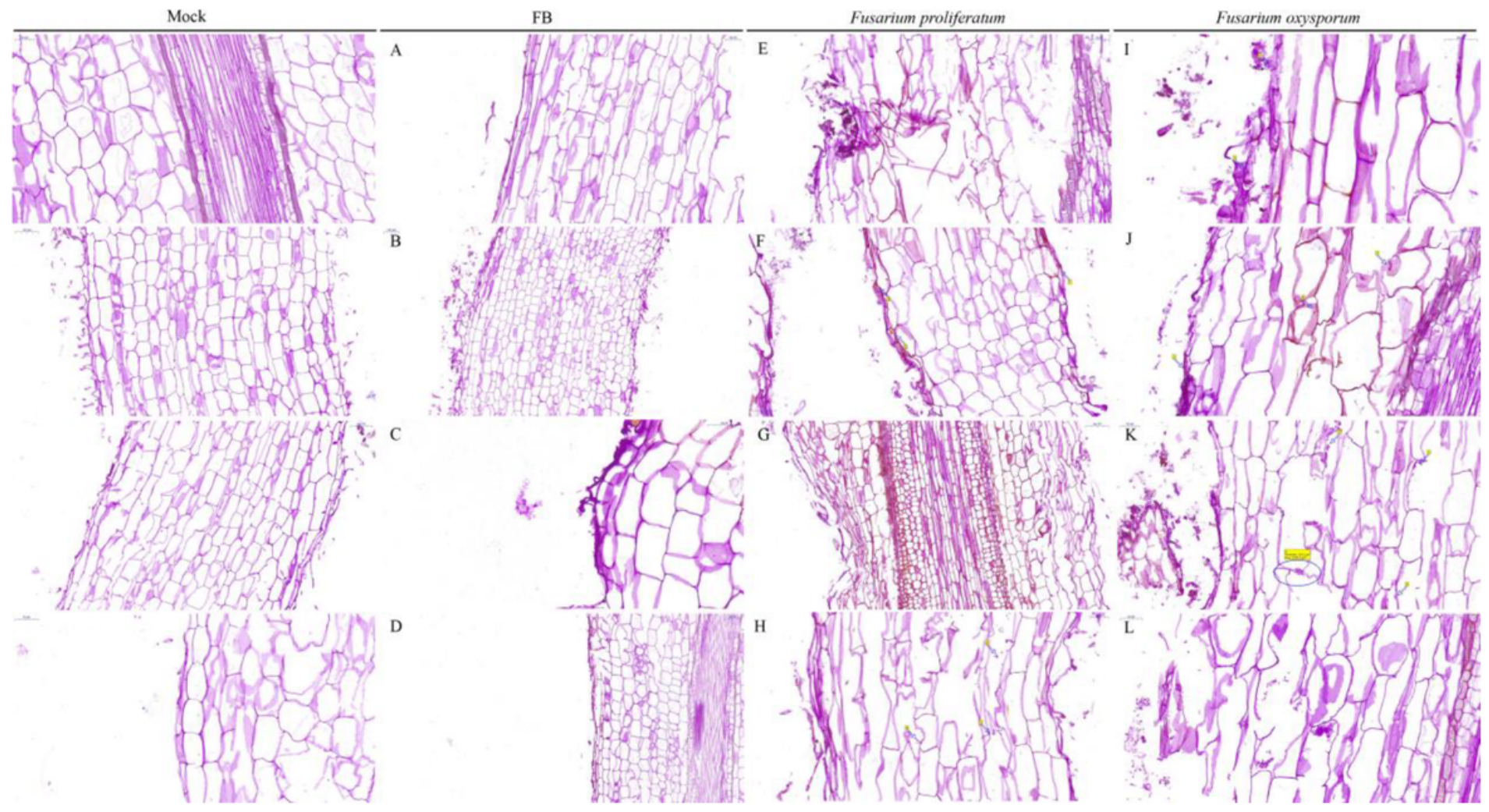

Figure 8

Microscopic observation of the plant root stained by PAS. Mock Sterile distilled water, FB fermentation broth. F. proliferatum and F. oxysporum: conidia suspension. PAS staining turns the polysaccharides on the fungal wall purple-red. Mock The root tissue was intact, the cell boundaries are clear and neatly arranged. FB The conidia and hyphae of Fusarium were attached to the epidermis, the epidermis and cortex cells were slightly broken, deformed, and the internal tissue structure is intact (A-D). E, G, I, L Dense mycelium appeared in the epidermis of the root system, and the epidermal and cortical cells appeared ruptured, and deformed (arrows), and the cells were arranged irregularly. F Cauliflower-like structure appeared in the infected root areas (arrows). $H$, J-L The conidia and hyphae of Fusarium appeared in the cortex and vascular column. G Viscous substances and starch granules appear in the cortex and vascular columns, which are densely accumulated on the cell wall. 
(A)
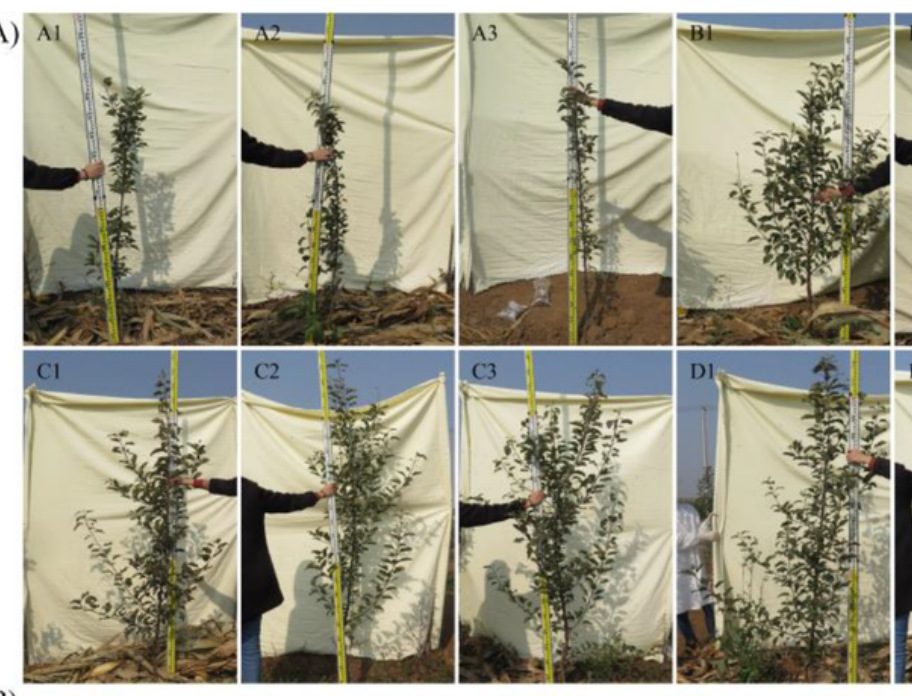

B)
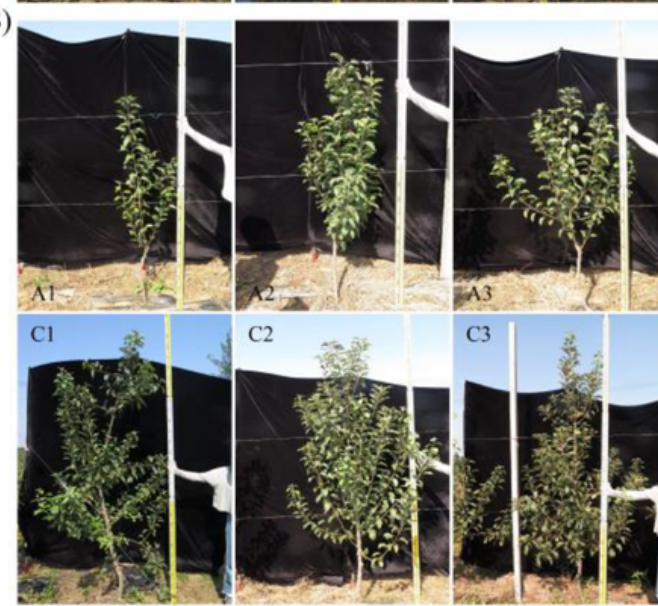

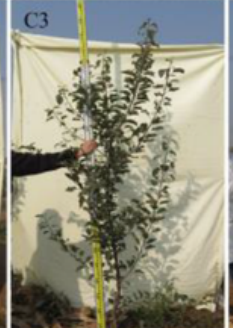

C3

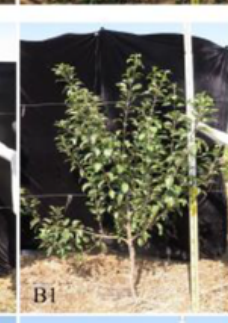

D1

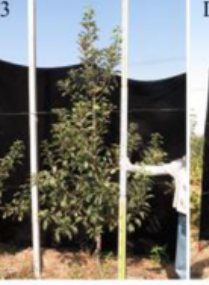

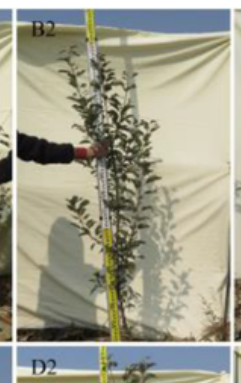

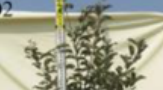

,

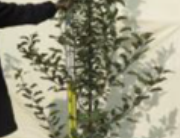

.
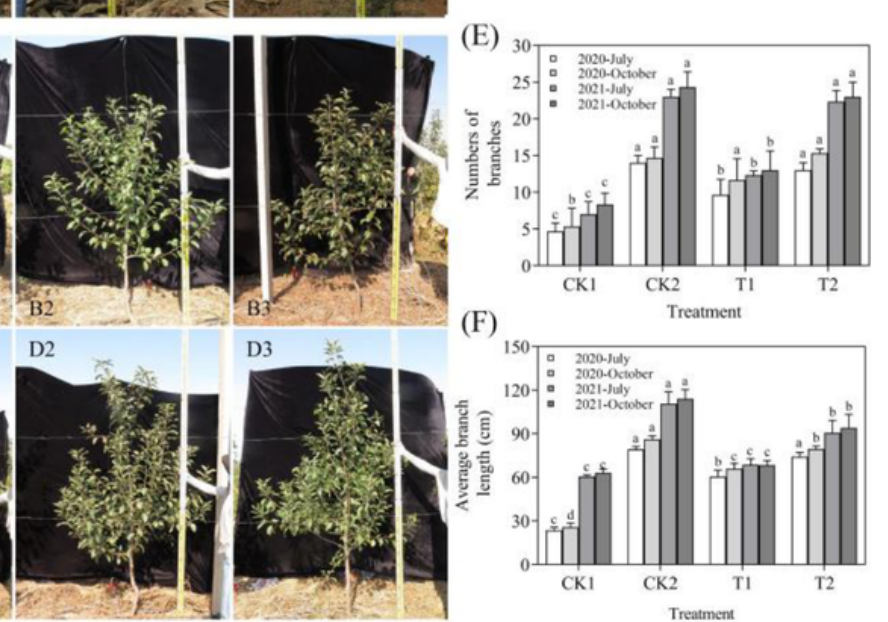

(E) 3

(F)

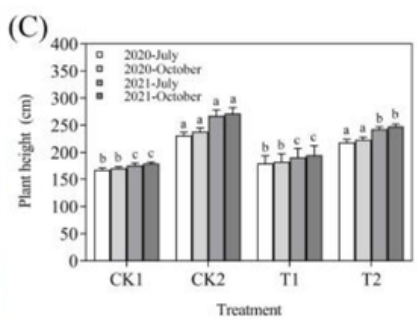

(D)
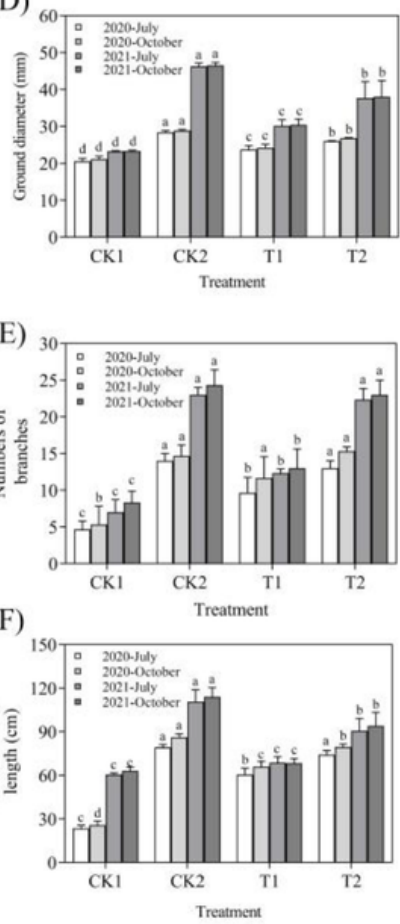

Figure 9

The biomass of young apple trees in different treatments, including plant height (C), ground diameter (D), numbers of branches (E), and average branch length (F). (A) The growth of young apple trees in different treatments in October 2020. (b) The growth of young apple trees in different treatments in October 2021. A1-A3: CK1 25-year-old orchard soil, C1-C3: CK2 Methyl bromide fumigation, B1-B3: T1 Fertilizer carrier, D1-D3: T2 XNRB-3 bacterial fertilizer. Lowercase letters above the columns indicate a significant difference at $p<0.05$. Values are mean $\pm S D$. 
A

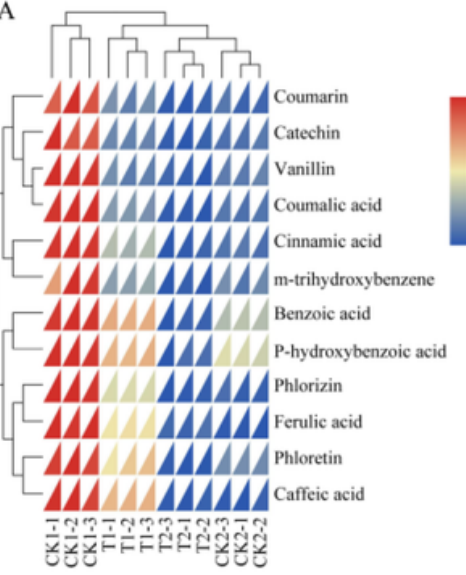

B

मिति

- 1/////// Cinnamic acid

- M/1/1///4m-trihydroxybenzene

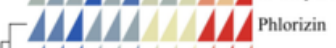

L/////// Coumalic acid

- M/M/Manillin

-1/1//1/1/2atechin

- 1/1/1/M Ferulic acid

- M/1///// Caffeic acid

- $/$ /

/ $/ / / / / / / / /$ Phloretin

L// $/ / / / / / /$ Benzoic acid

1/1/////// P-hydroxybenzoic acid

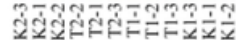

C
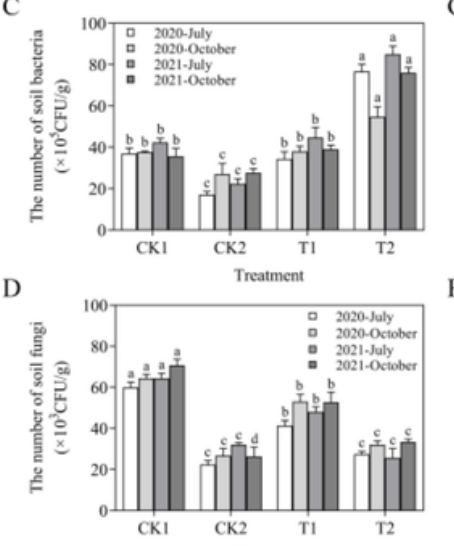

E
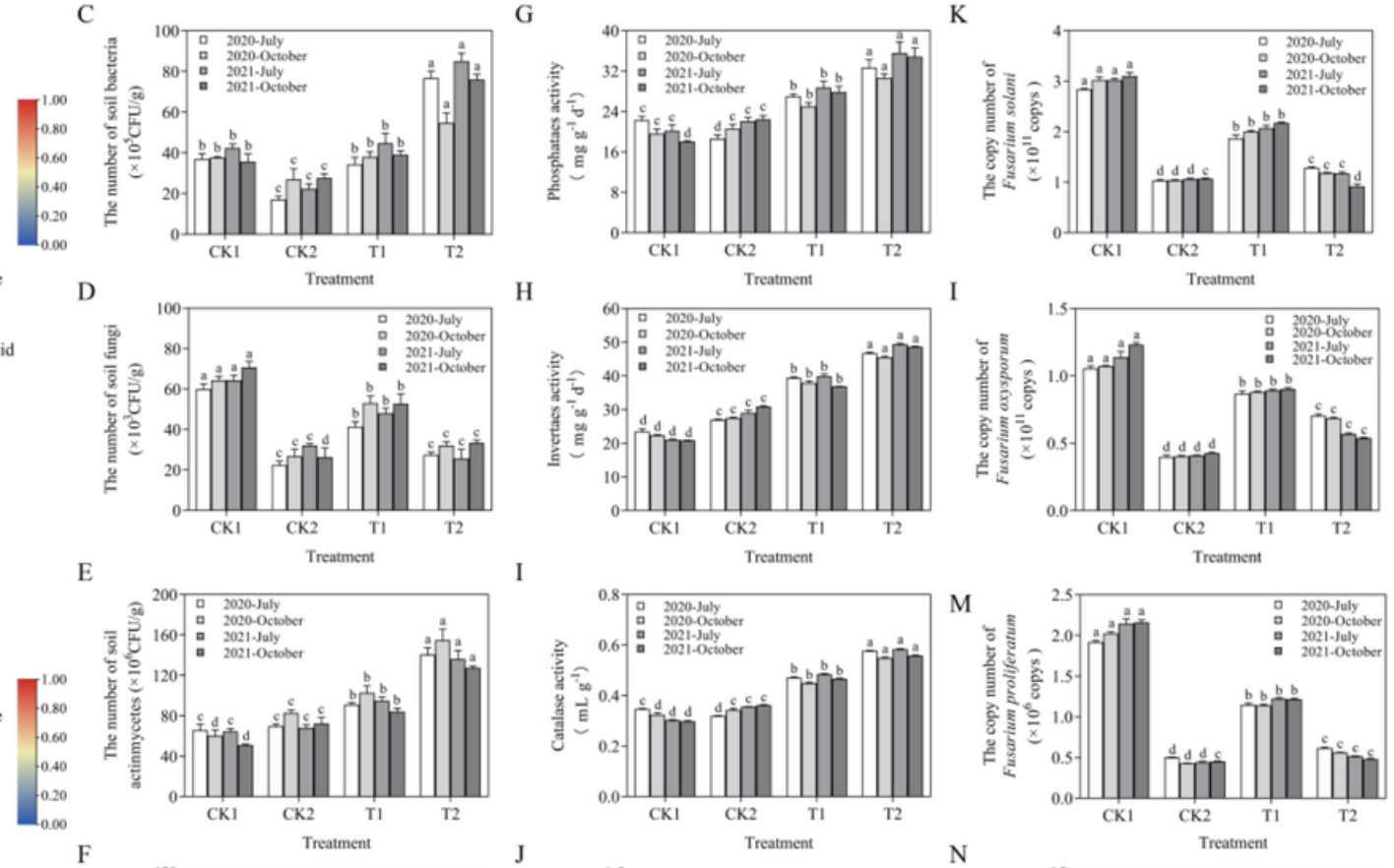

$\mathbf{J}$
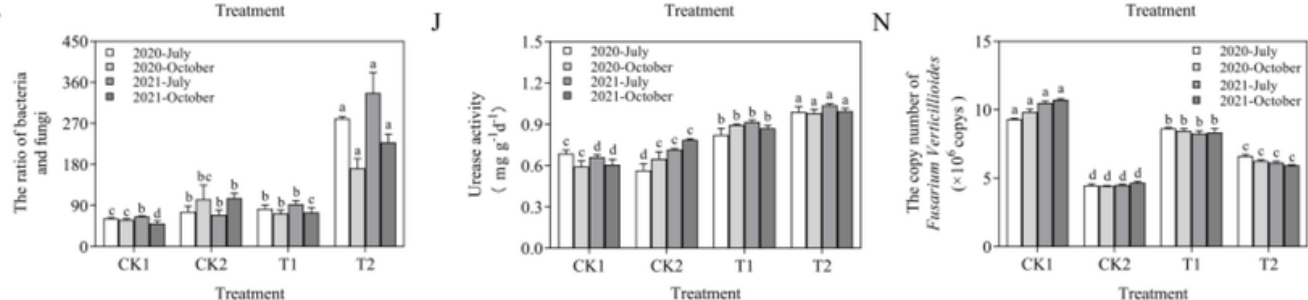

Figure 10

A: Effects of different treatments on soil phenolic acid in October 2020. B: Effects of different treatments on soil phenolic acid in October 2021. C-F: The effect of strain XNRB-3 on the density of microorganisms in the rhizosphere of young apple trees. G-J: Effect of different treatments on soil enzyme activities. K-N: Effect of different treatments on the gene copy number of four fungal pathogens by using real-time qPCR. CK1 25-year-old orchard soil, CK2 Methyl bromide fumigation, T1 Fertilizer carrier, T2 XNRB-3 bacterial fertilizer. Lowercase letters above the columns indicate a significant difference at $\mathrm{p}<0.05$. Values are mean \pm SD. 

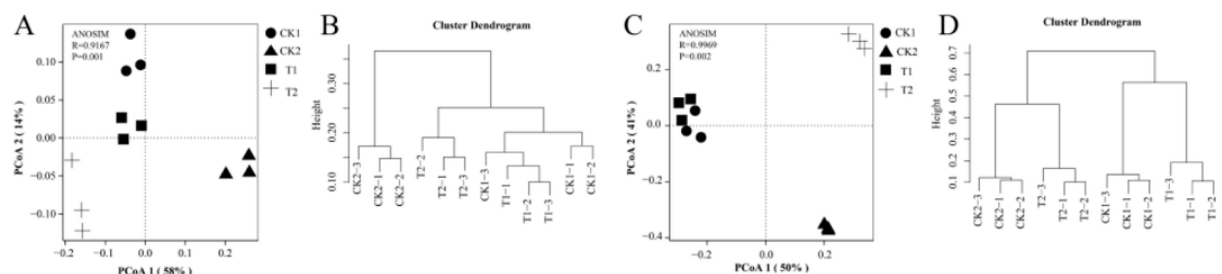
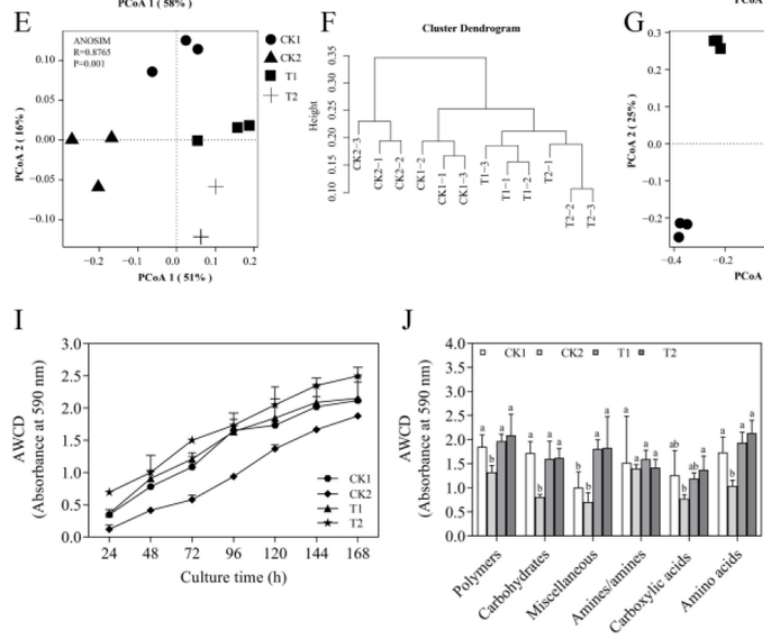

Catagprised carbon sources

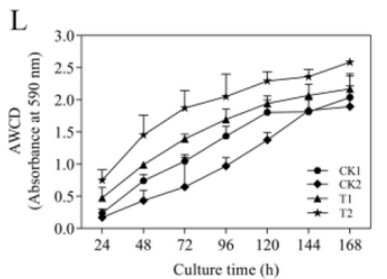

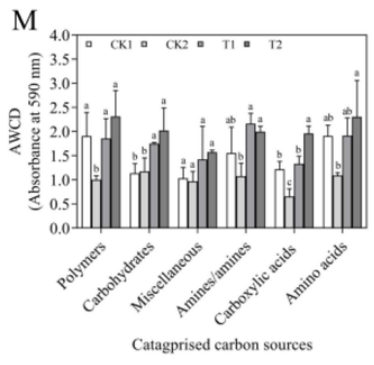
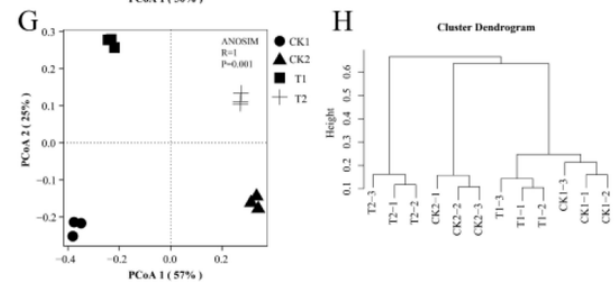

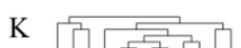

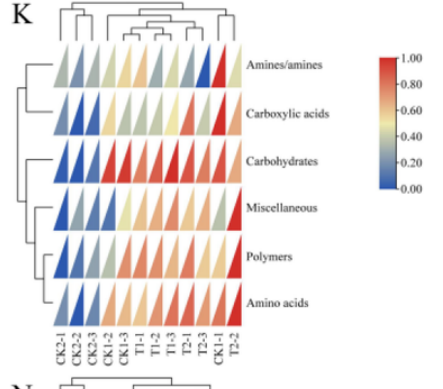

$\mathrm{N}$ Пिमिमिम

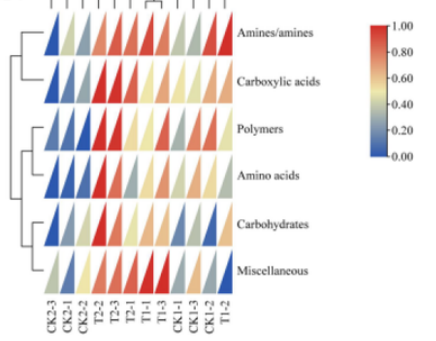

\section{Figure 11}

A-B and I-K(October, 2020), E-F and L-N(October, 2021): Utilization of different carbon substrates by rhizosphere soil samples under different treatments using Biolog Eco plates. A-B, E-F: The PCA of potential community functional diversity of soil microbes. I, L: Variation in average well color development (AWCD) after $168 \mathrm{~h}$ of incubation.J-K, M-N: Categorized substrates utilization pattern by microbial communities from rhizosphere soils after $96 \mathrm{~h}$ of incubation. G-H (bacteria) and C-D (fungi): Microbial community structures in the different treatments based on the T-RFLP data in October 2021. Principal coordinate analysis $(P C O A)(C, G)$ and cluster analysis $(D, H)$ plot based on the OTUs of Bray_Curtis distance. $R=1>0, p<0.05$ means that the difference between groups is greater than the difference within groups, and there are significant differences between different treatments. CK1 25-year-old orchard soil, CK2 Methyl bromide fumigation, T1 Fertilizer carrier, T2 XNRB-3 bacterial fertilizer. Lowercase letters above the columns indicate a significant difference at $p<0.05$. Values are mean $\pm S D$. 


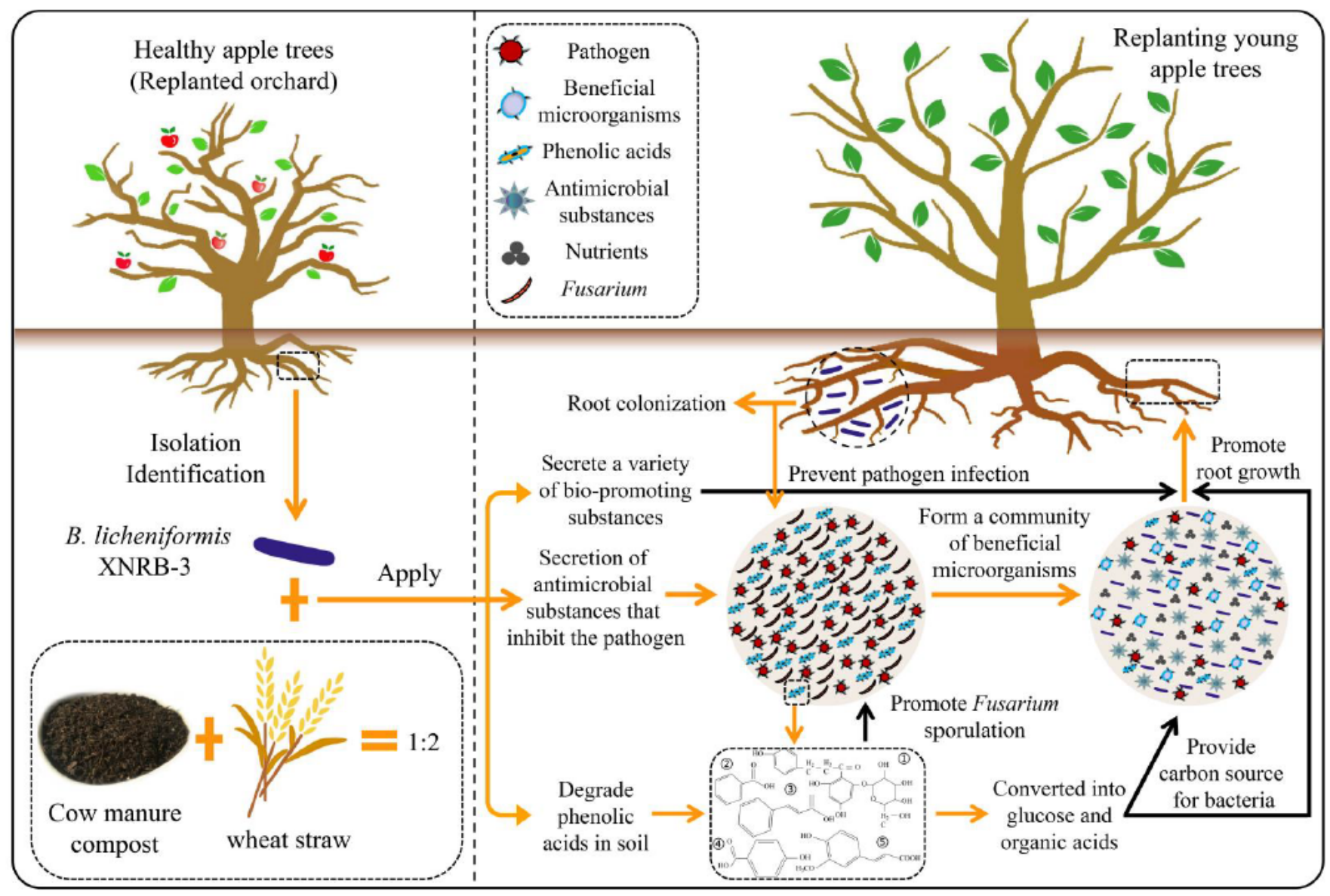

Figure 12

Conceptual model displaying the potential role of strain XNRB-3 influencing the pathogen density (qPCR) in the soil and the occurrence of ARD.

\section{Supplementary Files}

This is a list of supplementary files associated with this preprint. Click to download.

- SupplementaryFigure.docx

- SupplementaryTable.docx 